\title{
PROCESSAMENTO DE VÍDEO ESTEREOSCÓPICO EM TEMPO REAL PARA EXTRAÇÃO DE MAPA DE DISPARIDADES
}

\author{
Dissertação apresentada à Escola de \\ Engenharia de São Carlos da \\ Universidade de São Paulo, como parte \\ dos requisitos para obtenção do Título de \\ Mestre em Engenharia Elétrica.
}

Orientador: Prof. Dr. Valentin O. Roda

São Carlos 

Um singelo obrigado aos meus pais e minha noiva, pela compreensão e apoio incondicional durante essa caminhada. 
PÁGINA INTENCIONAMENTE DEIXADA EM BRANCO 


\section{AGRADECIMENTOS}

Um agradecimento à Vanderlei Bonato por gentilmente ceder o material de pesquisa de sua dissertação "Projeto de um módulo de aquisição e préprocessamento de imagem colorida baseado em computação reconfigurável e aplicado a robôs móveis", sendo esta de grande valia durante o desenvolvimento desta pesquisa.

A Universidade de São Paulo, pela infra-estrutura oferecida, e aos funcionários da graduação e pós-graduação pela pronta disposição na solução de problemas.

Ao meu orientador, Prof. Dr. Valentin Obac Roda, por toda ajuda e orientação despendida. 
PÁGINA INTENCIONAMENTE DEIXADA EM BRANCO 
"Today's scientists have substituted mathematics for experiments, and they wander off through equation after equation, and eventually build a structure which has no relation to reality" 
PÁGINA INTENCIONAMENTE DEIXADA EM BRANCO 


\section{RESUMO}

CALIN, G. (2007). Processamento de vídeo estereoscópico em tempo real para extração de mapa de disparidades. Dissertação (Mestrado) - Escola de Engenharia de São Carlos, Universidade de São Paulo, São Carlos, 2007.

A análise em tempo real de pares de imagens estereoscópicas para extração de características dimensionais da cena tem apresentado crescente interesse, possibilitando robusta navegação robótica e identificação de objetos em cenários dinâmicos. A presente dissertação propõe um método que emprega a análise pixel a pixel e observação de janelas, em pares de imagens estereoscópicas, para extração de denso mapa de disparidades. A arquitetura de processamento proposta é única em sua constituição, misturando elementos de processamento concorrente e seqüencial. $O$ algoritmo estrutura-se em processamento pipeline, permitindo sua implementação em dispositivos de lógica programável e obtenção de resultados em tempo real.

Palavras-chave: visão estereoscópica; lógica programável; processamento em tempo-real; processamento pipeline. 


\section{ABSTRACT}

CALIN, G. (2007). Real-time disparity map extraction in a dual head stereo vision system. M.Sc. Dissertation - Escola de Engenharia de São Carlos, Universidade de São Paulo, São Carlos, 2007.

Real-time analysis of stereo images for extraction of dimensional features has been focus of great interest, providing means for autonomous robot navigation and identification of objects in dynamic environments. This work describes a method based in pixel-to-pixel and windows based matching analysis, in stereo images, for constructing dense disparity maps. The proposed processing structure is unique, mixing concurrent and sequential elements. Pipelines structure is employed, targeting implementation in FPGA devices and enabling real-time results.

Keywords: stereo vision; programmable logic; real-time processing; pipeline processing. 


\section{LISTA DE FIGURAS}

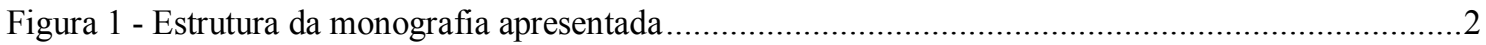

Figura 2 - Típica situação problema em visão estereoscópica.................................................................

Figura 3 - Representação esquemática espacial de um sistema de visão estereoscópico..............................4

Figura 4 - Projeção $(\mathrm{y}=0)$ do modelo do sistema de visão estereoscópico..................................................

Figura 5 - Ciclo de vida típico de um projeto VHDL ............................................................................ 8

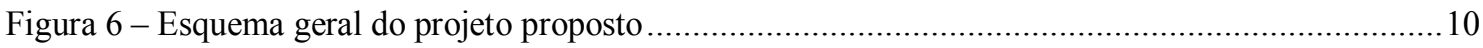

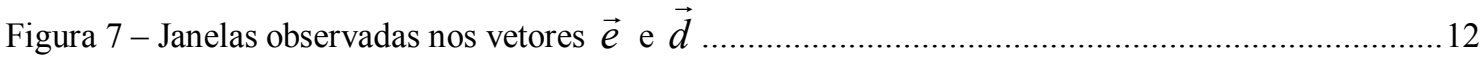

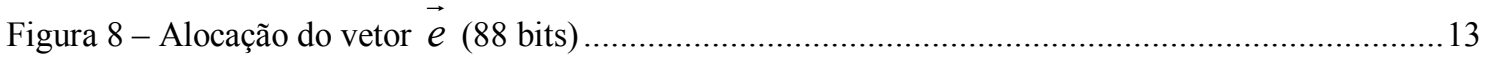

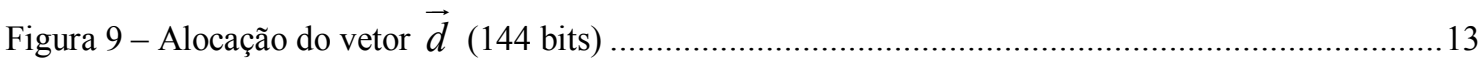

Figura 10 - Diagrama dos sinais fundamentais de clock................................................................... 14

Figura 11 - Estrutura geral de processamento em pipeline para o algoritmo proposto …...........................15

Figura 12 - Fase 1 do pipeline - Ciclo de clock sclk0 - Cópia do vetor $\vec{e}$............................................... 16

Figura 13 - Fase 1 do Pipeline - Ciclo de clock sclk0 - Cópia do vetor $\vec{d}$.......................................... 16

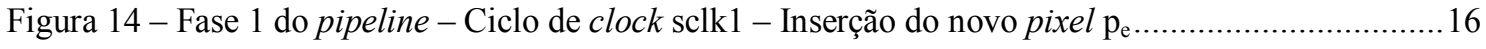

Figura 15 - Fase 1 do pipeline - Ciclo de clock sclk1 - Inserção do novo pixel $\mathrm{p}_{\mathrm{d}}$...................................16

Figura 16 - Fase 2 do pipeline - Cálculo da diferença de intensidade - Janela $j=-\beta+1 \ldots \ldots \ldots \ldots \ldots \ldots . . .17$

Figura 17 - Fase 2 do pipeline - Cálculo da diferença de intensidade - Janela $j=-\beta+2 \ldots \ldots \ldots \ldots \ldots \ldots . . .18$

Figura 18 - Fase 2 do pipeline - Cálculo da diferença de intensidade - Janela $j=+\beta$........................18

Figura 19 - Fase 2 do pipeline - Matriz resultante diferença $D(i, j)$................................................. 18

Figura 20 - Fase 3 do pipeline - Execução da função quadrática ………………………………….........19

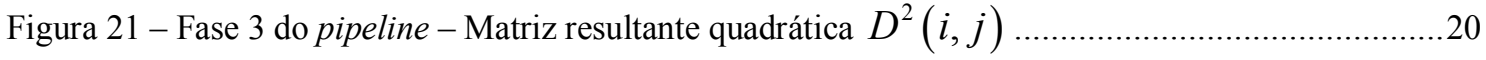

Figura 22 - Fase 4 do pipeline - Processamento da função somatória ........................................................21

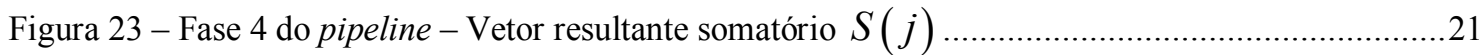

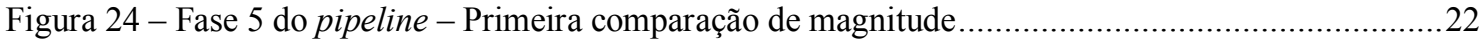

Figura 25 - Fase 5 do pipeline - Segunda comparação de magnitude.....................................................22

Figura 26 - Fase 5 do pipeline - Terceira comparação de magnitude .....................................................22 
Figura 27 - Fase 5 do pipeline - Quarta comparação de magnitude .............................................. 22

Figura 28 - Fase 5 do pipeline - Última comparação de magnitude................................................... 22

Figura 29 - Fase 5 do pipeline - Armazenamento da diferença mínima observada..............................223

Figura 30 - Estrutura funcional básica do programa de simulação .................................................. 24

Figura 31 - Janela do programa de simulação................................................................. 24

Figura 32 - Hardware utilizado na pesquisa. Kit de desenvolvimento da Xilinx e duas câmeras CMOS

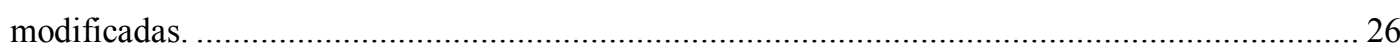

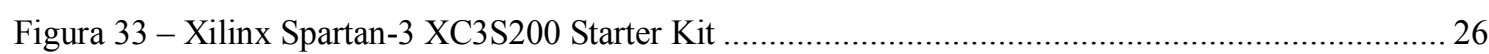

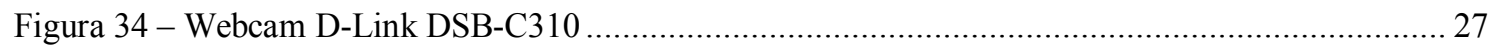

Figura 35 - Modificações para acesso aos sinais do sensor CMOS …......................................... 28

Figura 36 - Esquema elétrico de conexão com o sensor CMOS OV7648 ........................................2 28

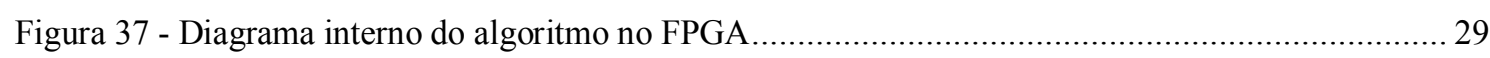

Figura 38 - main.sch - diagrama interno dos blocos constituintes do algoritmo no FPGA.................... 31

Figura 39 - Estrutura interna módulo de interface com o sensor CMOS Omnivision............................ 32

Figura 40 - Estrutura interna módulos de comunicação serial...................................................... 40

Figura 41 - Estrutura interna de interface com os bancos de memória SRam 2x256kx16 .................. 43

Figura 42 - Estrutura interna da interface sensor CMOS com a memória externa SRam ..................... 44

Figura 43 - Estrutura interna da interface de comunicação entre a memória externa SRam e o módulo de

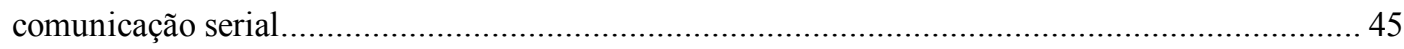

Figura 44 - Exemplo de aplicação do mapa de disparidade............................................................ 52 


\section{LISTA DE TABELAS}

Tabela 1 - Resultado da síntese do módulo VHDL omnivision_interface.vhd para o FPGA Xilinx 3s200pq208-4.

Tabela 2 - Resultado da síntese do módulo VHDL omnivision_sccb.vhd para o FPGA Xilinx

3 s200pq208-4.

Tabela 3 - Resultado da síntese do módulo VHDL sccb_clk.vhd para o FPGA Xilinx 3s200pq208-4.....34

Tabela 4 - Resultado da síntese do módulo VHDL rgb_to_grayscale.vhd para o FPGA Xilinx 3 s200pq208-4. 35

Tabela 5 - Resultado da síntese do módulo VHDL kd.vhd para o FPGA Xilinx 3s200pq208-4 …...........36

Tabela 6 - Resultado da síntese do módulo VHDL ke.vhd para o FPGA Xilinx 3s200pq208-4................36

Tabela 7 - Resultado da síntese do módulo VHDL diff_kdke.vhd para o FPGA Xilinx 3s200pq208-4 ...37

Tabela 8 - Resultado da síntese do módulo VHDL mul_d.vhd para o FPGA Xilinx 3s200pq208-4 .........38

Tabela 9 - Resultado da síntese do módulo VHDL sum_dii.vhd para o FPGA Xilinx 3s200pq208-4 ......39

Tabela 10 - Resultado da síntese do módulo VHDL cmp_S.vhd para o FPGA Xilinx 3s200pq208-4......40

Tabela 11 - Resultado da síntese do módulo Verilog sasc_brg.v para o FPGA Xilinx 3s200pq208-4 _.....41

Tabela 12 - Resultado da síntese do módulo Verilog sasc_top.v para o FPGA Xilinx 3s200pq208-4 ......41

Tabela 13 - Resultado da síntese do módulo VHDL sram.vhd para o FPGA Xilinx 3s200pq208-4 .........43

Tabela 14 - Resultado da síntese do módulo VHDL sram_interface.vhd para o FPGA Xilinx 3s200pq2084. . .44

Tabela 15 - Resultado da síntese parcial do sistema para o FPGA Xilinx 3s200pq208-4 ….....................46

Tabela 16 - (a,b) Pares de imagens do repositório JISCT. (c) Mapa de disparidade resultante. …............47

Tabela 17 - (a,b) Pares de imagens do repositório Tsukuba. (c) Mapa de disparidade resultante..............48

Tabela 18 - (a,b) Pares de imagens sintéticas do repositório Bonn. (c) Mapa de disparidade resultante...49 
PÁGINA INTENCIONAMENTE DEIXADA EM BRANCO 


\section{SUMÁRIO}

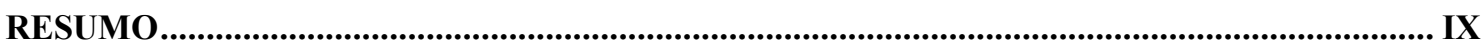

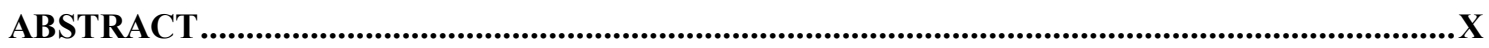

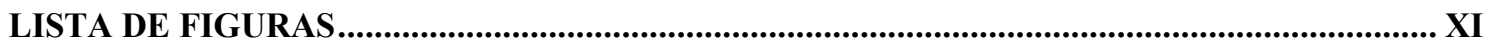

LISTA DE TABELAS .................................................................................................................... XII

1 INTRODUÇÃO

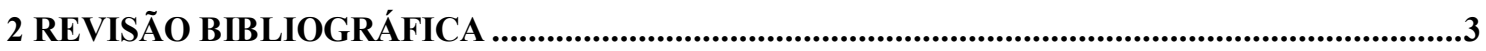

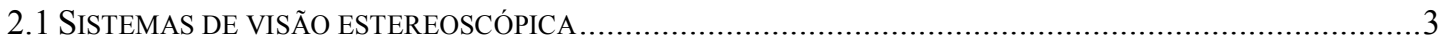

2.1 DISPOSITIVOS DE LÓGICA PROGRAMÁVEL - FPGAS.......................................................................

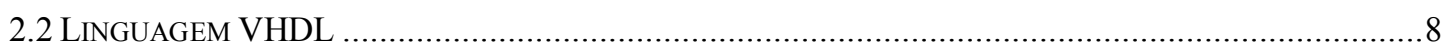

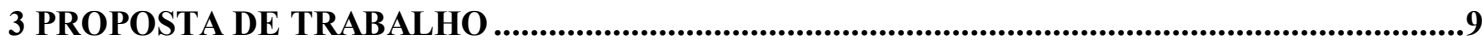

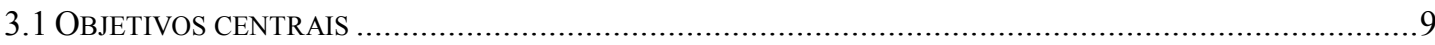

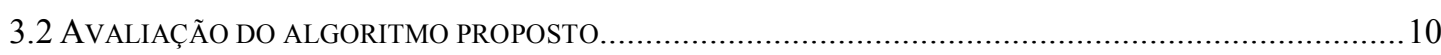

4 MODELAMENTO, SIMULAÇÕES E IMPLEMENTAÇÃO......................................................11

4.1 PARAMETRIZAÇão E MODELAMENTO MATEMÁTICO.................................................................11

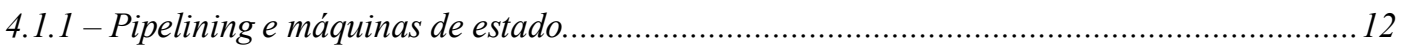

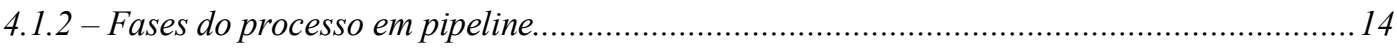

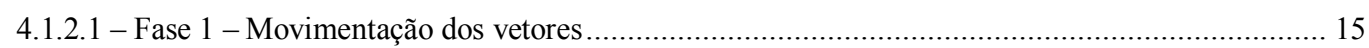

4.1.2.2 - Fase 2 - Cálculo de diferenças entre vetores.......................................................................... 17

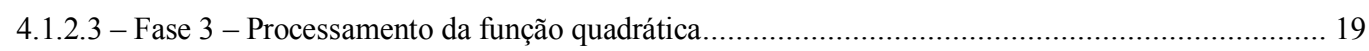

4.1.2.4 - Fase 4 - Processamento da função somatório ……………………………………………….... 20

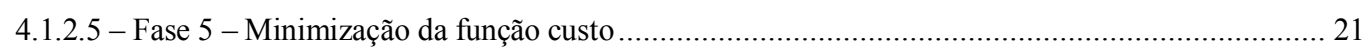

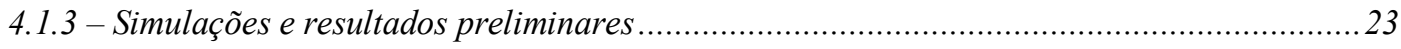

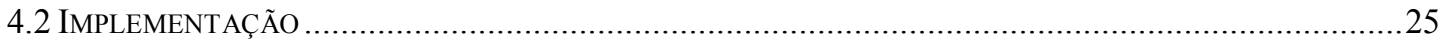

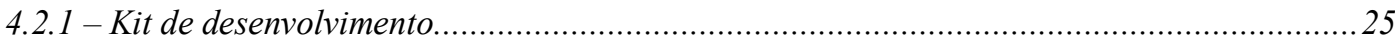

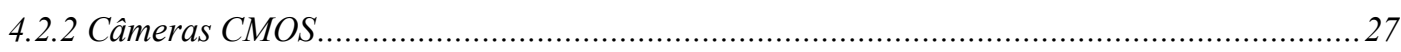

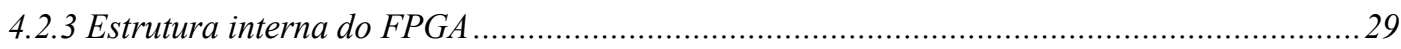

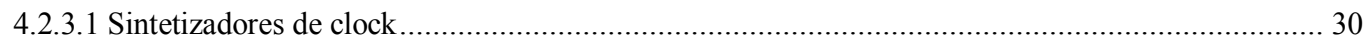




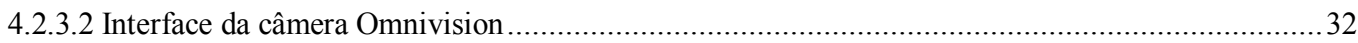

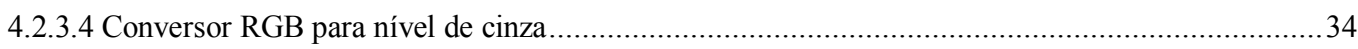

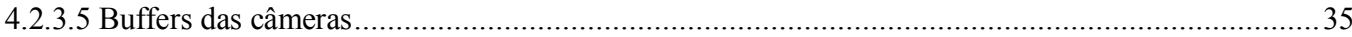

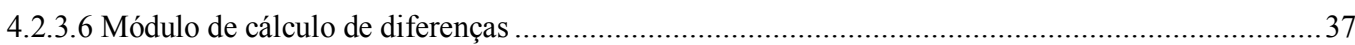

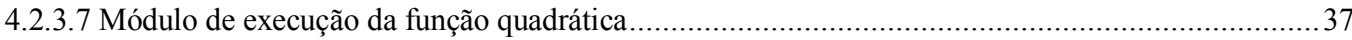

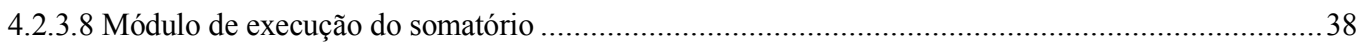

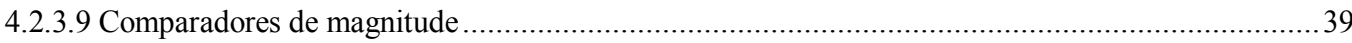

4.2.3.10 - Módulo de comunicação serial padrão RS-232 .......................................................................40

4.2.3.11 - Módulo de interface com os bancos de memória SRam ......................................................42

4.2.3.12 - Módulo de interface Câmera-SRam........................................................................................4

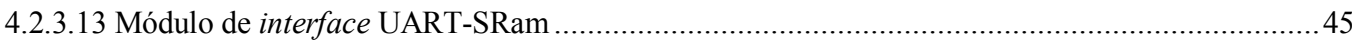

4.2.3.14 Montagem do pipeline e módulos acessórios........................................................................45

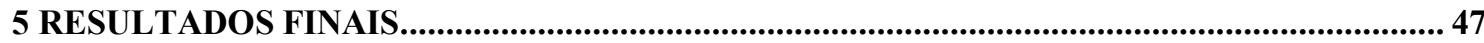

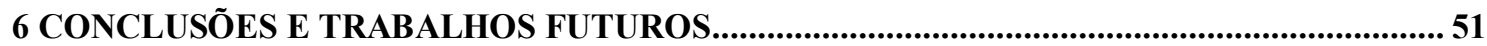

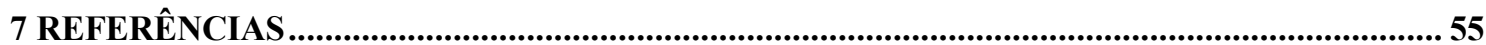

ANEXO A - ARTIGO PERIÓDICO LAAR.......................................................................5 57

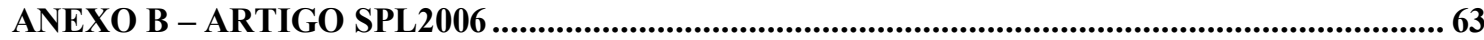




\section{INTRODUÇÃO}

A navegação autônoma de robôs e veículos autônomos tem apresentado considerável dificuldade quando tratada em ambientes dinâmicos.

Sistemas robóticos capazes de se adaptar a ambientes desconhecidos devem observar o mundo que os cerca e extrair características relevantes para execução de suas tarefas (navegação, identificação de objetos, etc.).

Para resolução de tais problemas pesquisadores têm utilizado uma ampla gama de transdutores (ultra-som, infravermelho, interferômetros laser, etc.) para extração de características tridimensionais do cenário, ou seja, avaliação de distância, forma e mesmo velocidade relativa de objetos.

Dos sistemas pesquisados, grande atenção tem sido dada aos módulos de visão estereoscópica. Estes módulos, constituídos tipicamente de um par de câmeras, têm o objetivo de obter múltiplas imagens de uma mesma cena sob diferentes pontos de vista, e processando-as adequadamente, extrair informações dimensionais da cena, permitindo finalmente a elaboração de uma aproximação tridimensional dos objetos observados.

Alvo de estudo e desenvolvimento nesta pesquisa, se definiu um algoritmo básico para extração de características de pares de imagens 2D, visualizando aplicação em dispositivos de lógica programável.

Em especial, foram utilizados como principal referência os métodos propostos por BIRCHFIELD e TOMASI (1998) e os trabalhos de HILE e ZENG (1996).

Para desenvolvimento do projeto selecionaram-se diversas ferramentas, dentre elas a plataforma de programação Delphi, o software para FPGA Xilinx ISE 6.3, e o simulador VHDL MentorGraphics ModelSim. 
A Figura 1 exibe de forma estruturada a organização dos estudos e desenvolvimento, referenciando a cada um dos capítulos desta tese.

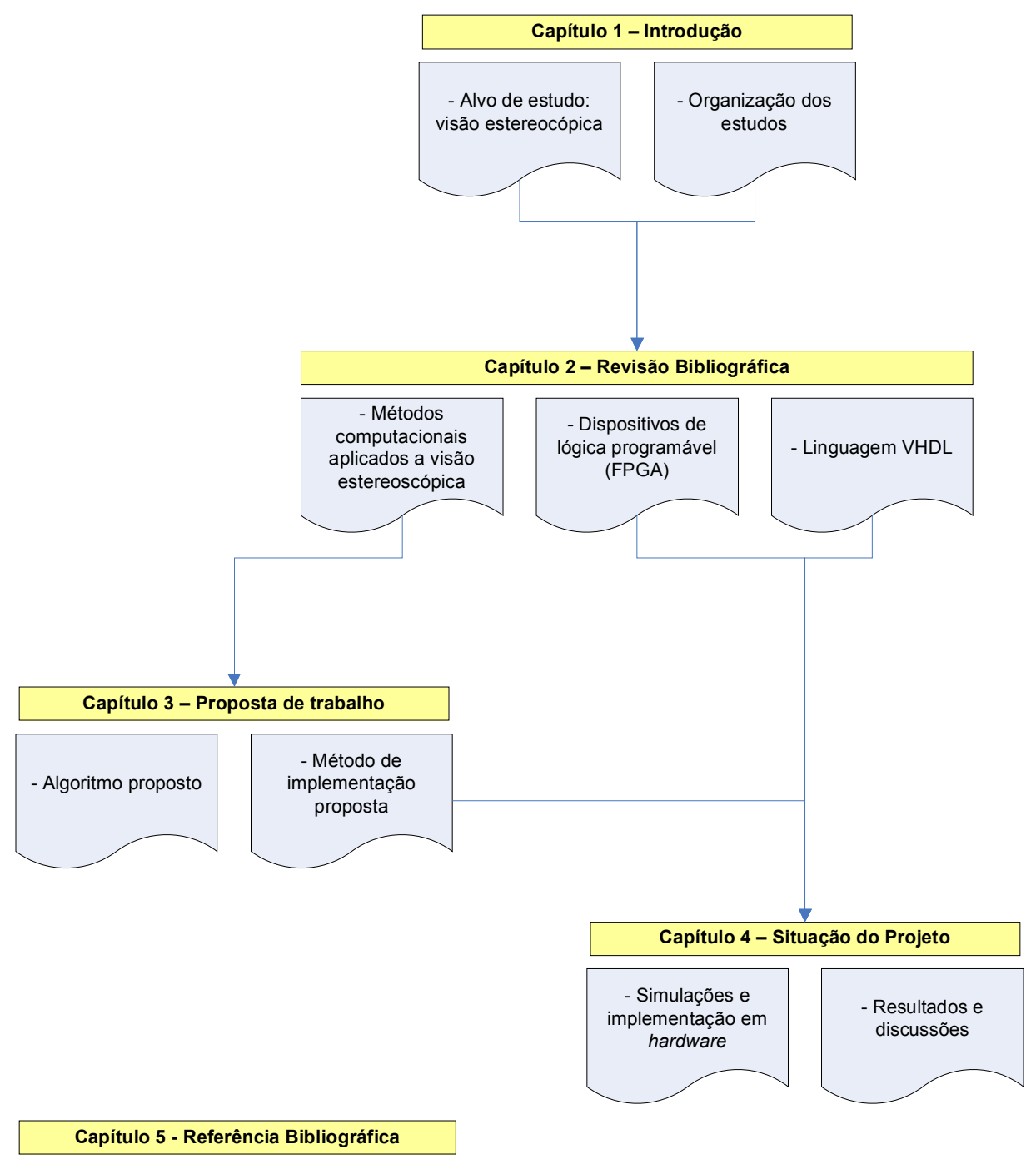

Figura 1 - Estrutura da monografia apresentada 


\section{REVISÃO BIBLIOGRÁFICA}

\subsection{Sistemas de visão estereoscópica}

O núcleo funcional de qualquer sistema de visão estereoscópica está no processo de combinação das duas imagens com o objetivo de identificar pontos cuja origem é de um mesmo elemento da cena observada.

Este processo de identificação e quantização das distâncias entre as imagens apresenta uma série de dificuldades, especialmente devido à presença de ruído nas imagens, descontinuidades e oclusão de elementos.
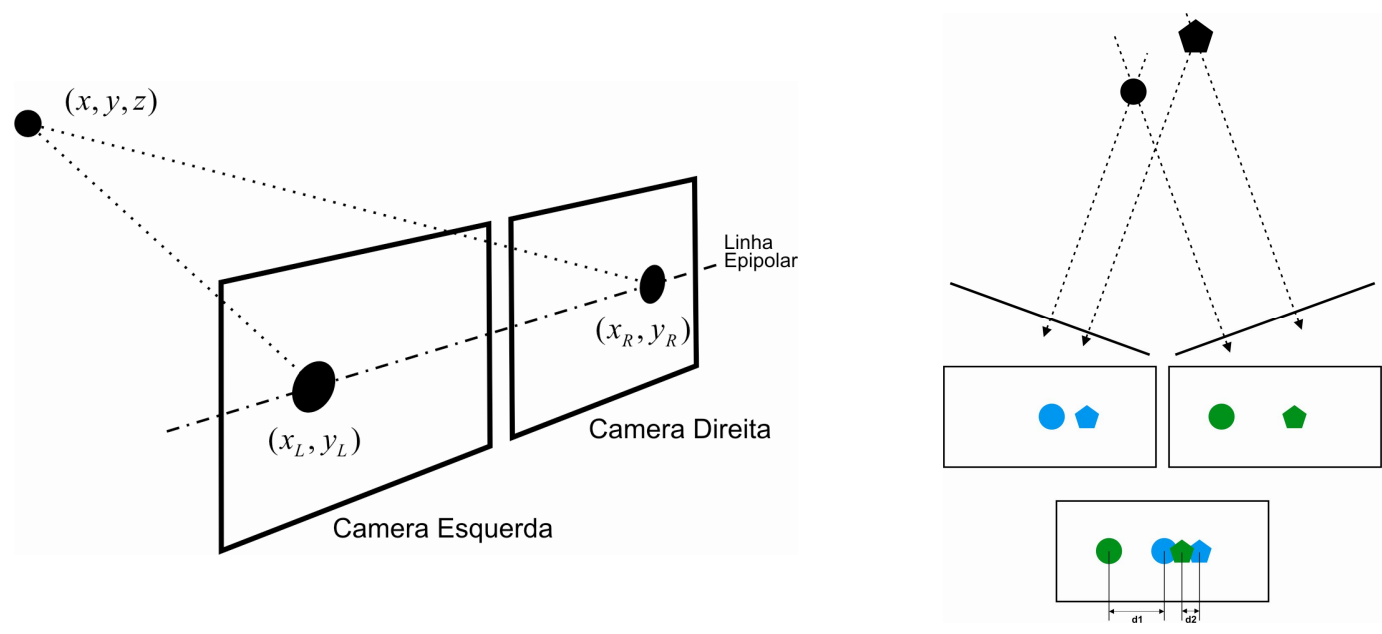

Figura 2 - Típica situação problema em visão estereoscópica

A Figura 2 exibe a típica situação problema em visão estereoscópica onde duas câmeras, observando uma cena, obtêm duas representações bidimensionais de um mesmo objeto tridimensional. Processamento adequado permite que as duas imagens sejam recombinadas, regenerando as informações tridimensionais perdidas. 
Conforme modelamento do problema por GROSSO e TISTARELLI (1995), a extração da característica de profundidade pode ser obtida utilizandose algumas observações trigonométricas.

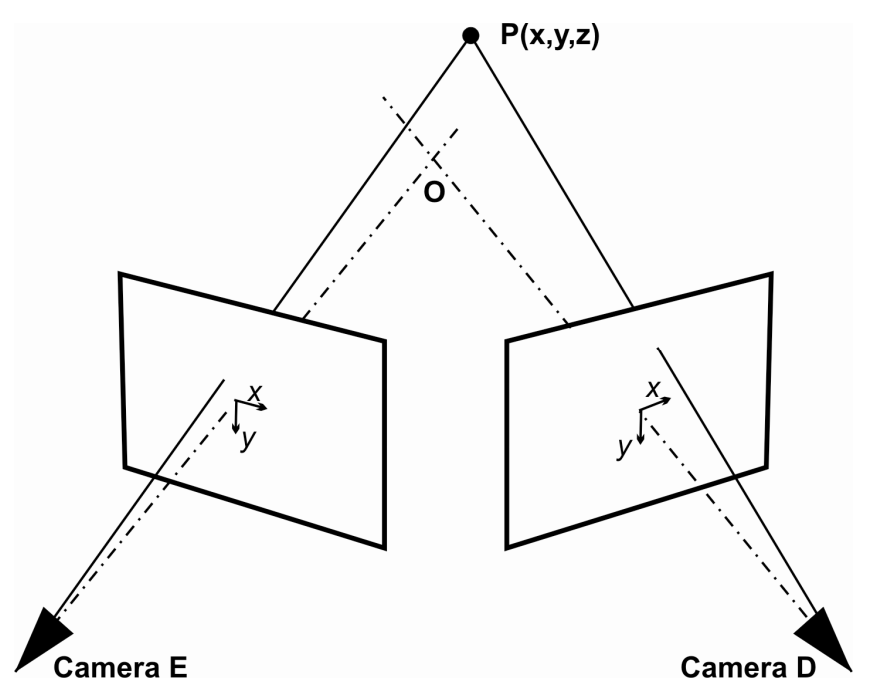

Figura 3 - Representação esquemática espacial de um sistema de visão estereoscópico.

Para análise do problema é definida uma representação espacial para a montagem típica de um sistema de visão estereoscópica, conforme mostrado na Figura 3. No esquema, o ponto $P(x, y, z)$ é observado por duas câmeras e os eixos y das câmeras são paralelos e ortogonais ao plano definido pelos eixos ópticos. $O$ ponto $O$ indica o ponto de convergência focal das câmeras.

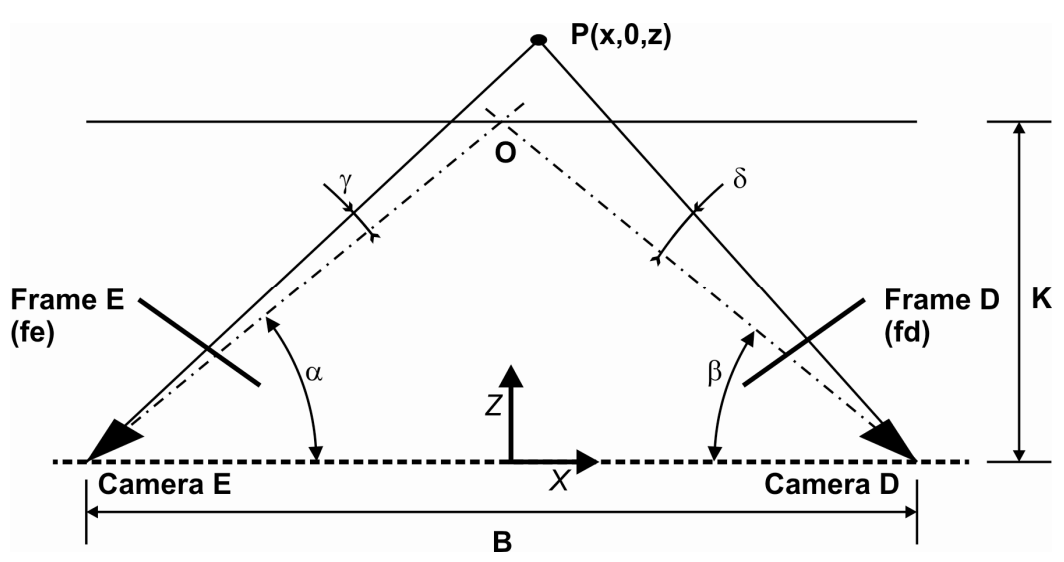

Figura 4 - Projeção $(y=0)$ do modelo do sistema de visão estereoscópico.

Os parâmetros de interesse do sistema estudado estão identificados na Figura 4. 
A fim de demonstrar que a profundidade do ponto $P$ pode ser diretamente inferida dos parâmetros do sistema, será definida a função $K$, conforme indicado na eq. (1).

$$
K(\alpha, \beta, \gamma, \delta)=\frac{\tan (\alpha-\gamma) \cdot \tan (\beta+\delta)}{\tan (\alpha-\gamma)+\tan (\beta+\delta)}
$$

$\alpha$ e $\beta$ são respectivamente os ângulos de vergência das câmeras esquerda e direita. Pode-se observar que $\gamma$ e $\delta$ definem a disparidade angular dos de dois pontos correspondentes nos planos de imagem fe e fd, onde a posição relativa destes pontos difere de $f d=f e+D$, sendo $D$ o parâmetro disparidade, foco de estudo deste trabalho.

Os parâmetros $\gamma$ e $\delta$ podem ser equacionados conforme indicados na eq. (2) e eq. (3).

$$
\begin{aligned}
& \gamma=\arctan \left(\frac{f e}{F e}\right) \\
& \delta=\arctan \left(\frac{f d}{F d}\right)
\end{aligned}
$$

Fe e Fd definem as distâncias focais das câmeras, em pixels.

Dessa forma é possível mostrar que a profundidade do ponto $P$, em referência ao eixo $Z$ do sistema de coordenadas, é função dos demais parâmetros citados, conforme eq. (4).

$$
Z=B \cdot K(\alpha, \beta, \gamma, \delta)
$$

B define a distância base entre as câmeras, e é um parâmetro fixo do sistema.

Vale notar que a medição da profundidade, referenciada no ponto $O$ deve depender apenas dos ângulos de vergência das câmeras. 
Atualmente existem três grandes vertentes de estudos para detecção e criação de mapas de disparidades. Suas bases fundamentam-se na análise de intensidade, características locais e fase.

BIRCHFIELD e TOMASI (1998), COX et al. (1996), BELHUMER (1993) propuseram no passado algoritmos cujo núcleo funcional se baseia na minimização de funções de custo, onde são computadas as diferenças absolutas ou quadráticas das intensidades de pixels em pares de imagens epipolares. Estes métodos, apesar de resultados satisfatórios, são baseados em programação dinâmica, resultando custo computacional proibitivo para processamento em tempo real, sendo assim inadequados para implementação em hardware.

HILE e ZENG (1996), YOSHIDA e HIROSE (1992), propõem algoritmos também baseados na observação da intensidade de pixels, porém estruturados para implementação em dispositivos de lógica programáveis, o que confere processamento em tempo real, a custo de insensibilidade a oclusões e limitada região de análise para detecção de correspondências.

Outros pesquisadores, como TAKENO e HACHIYAMA (1991), MURRAY e JENNINGS (1991), GROSSO e TISTARELLI (1995) mostraram em seus estudos as novas possibilidades de caracterização de cena e navegação, fruto da obtenção em tempo real de informações tridimensionais do ambiente, mais especificadamente através da análise do mapa de disparidades.

O alvo de estudo desta pesquisa fundamenta-se na análise da intensidade local de pixels, associada a estruturas de processamento concorrente. 


\subsection{Dispositivos de lógica programável - FPGAs}

FPGAs (Field Programmable Gate Array) são circuitos integrados passíveis de configuração por software, permitindo a implementação física de circuitos digitais, desde simples estruturas lógicas, como interfaces e decodificadores, até sistemas complexos, como processadores e controladores. Sua estrutura interna consiste de um arranjo fortemente condensado de blocos idênticos, compostos por portas lógicas, dispositivos flipflop e acionadores de Entrada/Saída. As conexões entre blocos são implementadas através de um mapa de conexões, realizado fisicamente (programação por fusíveis) ou espelhado em um dispositivo de memória.

Dispositivos modernos FPGA possuem basicamente três conjuntos de elementos configuráveis. O primeiro consiste de vários circuitos idênticos, compostos por flip-flops e lógica combinacional, conhecidos por CLBs (Configuration Logical Blocks). Os CLBs possuem os elementos funcionais básicos para implementação de lógicas seqüenciais e combinacionais. Usualmente são constituídos por 2 a 4 flip-flops agregados a um conjunto genérico de lógicas combinacionais.

O segundo conjunto de elementos configuráveis consiste de circuitos de interface das saídas dos CLBs com o exterior do FPGA, conhecidos como IOBs (Input-Output Blocks). Estes são constituídos por buffers bidirecionais e saídas de alta-impedância. Através da programação adequada de um IOB, é possível obter pinos com função de entrada, saída, bidirecional ou coletor-aberto.

O terceiro e último grupo é composto pelas interconexões. As interconexões apresentam condensados de trilhas capazes de interconectar as entradas e saídas dos CLBs e IOBs para formar os circuitos digitais desejados. Geralmente a configuração é estabelecida por programação interna das células de memória estática, que determinam funções lógicas e conexões internas implementadas no FPGA. O processo de escolha das interconexões é chamado de roteamento e pode ser executado manualmente ou com auxílio de ferramentas de desenvolvimento. 


\subsection{Linguagem VHDL}

Com a crescente sofisticação e diversificação tecnológica dos dispositivos de lógica programável tornou-se necessária a elaboração de uma linguagem de programação que permitisse a geração de circuitos lógicos a partir de descrições textuais algorítmicas.

Desenvolvido nos meados da década de 80 pelo Departamento de defesa dos EUA, a linguagem VHDL - VHSIC Hardware Description Language - tornou-se atualmente a principal ferramenta para programação de dispositivos de lógica programável, garantindo grande portabilidade no código e alto grau de abstração dos algoritmos programados.

Estruturado como uma linguagem de programação completa, os compiladores VHDL atuais permitem a programação de algoritmos estruturados baseado em modelos de hardware, verificação funcional através de ferramentas de simulação e por fim geração do mapeamento físico específico para implementação da lógica em um dispositivo ASIC ou FPGA.

A Figura 5 mostra um ciclo típico de desenvolvimento VHDL. Assim como uma linguagem de programação tradicional, o ciclo típico de programação parte de alta abstração (algorítmica) movendo-se em direção do código de máquina ou netlist, no caso da linguagem VHDL.

Durante este processo, a depuração se torna possível por simuladores específicos, capazes de analisar características dos circuitos lógicos sem a necessidade de implementação no dispositivo físico.

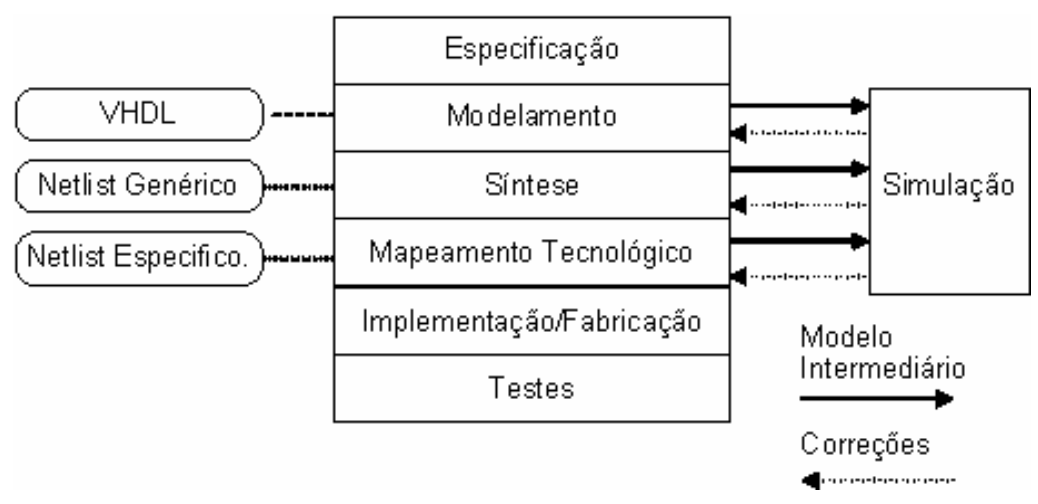

Figura 5 - Ciclo de vida típico de um projeto VHDL 


\section{PROPOSTA DE TRABALHO}

\subsection{Objetivos centrais}

O projeto desenvolvido teve por objetivo a elaboração e implementação de um algoritmo para extração do mapa de disparidades de imagens estereoscópicas, focando futuras aplicações em dispositivos de lógica programável.

Neste sentido foi proposto um algoritmo que utiliza uma técnica de observação de intensidade dos pixels constituintes de cada imagem e, mistura características de varredura de janelas e avaliação pixel-a-pixel para levantamento do mapa de disparidades.

A arquitetura proposta é única em sua construção uma vez que mistura elementos de processamento concorrente e seqüencial, visando sua implementação em dispositivos de lógica programável.

Para análise objetiva e comparação com resultados obtidos por outros pesquisadores - em especial BIRCHFIELD, S.; TOMASI, C. (1998) - foram utilizadas pares de fotos do repositório JISCT. Adicionalmente foram comparados resultados com pares de imagens estereoscópicas disponibilizadas pelo grupo de visão computacional da universidade de Tsukuba, e com pares de imagens estereoscópicas sintéticas (geradas através de algoritmos de ray-tracing) disponibilizadas pelo grupo de visão computacional da Universidade de Bonn.

Os objetivos deste trabalho foram realizados em duas fases distintas: simulação e implementação em lógica programável. Com isso procurou-se demonstrar as funcionalidades do algoritmo proposto, tanto como sua aplicabilidade em dispositivos de lógica programável. 


\subsection{Avaliação do algoritmo proposto}

Um sistema típico de visão estereoscópica, constituído de um par de câmeras CMOS, uma placa de desenvolvimento (contendo um dispositivo de lógica programável), um computador (para monitoramento e programação) e interfaces de hardware acessórias ao desenvolvimento, foram utilizados para avaliação do método proposto.

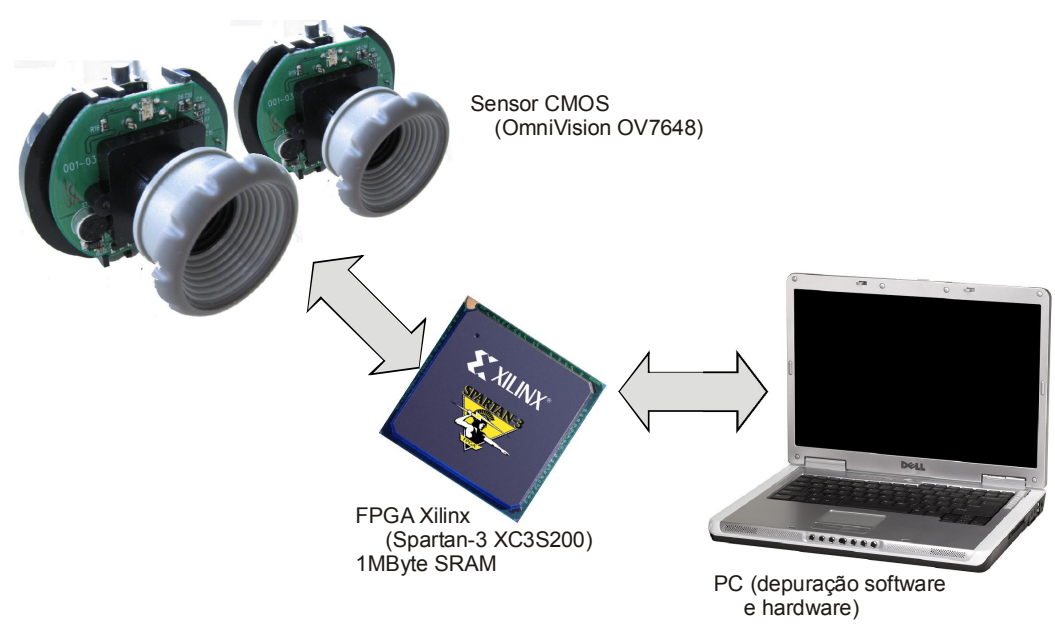

Figura 6 - Esquema geral do projeto proposto

Em uma primeira fase dos estudos o algoritmo proposto foi simulado utilizando software especialmente desenvolvido - e posteriormente implementado em um dispositivo de lógica programável, demonstrando sua capacidade de processar em tempo real as informações provenientes das câmeras CMOS e disponibilizar, em uma memória externa SRAM, as informação processadas. 


\section{MODELAMENTO, SIMULAÇÕES E IMPLEMENTAÇÃO}

\subsection{Parametrização e modelamento matemático}

Para descrição do método proposto serão denotados $F_{e}$ e $F_{d}$ as imagens pré-processadas dos sensores CMOS, localizados respectivamente à direita e esquerda na montagem de ensaio. As imagens pré-processadas possuem largura de $w$ pixels por $h$ pixels de altura, sendo que cada pixel destas imagens representa uma de 256 possíveis intensidades de cinza (quantização de 8-bit em níveis de cinza).

As imagens $F_{e}$ e $F_{d}$ serão tratadas na seqüência deste documento como sendo respectivamente os vetores $\vec{e}$ e $\vec{d}$, de comprimento (w.h).

$I_{e}(k)$ e $I_{d}(k)$ denotam as intensidades de um dado pixel $k$ nos vetores $\vec{e}$ e $\vec{d}$, onde $k \in\{0,1, \ldots,(w \cdot h)-1\}$.

É definido o parâmetro $\omega$ como sendo a largura das janelas utilizadas, e $\beta$ a região de observação em torno do pixel $k$.

Define-se a função similaridade como sendo

$$
S(j)=\sum_{i=k-\frac{1}{2} \omega}^{k+\frac{1}{2} \omega}\left[I_{e}(i)-I_{d}(i+j)\right]^{2} \text { com } i \in Z, \omega \in\{1,3,5,7, \ldots\}
$$

Define-se a função custo como sendo

$$
C(k)=\min _{-\beta+1 \leq j \leq \beta}\{S(j)\}
$$


O cálculo do mapa de disparidade ocorre pixel a pixel; envolve, entretanto, a observação de janela centradas no pixel em observação $k$, como mostra esquematicamente a Figura 7 .

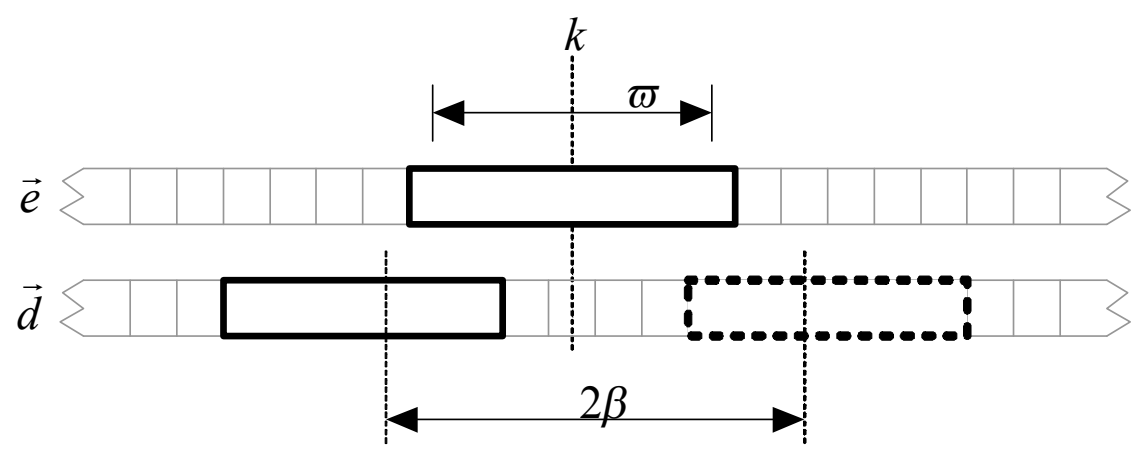

Figura 7 - Janelas observadas nos vetores $\vec{e}$ e $\vec{d}$

O modelamento algorítmico para processamento das funções similaridade e custo são apresentados nos tópicos a seguir.

\subsection{1 - Pipelining e máquinas de estado}

Para que a implementação do algoritmo no FPGA permita análise em tempo real das imagens, foi estudado e desenvolvido um forte arranjo híbrido, utilizando processamento em pipeline associado ao processamento seqüencial de diversas máquinas de estado. Isto permite que, após um desprezível atraso inicial (tipicamente inferior a $1 \mu \mathrm{s}$, variando conforme profundidade dos buffers de entrada), seja possível obter o mapa de disparidades da cena em tempo real.

Serão definidas diversas regiões de memória, utilizadas para processamento do algoritmo durante as diversas fases de pipeline e subprocessos seqüenciais.

As fases de pipeline foram estruturadas baseadas nos resultados de simulação, onde:

Dimensões de um quadro $(w \times h)=160 \times 120$ pixels

Largura da janela $\omega=11$ pixels

Região de observação $\beta=4$ pixe/s 
Como o algoritmo requer apenas uma limitada janela de observação para processamento da disparidade, é armazenada na memória interna do FPGA apenas uma pequena seqüência de pixels provenientes das câmeras CMOS. Desta forma os vetores $\vec{e}$ e $\vec{d}$ podem ser limitadamente observados em torno de um dado pixel $k_{0}$. Sendo assim, os vetores $\vec{e}$ e $\vec{d}$ serão tratados, para efeito de entendimento, como vetores das imagens das câmeras CMOS, possuindo entretanto apenas um limitado número de posições acessíveis para processamento.

Para alocação do vetor $\vec{e}$ serão utilizados $R A M$ blocks internos do FPGA, consistindo de $\omega$ blocos com 8-bit de largura e designados por $e=\left\{k e_{-5}, k e_{-4}, \ldots, k e_{0}, \ldots, k e_{+5}\right\}$, conforme esquema da Figura 8.

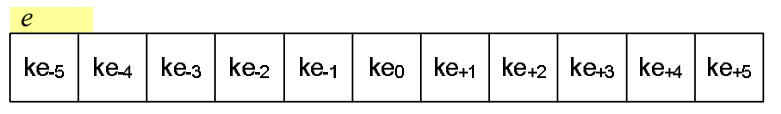

Figura 8 - Alocação do vetor $\vec{e}$ (88 bits)

De forma análoga, para alocação do vetor $\vec{d}$ serão utilizados $R A M$ blocks internos do FPGA, consistindo de $[\omega+(2 \cdot \beta-1)]$ blocos com 8-bit de largura e designados por $d=\left\{k d_{-8}, k d_{-7}, \ldots, k d_{0}, \ldots, k e_{+9}\right\}$, conforme esquema da Figura 9.

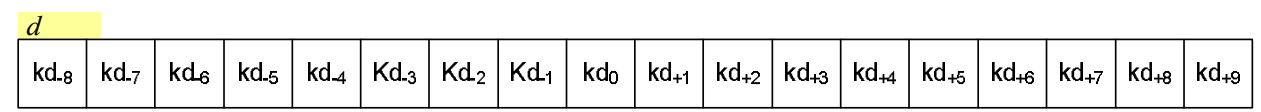

Figura 9 - Alocação do vetor $\vec{d}$ (144 bits)

Para execução do processamento síncrono das informações dos sensores CMOS e formação da cadeia em pipeline são necessários três sinais fundamentais de clock, como indicado na Figura 10. 


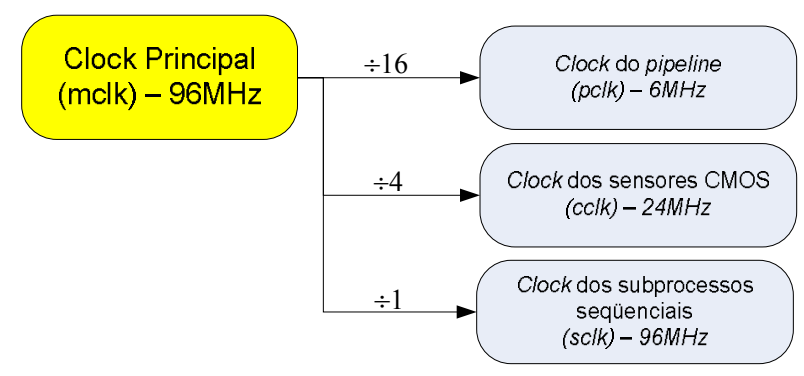

Figura 10 - Diagrama dos sinais fundamentais de clock

O clock principal (mclk) é sintetizado internamente ao FPGA, a partir do oscilador externo de $50 \mathrm{MHz}$, disponível na placa de desenvolvimento. Este sinal de clock é base para geração dos demais sinais necessários, permitindo sincronização dos processos de transferência e máquinas de estado.

O clock do pipeline (pclk) é responsável pela execução de cada uma de suas fases, discutidas nas seções posteriores.

O clock dos sensores CMOS (cclk) é utilizado para obtenção e redução de $4: 1$ dos pixels recebidos.

O clock dos sub-processos seqüenciais (sclk) é utilizado em diversas fases do processo em pipeline para execução de rotinas que não podem ser processadas concorrentemente, isto é, as máquinas de estado internas a cada uma das fases do processo de pipeline.

\subsection{2 - Fases do processo em pipeline}

As próximas seções detalham cada uma das fases do processo de pipeline, responsáveis pela movimentação, transformação e avaliação das informações obtidas das câmeras CMOS. Vale notar que, apesar da estruturação do processo em fases, estas ocorrem de forma concorrente, permitindo assim o fluxo contínuo de informações. Um esquema geral do processo é mostrado na Figura 11. 


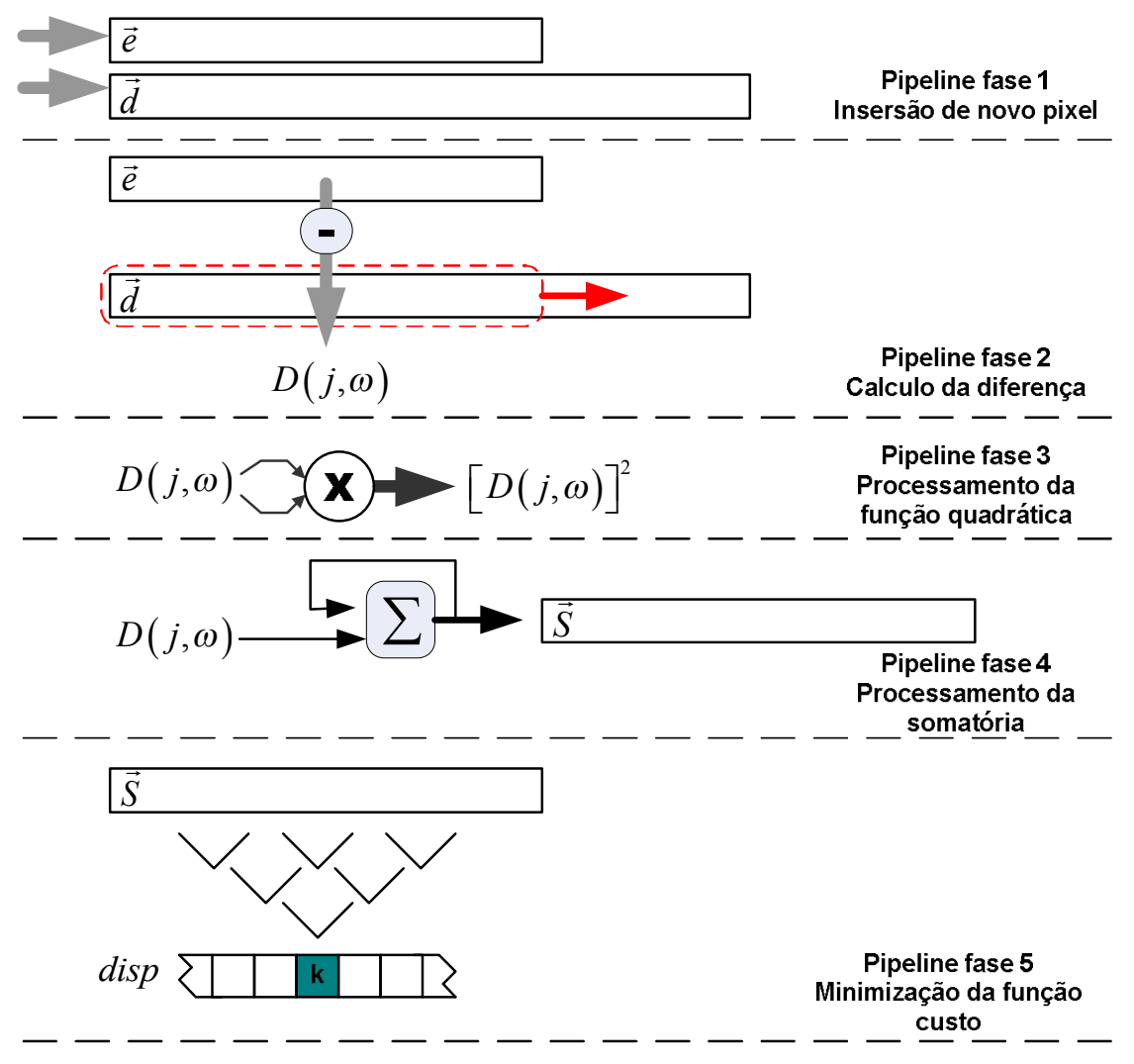

Figura 11 - Estrutura geral de processamento em pipeline para o algoritmo proposto

\subsubsection{1 - Fase 1 - Movimentação dos vetores}

A fase 1 do pipeline consiste em movimentar ambos os vetores para a esquerda, descartando os pixels nas posições $k e_{-5}$ e $k d_{-8}$ e liberando as posições $k e_{+5}$ e $k d_{+9}$ para dois novos pixels, proveniente dos respectivos sensores CMOS.

Esta fase é realizada seqüencialmente em dois ciclos de clock, onde no primeiro sinal clock (sclk0), os vetores $\vec{e}$ e $\vec{d}$ são copiados para posições temporárias de memória, respectivamente $e_{t m p}$ (alocado 80 bits) e $d_{t m p}$.(alocado 136 bits), indicado na Figura 12 e Figura 13.

O segundo clock da fase 1 , sclk2, é sincronizado com o clock dos sensores CMOS (cclk), efetuando a cópia do conteúdo dos vetores temporários para os vetores originais e armazenando os novos pixels disponíveis nas posições vagas, conforme indicado na Figura 14 e Figura 15. 


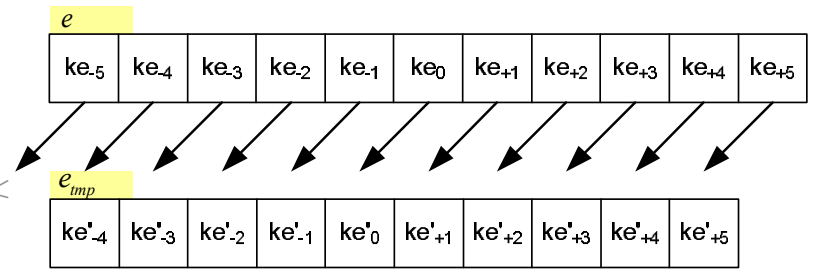

Figura 12 - Fase 1 do pipeline - Ciclo de clock sclk0 - Cópia do vetor $\vec{e}$

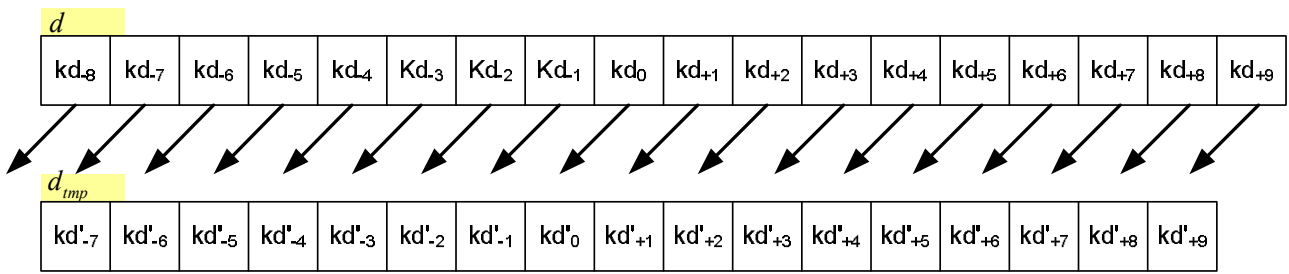

Figura 13 - Fase 1 do Pipeline - Ciclo de clock sclk0 - Cópia do vetor $\vec{d}$

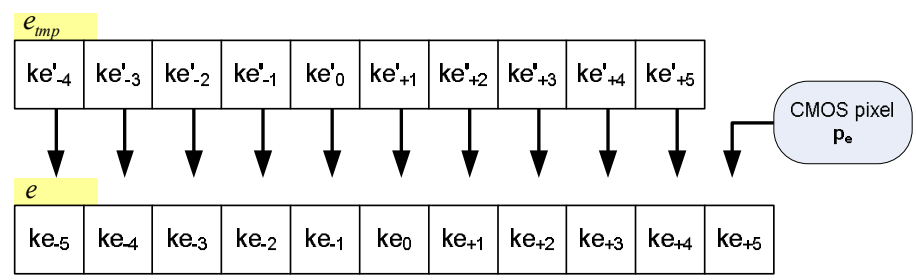

Figura 14 - Fase 1 do pipeline - Ciclo de clock sclk1 - Inserção do novo pixel $p_{\mathrm{e}}$

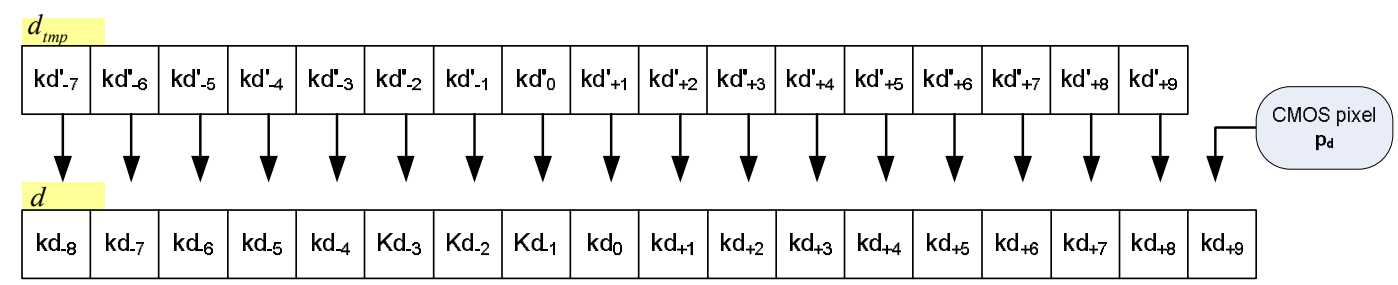

Figura 15 - Fase 1 do pipeline - Ciclo de clock sclk1 - Inserção do novo pixel $p_{d}$

Terminada a fase 1 os vetores $\vec{e}$ e $\vec{d}$ contêm novos pixels provenientes dos respectivos sensores CMOS e estão prontos para a seqüência de cálculos de diferenças realizadas na fase 2 . 


\subsubsection{2 - Fase 2 - Cálculo de diferenças entre vetores}

Nesta fase são calculadas as diferenças de intensidade entre os pixe/s $k e$ e $k d$, observando-se para cada conjunto de diferenças o vetor $\vec{e}$ e uma das janelas de comparação do vetor $\vec{d}$.

As diferenças obtidas são armazenadas em blocos de memória interna do FPGA com largura de 9-bits (8-bits + sinal), cujo endereços foram designados:.

$$
D(i, j)=I\left(k e_{i}\right)-I\left(k d_{(i+j)}\right)
$$

onde $i$ indica índice do vetor $\vec{e}$, com $i \in\{-5,-4, \ldots, 0, \ldots,+5\}$ e $j$ indica referência à janela utilizada no vetor $\vec{d}$, com $j \in\{-\beta+1, \ldots, 0, \ldots,+\beta\}=$ $\{-3,-2, \ldots, 0, \ldots,+4\}$.

Todos os cálculos ocorrem concorrentemente, sendo efetuado nesta fase de pipeline $\omega \cdot 2 \beta=88$ cálculos de diferenças, utilizando $88 \cdot 9=792$ bits da memória interna do FPGA.

A Figura 16 exibe esquematicamente o cálculo da diferença entre o vetor $\vec{e}$ e a janela $j=-\beta+1$ no vetor $\vec{d}$.

De forma concorrente todas as janelas no vetor $\vec{d}$ são avaliadas frente ao vetor $\vec{e}$. A Figura 17 e Figura 18 exibem esquematicamente o cálculo quando utilizado a janela $j=-\beta+2$ e a última janela, $j=+\beta$, no vetor $\vec{d}$, respectivamente.

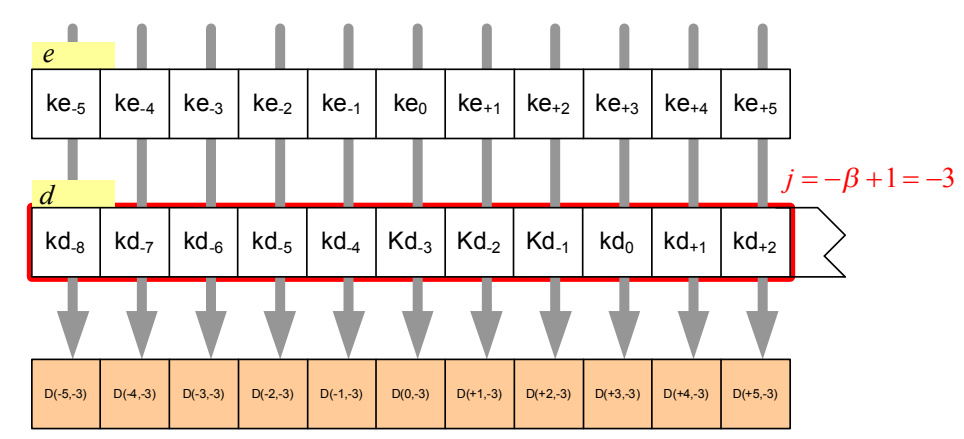

Figura 16 - Fase 2 do pipeline - Cálculo da diferença de intensidade - Janela $j=-\beta+1$ 


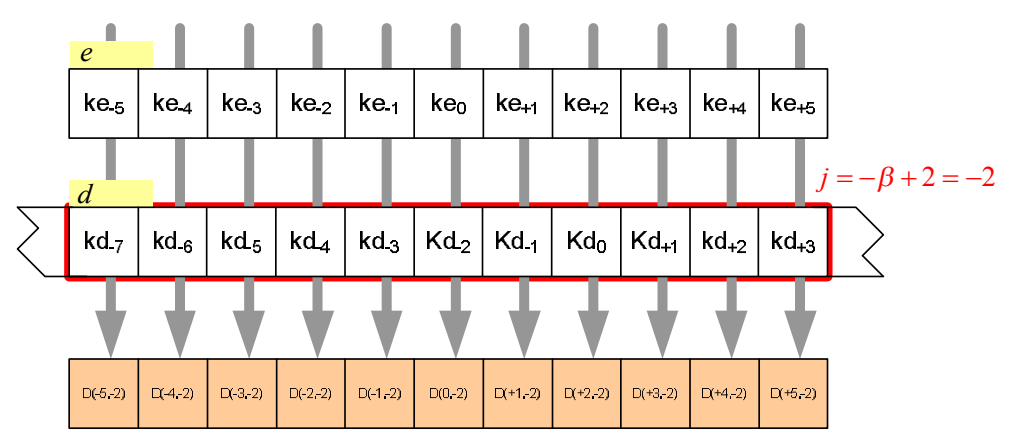

Figura 17 - Fase 2 do pipeline - Cálculo da diferença de intensidade - Janela $j=-\beta+2$

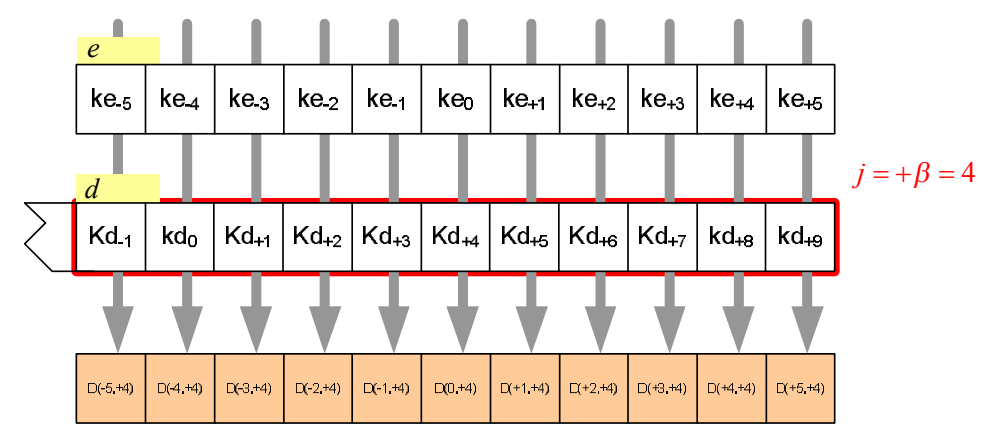

Figura 18 - Fase 2 do pipeline - Cálculo da diferença de intensidade - Janela $j=+\beta$

Como resultado da segunda fase do pipeline é obtido uma matriz contendo todas as diferenças calculadas (Figura 19).

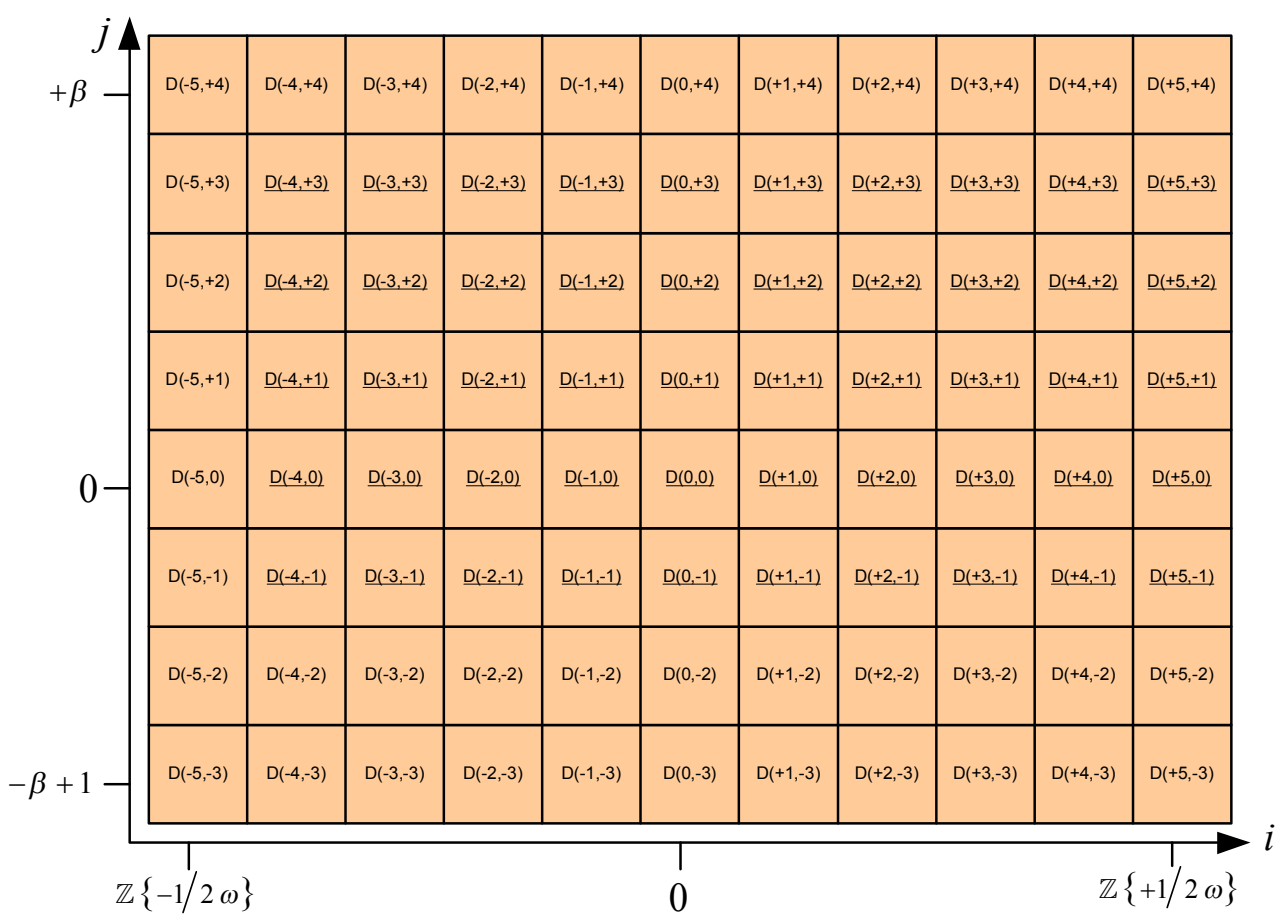

Figura 19 - Fase 2 do pipeline - Matriz resultante diferença $D(i, j)$ 


\subsubsection{3 - Fase 3 - Processamento da função quadrática}

A terceira fase do pipeline consiste em elevar ao quadrado cada uma das diferenças $D(i, j)$ calculadas na fase anterior. Esta fase é sequencialmente executada durante 8 ciclos de clock, sclk0 a sclk7.

O processamento utiliza concorrentemente, a cada ciclo de clock sclk, 11 multiplicadores (dos 12 disponíveis no FPGA Xilinx XC3S200), multiplicando cada uma das diferenças por ela mesma. $O$ resultado de cada uma destas multiplicações é armazenado nas posições de memória correspondentes $D^{2}(i, j)$, de 16-bit de largura.

Esta fase poderia ser condensada em um número menor de ciclos de clock caso houvesse um número maior de multiplicadores disponíveis (como, por exemplo, no modelo XC3S1500 da Xilinx que contém 32 multiplicadores disponíveis).

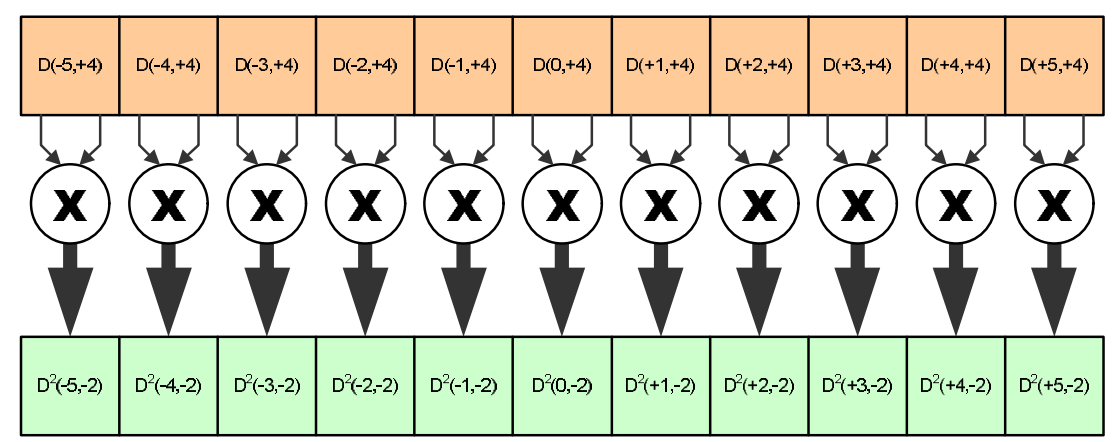

Figura 20 - Fase 3 do pipeline - Execução da função quadrática

Após término do sclk7 (oitavo ciclo de clock desta fase) estará disponível em memória o resultado de 88 operações de multiplicação, sendo alocado $88 \cdot 16=1408$ bits da memória do FPGA. 


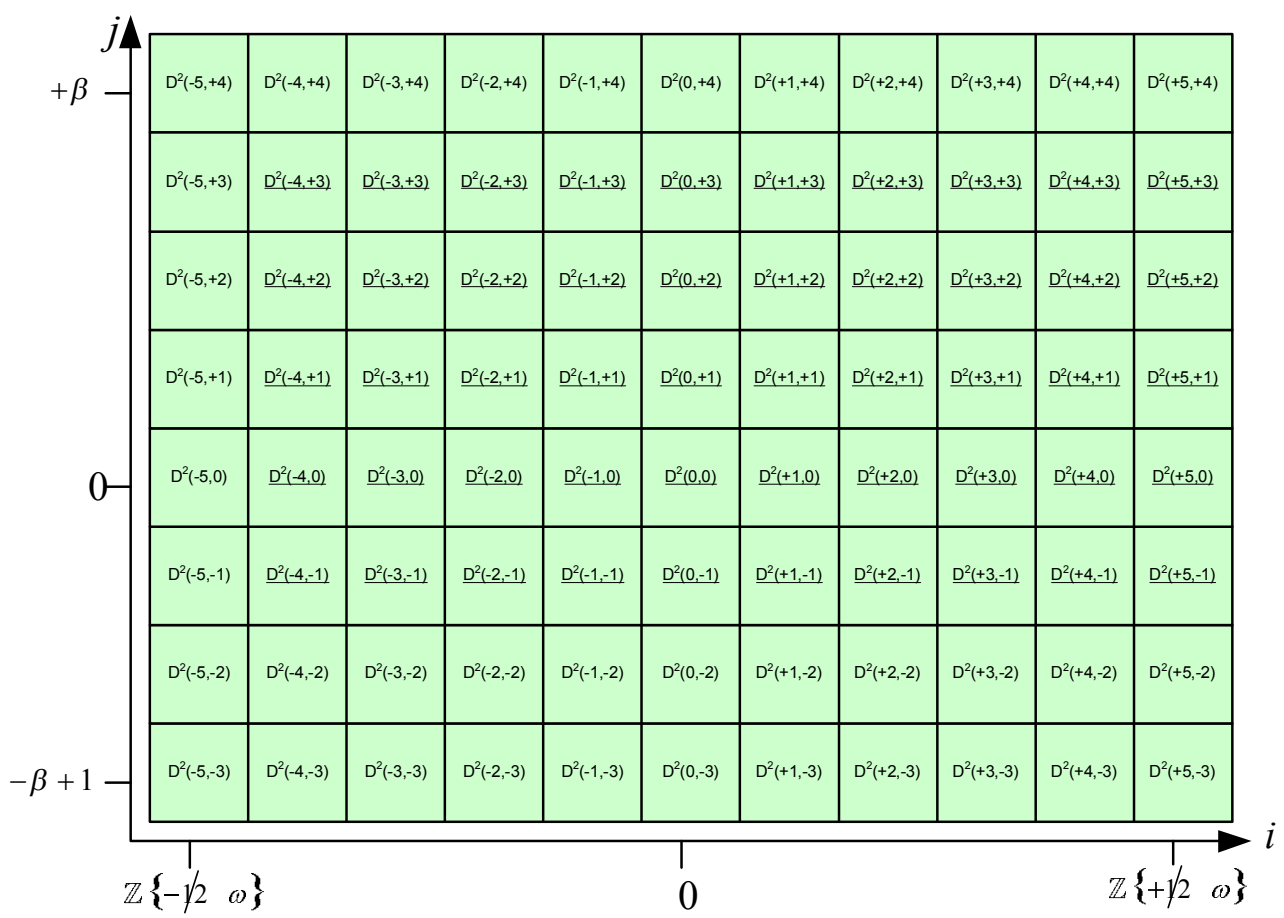

Figura 21 - Fase 3 do pipeline - Matriz resultante quadrática $D^{2}(i, j)$

\subsubsection{4 - Fase 4 - Processamento da função somatório}

A quarta fase do processo em pipeline consiste em efetuar a operação de somatório, necessária para avaliação da magnitude das janelas da fase 5 .

São alocados 8 somadores, responsáveis por executar concorrentemente os processos de soma de cada uma das linhas da matriz $D^{2}(i, j)$.

O processo da fase 4 é efetuado sequencialmente, consumindo 11 ciclos de clock (sclk0 a sclk10), onde, a cada ciclo de clock são efetuadas 8 operações de soma dos valores $D^{2}(i, j)$, resultando, ao final, o vetor $S(j)$. 


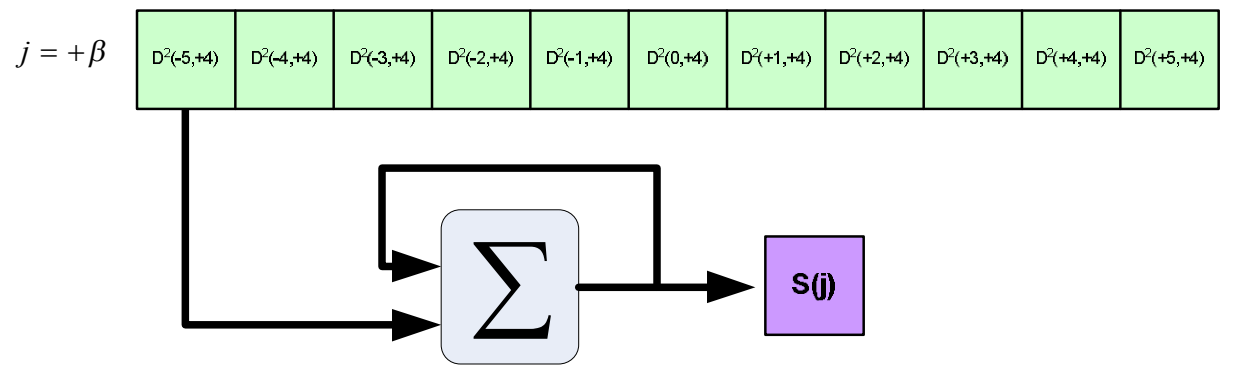

Figura 22 - Fase 4 do pipeline - Processamento da função somatória

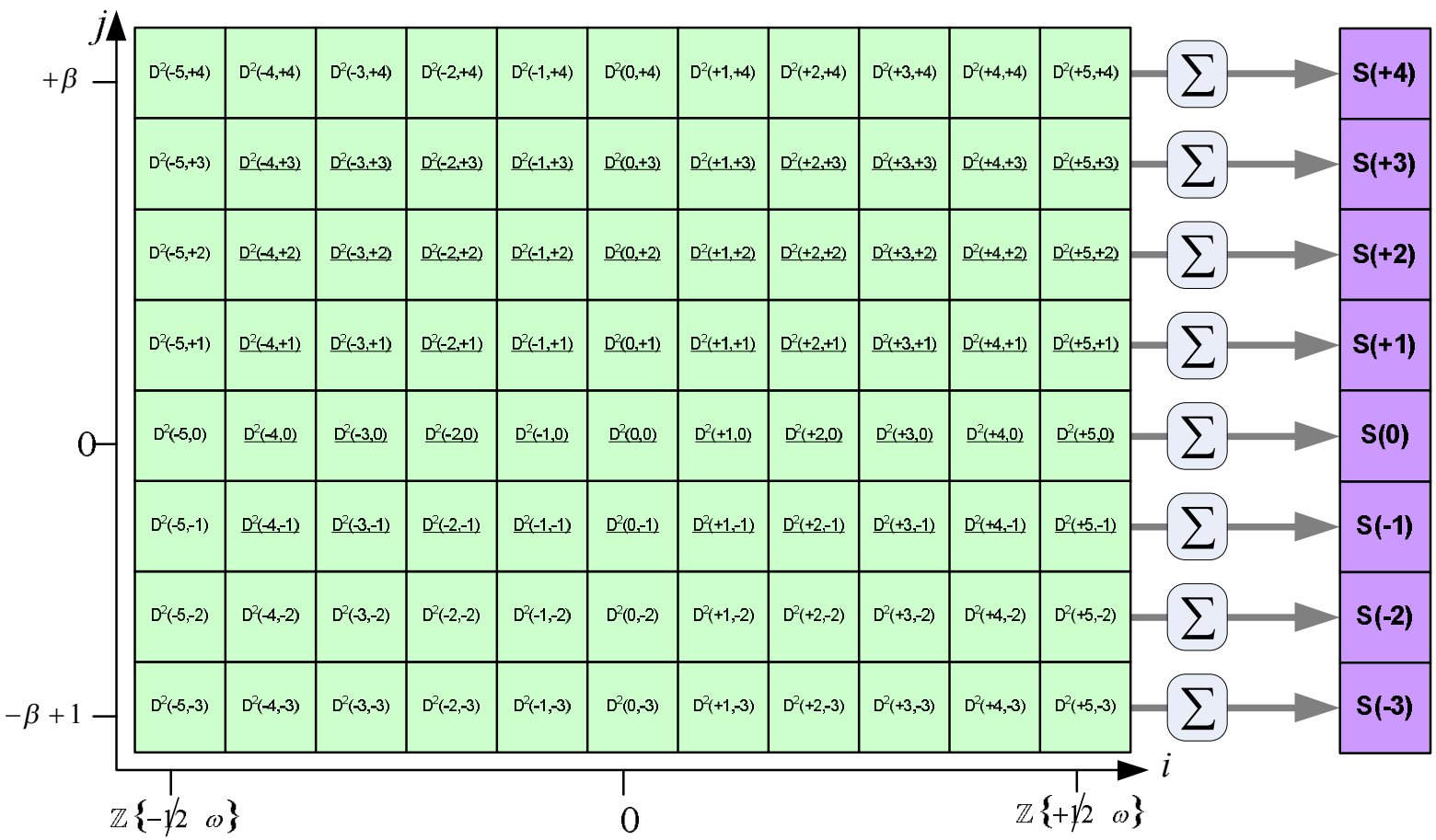

Figura 23 - Fase 4 do pipeline - Vetor resultante somatório $S(j)$

\subsubsection{5 - Fase 5 - Minimização da função custo}

A fase 5 do processamento em pipeline consiste em um processamento de comparações (estruturadas em topologia de árvore), responsável por executar a função $C(k)=\min _{-\beta+1 \leq j \leq \beta}\{S(j)\}$. Esta fase é composta por seis ciclos de clock, executando alternadamente comparações e movimentação de dados na memória. Na seqüência Figura 24, Figura 25, Figura 26, Figura 27, Figura 28 e Figura 29 é mostrado todo o processo de comparação até a obtenção e armazenamento do resultado final. 


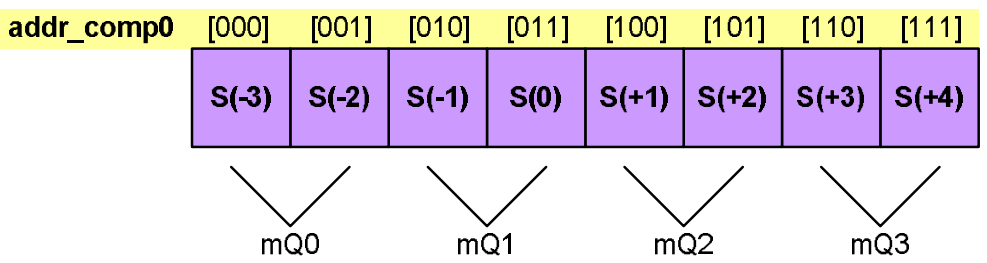

Figura 24 - Fase 5 do pipeline - Primeira comparação de magnitude

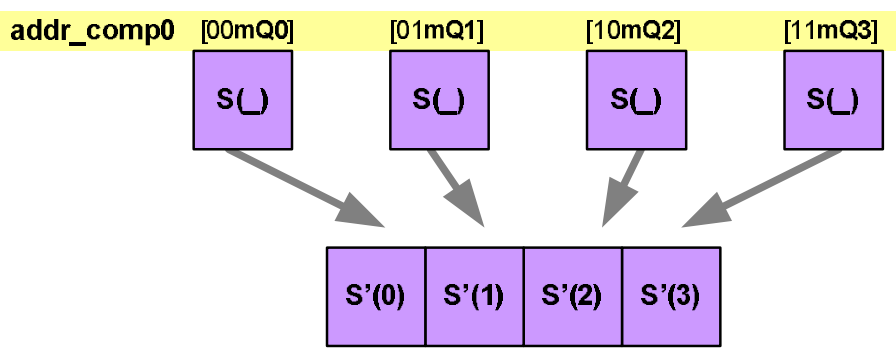

Figura 25 - Fase 5 do pipeline - Segunda comparação de magnitude

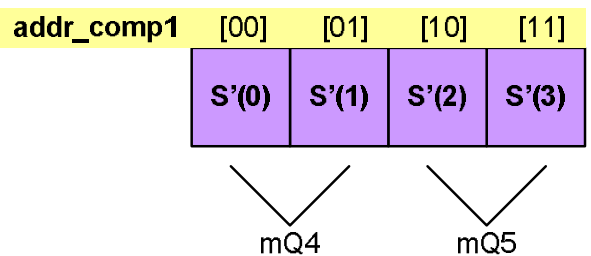

Figura 26 - Fase 5 do pipeline - Terceira comparação de magnitude

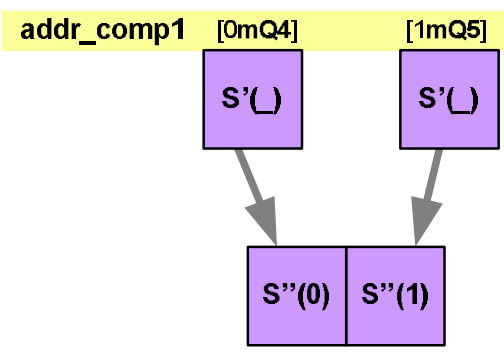

Figura 27 - Fase 5 do pipeline - Quarta comparação de magnitude

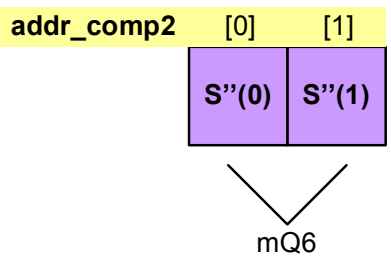

Figura 28 - Fase 5 do pipeline - Última comparação de magnitude 


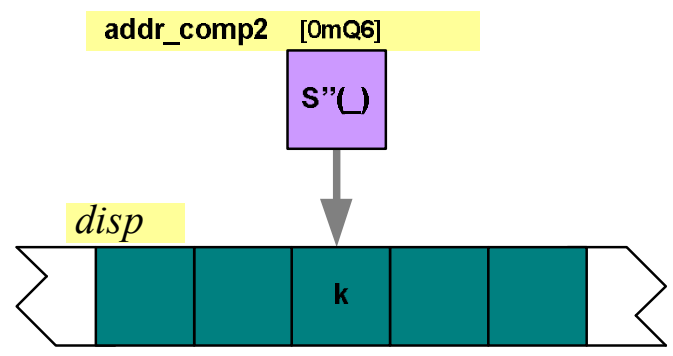

Figura 29 - Fase 5 do pipeline - Armazenamento da diferença mínima observada

\subsection{3 - Simulações e resultados preliminares}

Para avaliação do algoritmo proposto foi desenvolvido um programa de computador dedicado a emular funcionalmente o circuito digital a ser implementado no dispositivo FPGA.

O desenvolvimento deste programa dedicado surgiu das extremas limitações dos programas comerciais, como o Mentor Modelsim, em tratar informações complexas (quadros de vídeo, neste caso) e apresentar resultados graficamente representativos. Na maioria dos casos, o ciclo de simulação nestes softwares incorre em processos complexos de tratamento dos dados de entrada e saída, adicionando complexidade desnecessária, especialmente durante as fases iniciais de avaliação de viabilidade de um algoritmo.

A estrutura funcional básica do programa de simulação é mostrada na Figura 30.

A janela do programa de simulação é apresentada na Figura 31. Seu desenvolvimento foi realizado utilizando a plataforma de desenvolvimento Delphi.

Apesar do trabalho inicial, decorrência natural do desenvolvimento de um programa específico, esta ferramenta acelerou consideravelmente a avaliação do algoritmo e permitiu visualização gráfica e em detalhes de cada um dos sub-processos empregados durante o processamento das imagens. 


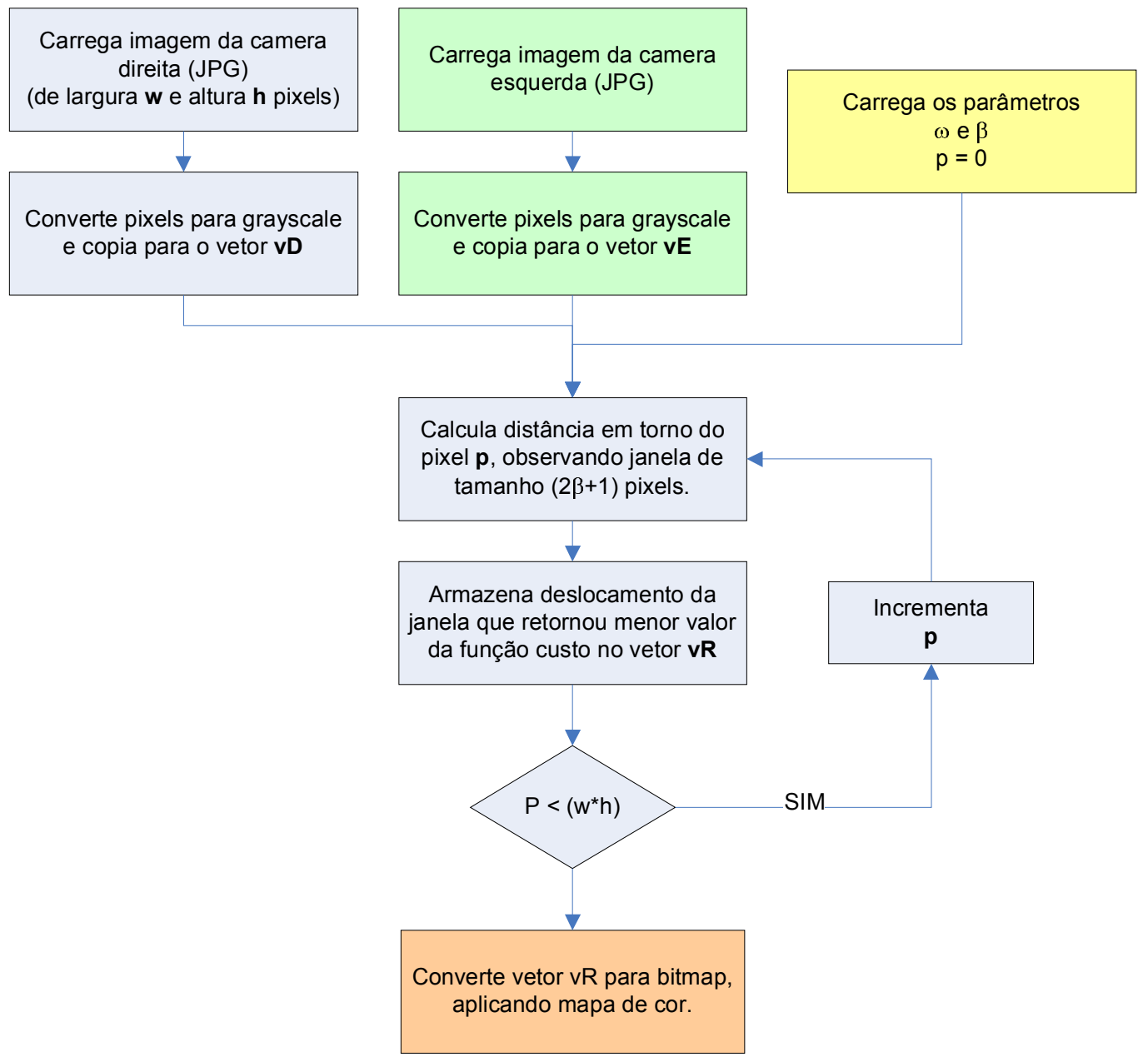

Figura 30 - Estrutura funcional básica do programa de simulação

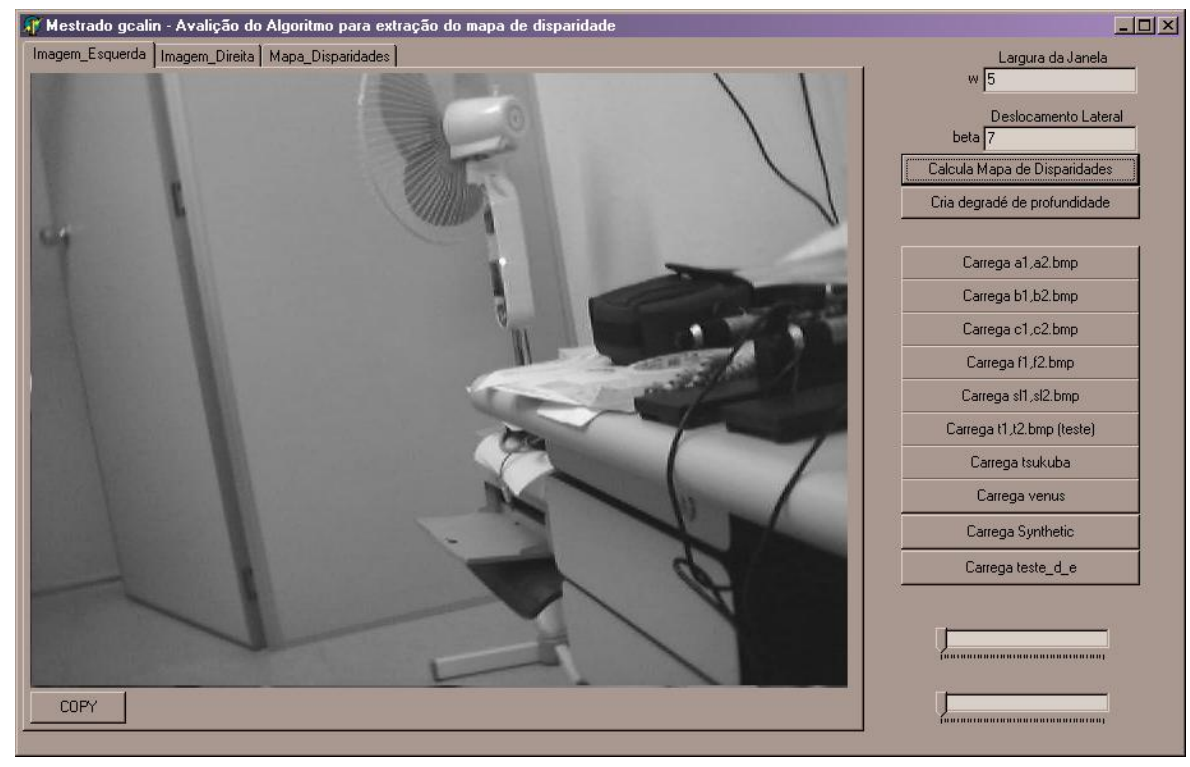

Figura 31 - Janela do programa de simulação 


\subsection{Implementação}

Durante a fase de estudos e modelamento do sistema proposto, foi desenvolvido uma série de sub-circuitos digitais aplicados ao FPGA Spartan-3, na placa de desenvolvimento Spartan-3 starter board.

Estes sub-circuitos possuem funções de interface e comunicação, sendo alguns deles diretamente necessários para implementação do algoritmo proposto, enquanto outros foram apenas utilizados durante a fase de depuração do código digital sintetizado.

Todos os códigos foram desenvolvidos utilizando linguagem de programação VHDL, garantindo portabilidade e simplificando a fase de depuração do circuito lógico.

\subsection{1 - Kit de desenvolvimento}

Para execução do projeto proposto foi escolhido 0 kit de desenvolvimento Spartan-3 Starter Board, fabricado pela empresa Digilent. Este kit integra um dispositivo FPGA Spartan-3 XC3S200, 2Mbyte de memória SRAM, interfaces JTAG, RS232C, VGA, PS2, além de micro-switches, displays de 7 segmentos e diversos leds auxiliares para uso durante o processo de depuração.

O modelo de FPGA XC3S200 disponível na placa de desenvolvimento conta com 200.000 blocos lógicos, 12 multiplicadores de 18-bits de largura, além de uma série de recursos para conexão e controle de periféricos externos. O kit também inclui uma versão da plataforma de desenvolvimento ISE 6, da própria Xilinx, empregada para o desenvolvimento do código VHDL deste projeto.

A Figura 32 exibe a montagem utilizada para avaliação do algoritmo, integrando duas câmeras CMOS à placa de desenvolvimento.

Um resumo das características técnicas do kit de desenvolvimento é mostrado na Figura 33. 


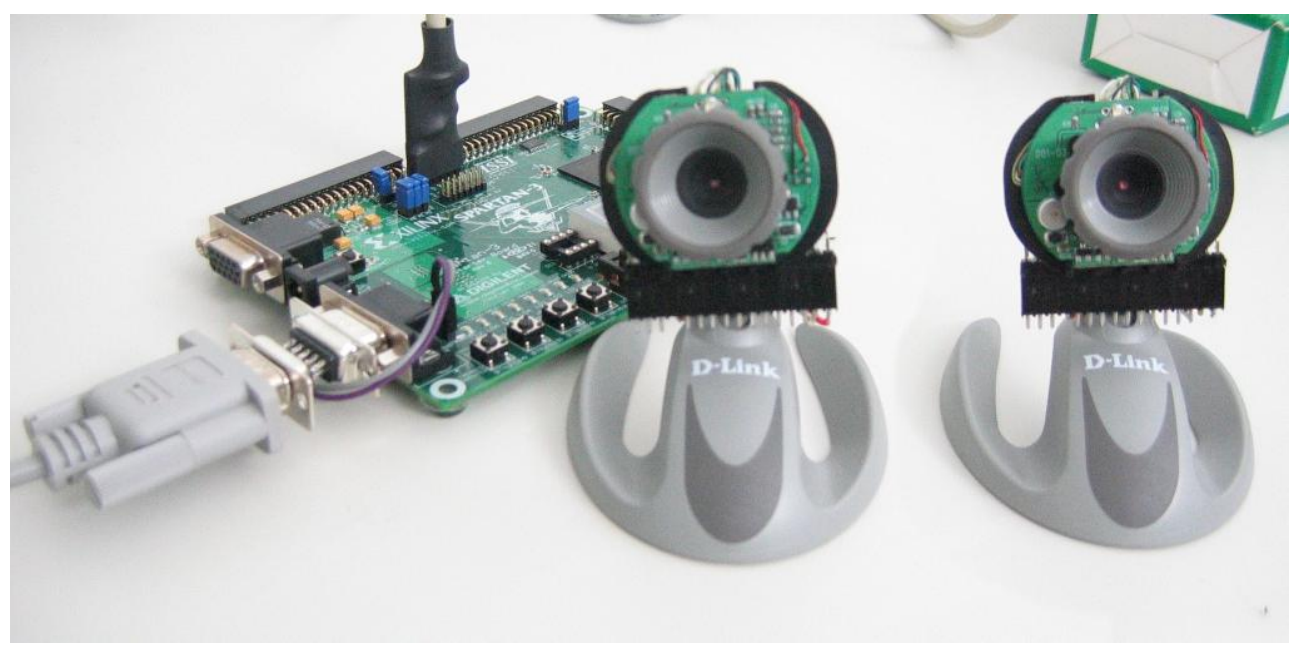

Figura 32 - Hardware utilizado na pesquisa. Kit de desenvolvimento da Xilinx e duas câmeras CMOS modificadas.

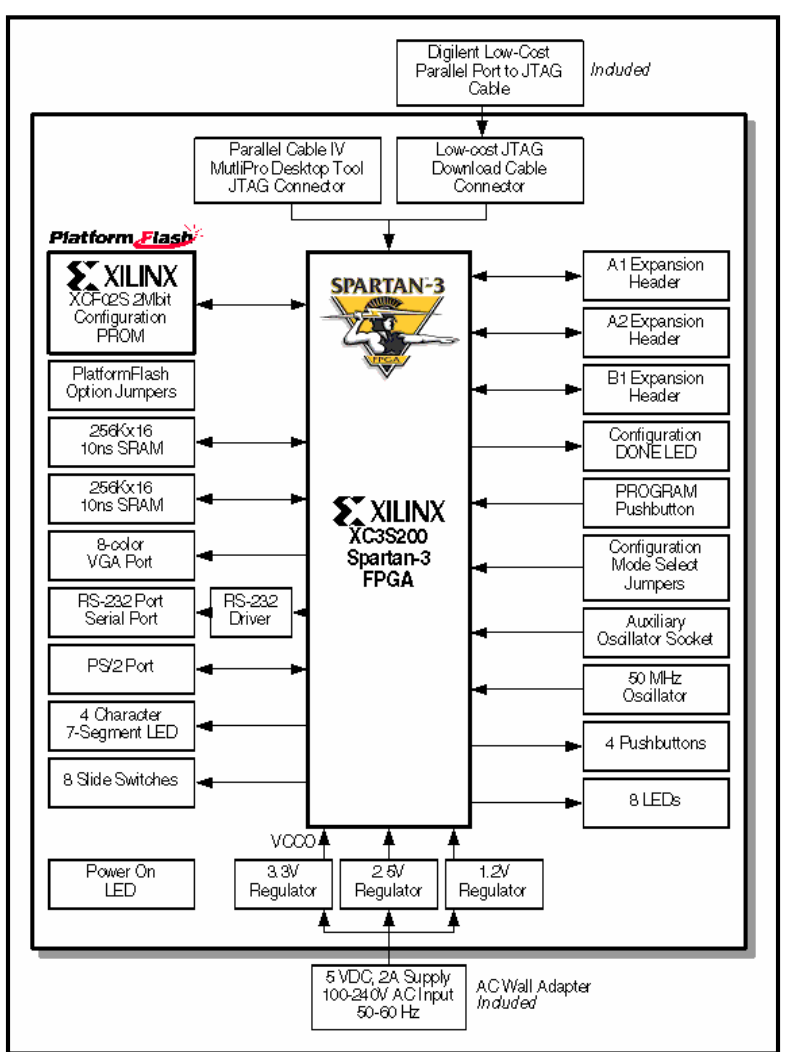

Figura 33 - Xilinx Spartan-3 XC3S200 Starter Kit 


\subsubsection{Câmeras CMOS}

Para obtenção das imagens do ambiente foram empregadas duas câmeras CMOS. Os sensores de imagens CMOS (acrônimo de complementary metal oxide semiconductor) utilizam uma matriz de pixels, cada qual contendo um ou mais transistores, para quantização da imagem observada.

O sensor CMOS escolhido foi o OV7648, fabricado pela empresa Omnivision. Este sensor CMOS é empregado em diversas câmeras de baixo custo utilizadas em micro-computadores.

Por simplicidade de utilização e aplicação, foram adquiridas duas webcam DSB-C310, da empresa D-Link, que empregam em seu interior o sensor CMOS escolhido.

As Figura 34 e Figura 35 exibem a câmera, assim como as modificações realizadas para acesso direto aos pinos de comunicação do sensor CMOS. Optou-se pela modificação de uma câmera comercial devido a dificuldade de obtenção de um kit de desenvolvimento contendo apenas o sensor CMOS. As modificações incluíram a remoção do circuito integrado OV519 (responsável pela interface USB e comunicação com o sensor CMOS OV7648) e adição de um conector externo, disponibilizando diretamente os pinos do sensor CMOS.

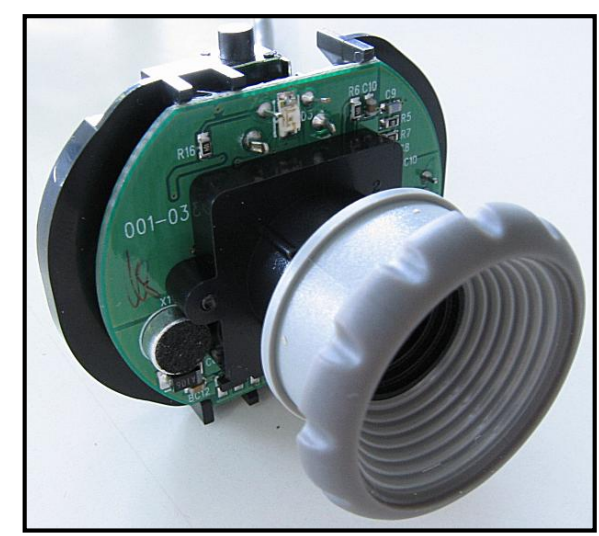

Figura 34 - Webcam D-Link DSB-C310

As modificações realizadas permitiram a conexão do sensor CMOS diretamente na placa de desenvolvimento utilizada no projeto, possibilitando a 
aquisição em tempo real, sem compressão ou pré-processamento, das informações observadas pela câmera.

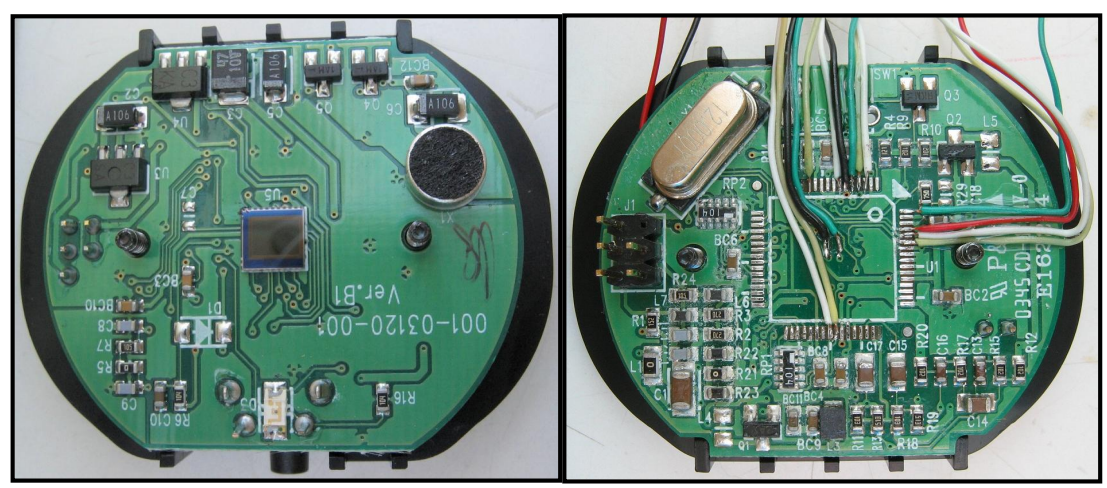

Figura 35 - Modificações para acesso aos sinais do sensor CMOS

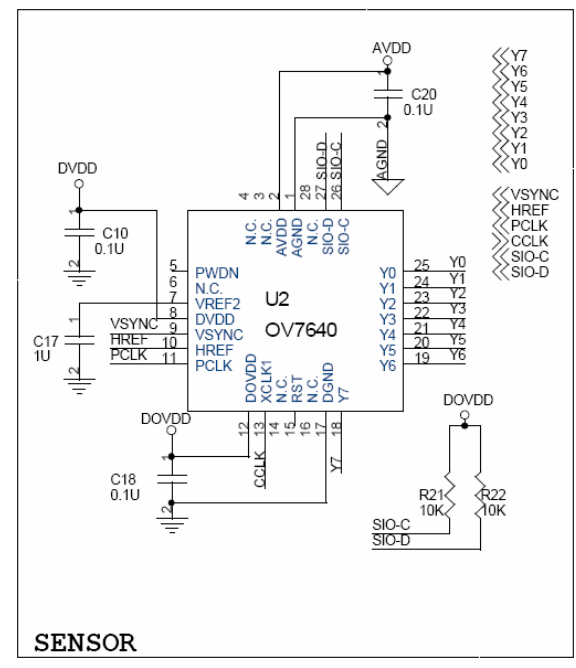

Figura 36 - Esquema elétrico de conexão com o sensor CMOS OV7648

O esquema elétrico da Figura 36 exibe os pinos de comunicação disponíveis no sensor CMOS utilizado. Os sinais VSYNC, HREF, PCLK e CCLK são utilizados para alinhamento dos quadros e para conexão dos sinais de clock necessários. O barramento serial SIO-C e SIO-D possibilita acesso a interface interna do sensor responsável pela programação de diversos parâmetros funcionais. $O$ barramento paralelo $Y[0 . .7]$ disponibiliza, sincronamente ao sinal PCLK, os dados componentes de cada um dos pixels do quadro. 


\subsubsection{Estrutura interna do FPGA}

A Figura 37 exibe esquematicamente a estrutura interna implementada no dispositivo FPGA. Cada bloco representa um sub-dispositivo digital que foi desenvolvido e testado isoladamente.

Constituindo uma máquina síncrona, o esquema exibe uma fonte primária de clock de $50 \mathrm{MHz}$ (gerada externamente através de um oscilador), seguida por dois blocos sintetizadores de clock (respectivamente de $96 \mathrm{MHz}$ e $27 \mathrm{MHz}$ ). Diversos sub-divisores foram empregados, disponibilizando todas as fontes de clock necessárias para movimentação dos processos e subprocessos da máquina síncrona.

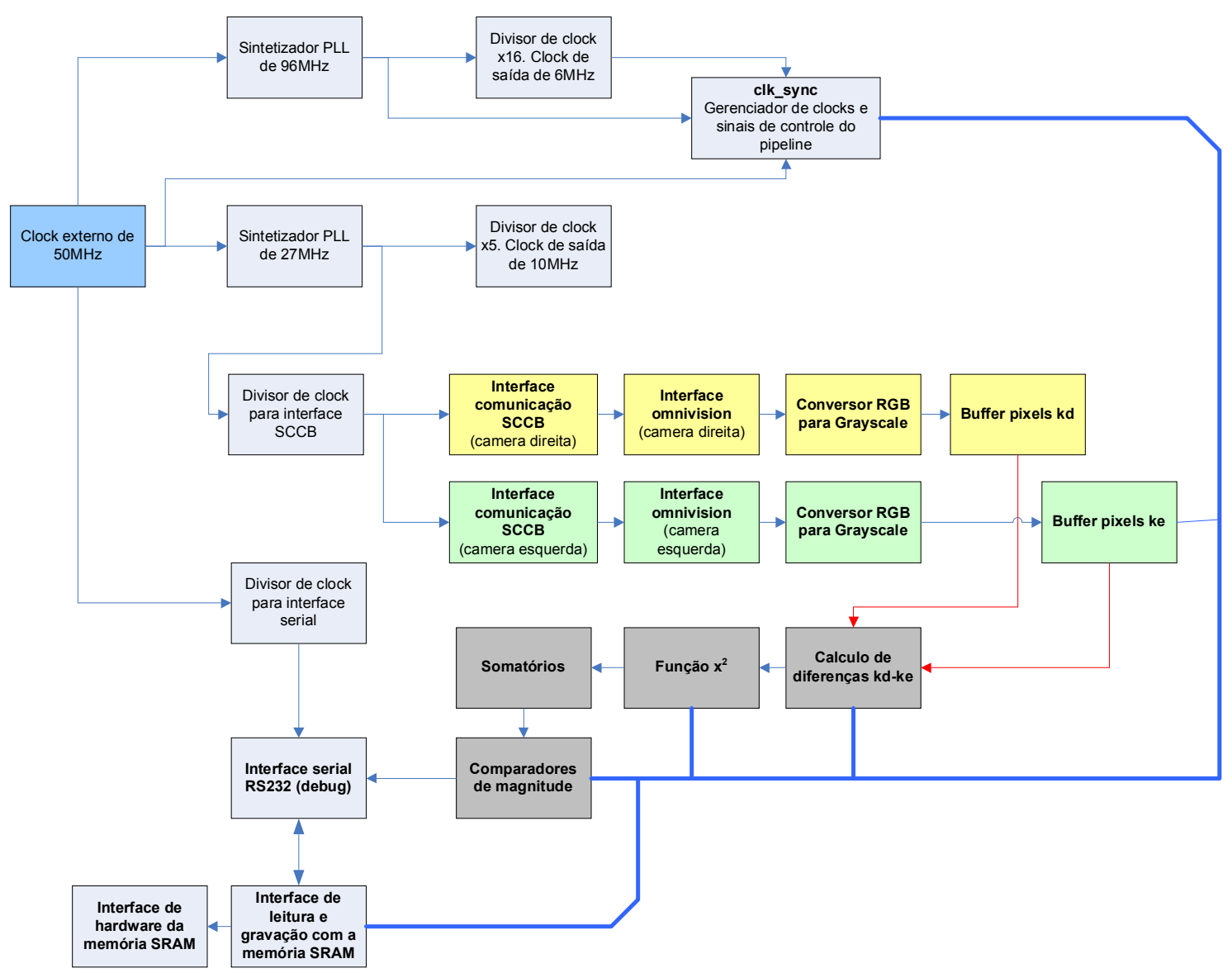

Figura 37 - Diagrama interno do algoritmo no FPGA 
Representados por blocos amarelos e verdes, a Figura 37 exibe os subprocessos responsáveis pela inicialização, leitura e disponibilização dos pixe/s da câmera direita e esquerda. Quando o sistema é executado pela primeira vez, o processo dispara o envio das configurações necessárias para os sensores CMOS (via interface serial SCCB). Terminado os processos de inicialização, estes sub-processos executam ciclicamente a leitura dos valores (RGB) que representam um pixel, sua conversão para um único valor em tom de cinza, e armazenam finalmente este resultado nos buffers kd e ke.

Os blocos representados em cinza escuro identificam os sub-processos envolvidos diretamente no processamento do algoritmo. Os demais blocos representam as ferramentas utilizadas para armazenamento final e depuração.

A Figura 38 exibe o esquemático detalhado dos blocos e a representação utilizada pelo programa de desenvolvimento ISE durante projeto do FPGA.

\subsubsection{Sintetizadores de clock}

Para correto funcionamento, diversas fontes de clock precisaram ser empregadas. Entretanto, apenas uma fonte de $50 \mathrm{MHz}$, gerada através de um oscilador externo, está disponível para uso na placa de desenvolvimento do FPGA Spartan-3.

Para obtenção dos demais sinais de clock empregaram-se sintetizadores de clock PLL, disponíveis internamente ao FPGA empregado.

Desta forma foi possível obter clocks de $96 \mathrm{MHz}$ e $27 \mathrm{Mhz}$, além dos demais sinais de clock submúltiplos, empregados em diversas máquinas de estado do pipeline.

Os sintetizadores de clock são disponibilizados na interface de desenvolvimento como blocos parametrizados não permitindo, portanto, observação do seu código fonte VHDL/Verilog. 


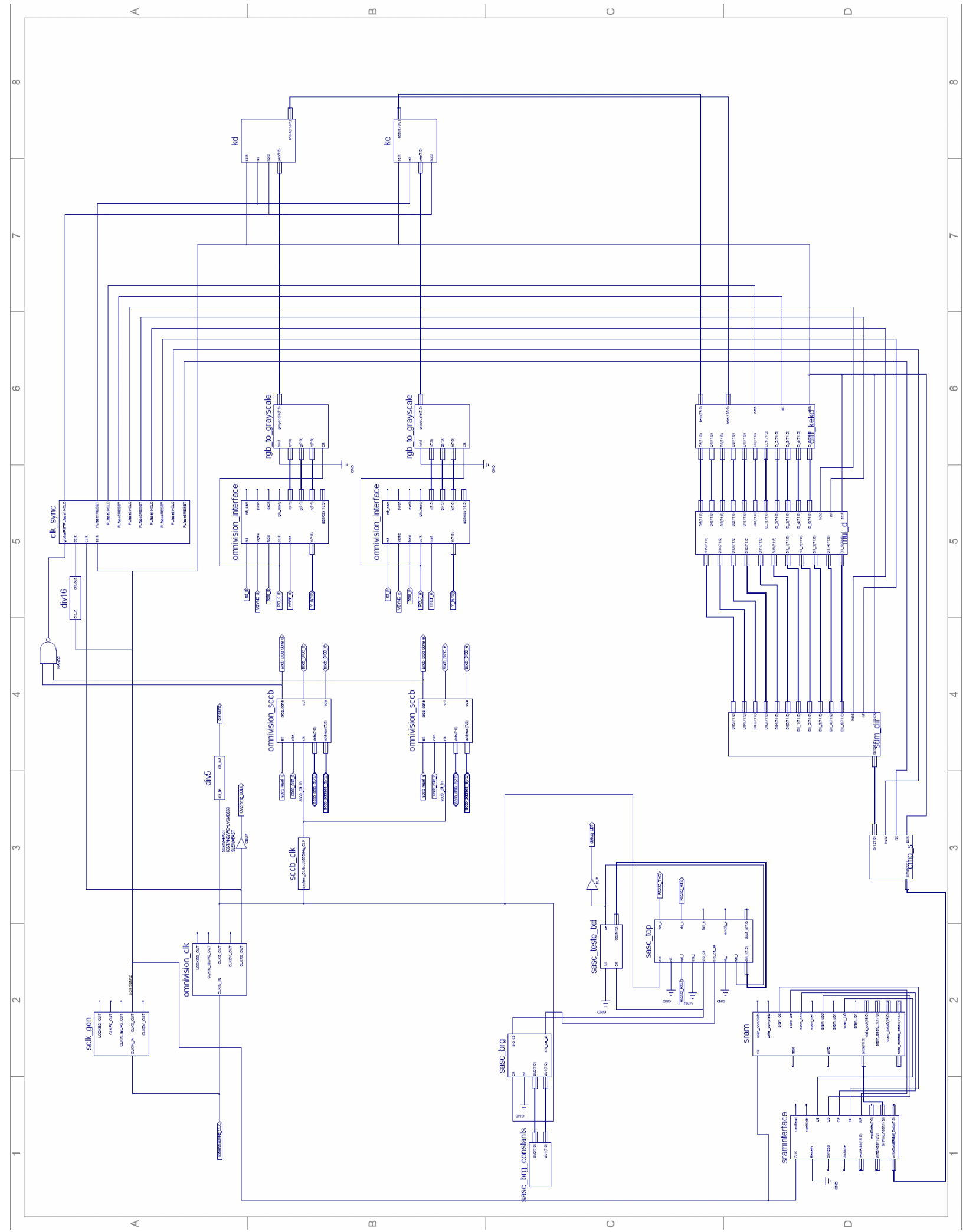

Figura 38 - main.sch - diagrama interno dos blocos constituintes do algoritmo no FPGA 


\subsubsection{Interface da câmera Omnivision}

A câmera de vídeo utilizada emprega em seu núcleo um sensor CMOS da empresa Omnivision (OV7648). Este sensor disponibiliza duas interfaces de comunicação, uma paralela - utilizada para transferência do frame buffer interno, e uma serial - utilizada para inicialização e ajuste das diversas opções disponíveis no sensor.

O sub-circuito apresentado na Figura 39 foi desenvolvido para conexão do sensor CMOS ao dispositivo FPGA, provendo todos os sinais de controle e barramento para recepção dos dados do sensor.

A interface serial VHDL contém anexada em seu interior uma seqüência padrão de comandos utilizada para inicialização do sensor, executados apenas fase de inicialização do sistema.

A interface paralela é agregada a circuitos lógicos e máquinas de estado adicionais para transferência dos dados recebidos para as células de memórias descritas no modelamento da seção 4.1 Parametrização e modelamento.

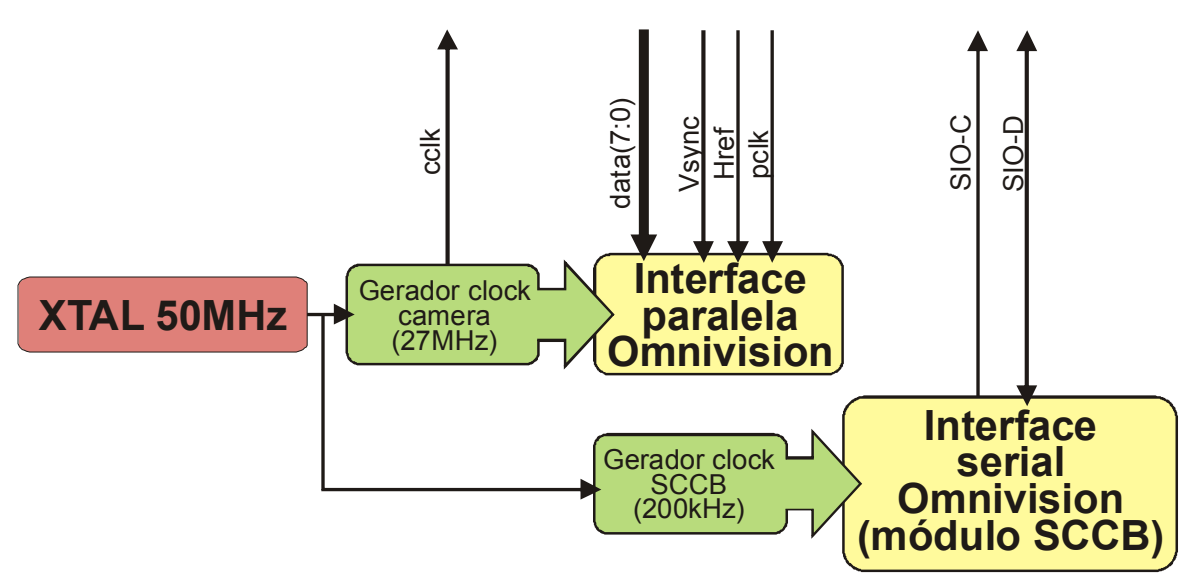

Figura 39 - Estrutura interna módulo de interface com o sensor CMOS Omnivision

O módulo de comunicação é composto dos arquivos fontes omniVision_CLK (gerado através do Xilinx Architecture Wizard), omnivision_interface (VHDL), omnivision_sccb (VHDL) e sccb_clk (VHDL).

A Tabela 1, 
Tabela 2 e Tabela 3 exibem os resultados da síntese dos códigos fonte VHDL utilizados nestes módulos.

Tabela 1 - Resultado da síntese do módulo VHDL omnivision_interface.vhd para o FPGA Xilinx 3s200pq208-4

\begin{tabular}{|c|c|c|}
\hline \multicolumn{3}{|c|}{ Resultados de alocação } \\
\hline \multicolumn{2}{|c|}{ Número de SLICEs utilizados } & 32 de $1920(1 \%)$ \\
\hline \multicolumn{2}{|c|}{ Número de SLICEs flip-flops utilizados } & 53 de $3840(1 \%)$ \\
\hline \multicolumn{2}{|c|}{ Número de IOBs de interface externa utilizados } & 49 de $141(34 \%)$ \\
\hline \multicolumn{2}{|c|}{ Número de LUTs de 4 entradas utilizadas } & 27 de $3840(0 \%)$ \\
\hline \multicolumn{2}{|c|}{ Number of GCLKs utilizados } & 1 de $8(12 \%)$ \\
\hline \multicolumn{3}{|c|}{ Quantidade de Macro dispositivos funcionais sintetizados } \\
\hline 1 & \multicolumn{2}{|l|}{ 17-bit adder } \\
\hline 3 & \multicolumn{2}{|l|}{ 1-bit register } \\
\hline 2 & \multicolumn{2}{|l|}{ 17-bit register } \\
\hline 3 & \multicolumn{2}{|l|}{ 8-bit register } \\
\hline \multicolumn{3}{|c|}{ Características temporais relevantes } \\
\hline \multicolumn{2}{|c|}{ Freqüência máxima do clock global pclk } & $180,050 \mathrm{MHz}$ \\
\hline \multicolumn{2}{|c|}{ Máximo atraso observável de uma saída após sinal do clock } & $5,835 n s$ \\
\hline
\end{tabular}

Tabela 2 - Resultado da síntese do módulo VHDL omnivision_sccb.vhd para o FPGA Xilinx 3s200pq208-4

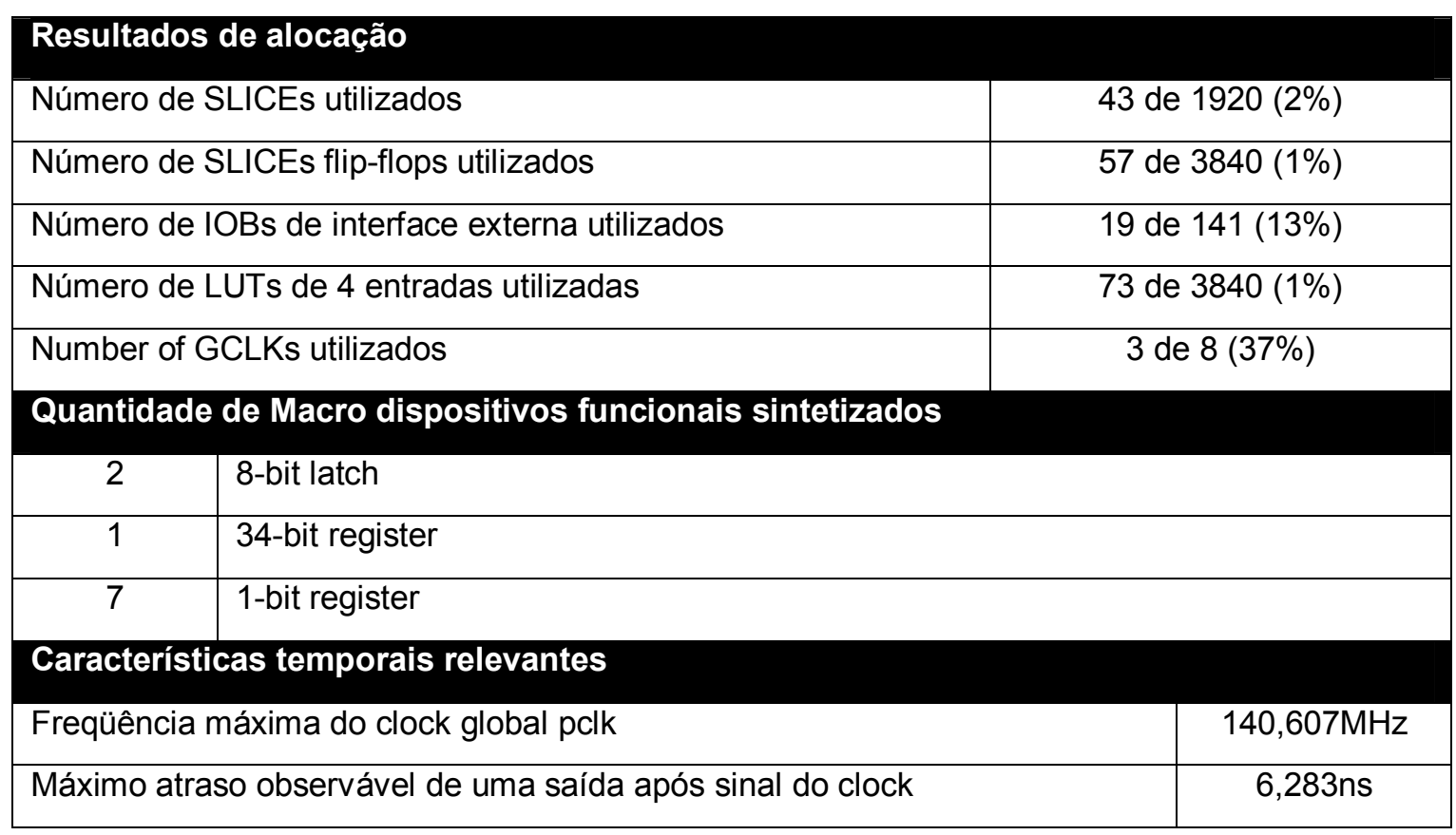


Tabela 3 - Resultado da síntese do módulo VHDL sccb_clk.vhd para o FPGA Xilinx 3s200pq208-4

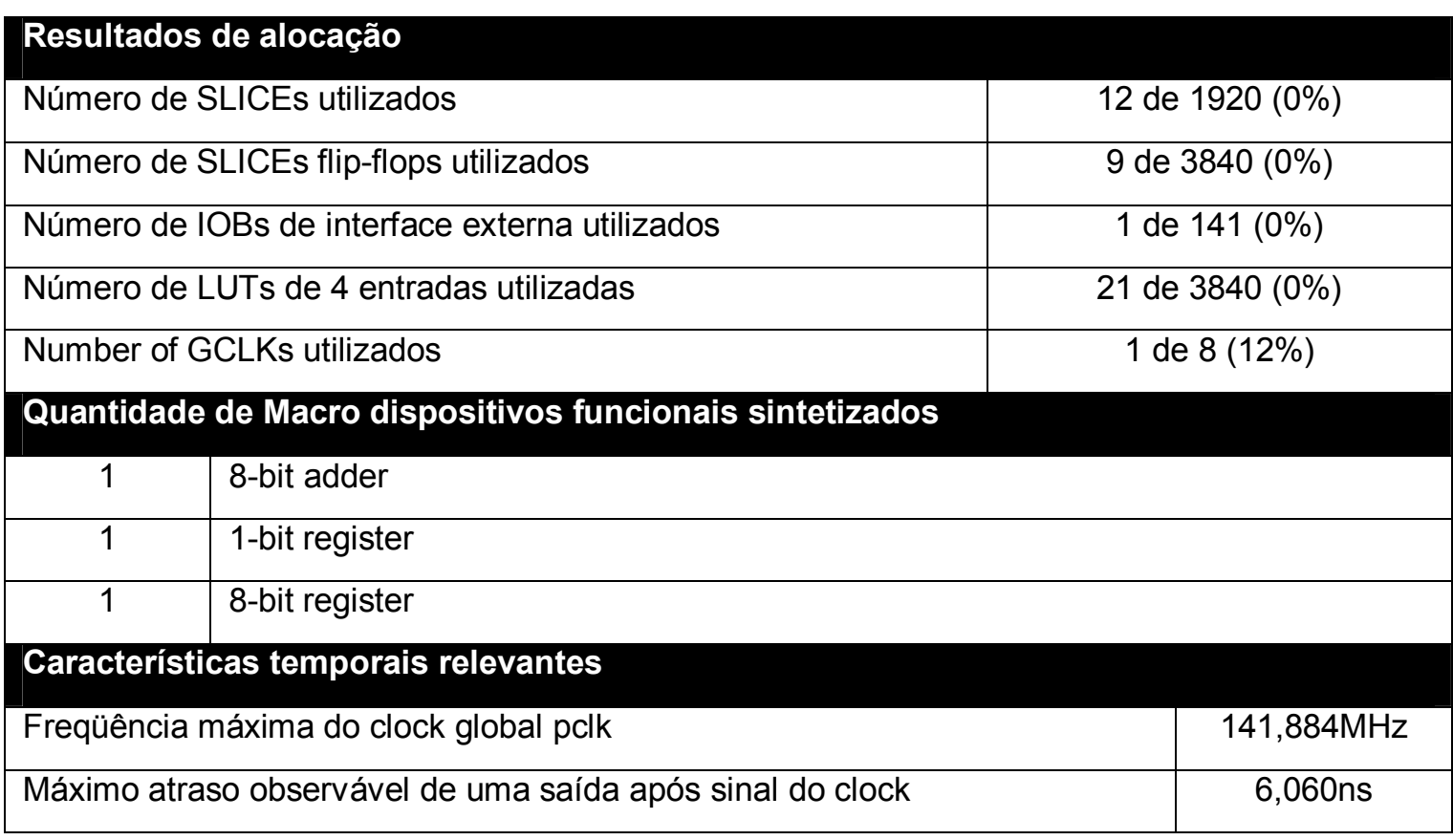

\subsubsection{Conversor RGB para nível de cinza}

A interface paralela das câmeras disponibiliza três bytes de informação para cada novo pixel amostrado, representando respectivamente as cores vermelho, verde e azul.

O algoritmo proposto se baseia no processamento de imagens em tonalidades de cinza, requerendo portanto a conversão de modo RGB para níveis de cinza.

O algoritmo implementado para esse fim utiliza a curva padrão indicada pela equação (8), onde $Y$ representa o valor resultante em níveis de cinza e $R$, $\mathrm{G}$ e $\mathrm{B}$ representam as componentes de cor do pixel analisado.

$$
Y=0,3 \cdot R+0,59 \cdot G+0,11 \cdot B
$$


Visando simplificar a implementação do módulo, os valores da curva padrão foram aproximados por razões com coeficientes $2^{n}$, como indicado na equação (9).

$$
Y=\frac{32 \cdot R}{128}+\frac{64 \cdot G}{128}+\frac{8 \cdot B}{128}=0,25 \cdot R+0,5 \cdot G+0,062 \cdot B
$$

A Tabela 4 exibe o resultado da síntese do código fonte VHDL utilizado para implementação do conversor descrito.

Tabela 4 - Resultado da síntese do módulo VHDL rgb_to_grayscale.vhd para o FPGA Xilinx 3s200pq208-4

\begin{tabular}{|c|c|c|}
\hline \multicolumn{3}{|c|}{ Resultados de alocação } \\
\hline \multicolumn{2}{|c|}{ Número de SLICEs utilizados } & 27 de $1920(1 \%)$ \\
\hline \multicolumn{2}{|c|}{ Número de SLICEs flip-flops utilizados } & 40 de $3840(1 \%)$ \\
\hline \multicolumn{2}{|c|}{ Número de IOBs de interface externa utilizados } & 0 de $141(0 \%)$ \\
\hline \multicolumn{2}{|c|}{ Número de LUTs de 4 entradas utilizadas } & 16 de $3840(0 \%)$ \\
\hline \multicolumn{2}{|c|}{ Number of GCLKs utilizados } & 1 de $8(12 \%)$ \\
\hline \multicolumn{3}{|c|}{ Quantidade de Macro dispositivos funcionais sintetizados } \\
\hline 2 & \multicolumn{2}{|l|}{ 32-bit adder } \\
\hline 1 & \multicolumn{2}{|l|}{ 32-bit up accumulator } \\
\hline 1 & \multicolumn{2}{|l|}{ 8-bit register } \\
\hline 1 & \multicolumn{2}{|l|}{ 32-bit register } \\
\hline 1 & \multicolumn{2}{|l|}{ 32-bit comparator less } \\
\hline 1 & \multicolumn{2}{|l|}{ 32-bit comparator greater } \\
\hline 1 & \multicolumn{2}{|l|}{ 32-bit 2-to-1 multiplexer } \\
\hline \multicolumn{3}{|c|}{ Características temporais relevantes } \\
\hline \multicolumn{2}{|c|}{ Freqüência máxima do clock global clk } & $229,358 \mathrm{MHz}$ \\
\hline \multicolumn{2}{|c|}{ Máximo atraso observável de uma saída após sinal do clock } & $5,835 \mathrm{~ns}$ \\
\hline
\end{tabular}

\subsubsection{Buffers das câmeras}

Os buffers de entrada da câmera são formados por registradores de deslocamento FIFO, responsáveis por armazenar um novo pixel (1 byte) e por 
descartar o pixel mais antigo a cada ciclo do clock cclock. O processo ocorre em dois estágios síncronos, controlado por uma máquina de estados e o clock sclk. O conteúdo dos registrados é disponibilizado paralelamente para o estágio seguinte, permitindo processamento concorrente de todos os dados dos buffers.

Os módulos VHDL kd.vhd e ke.vdh implementam as funcionalidades descritas. A Tabela 5 e Tabela 6 exibem os resultados da síntese dos códigos fonte VHDL utilizados.

Tabela 5 - Resultado da síntese do módulo VHDL kd.vhd para o FPGA Xilinx 3s200pq208-4

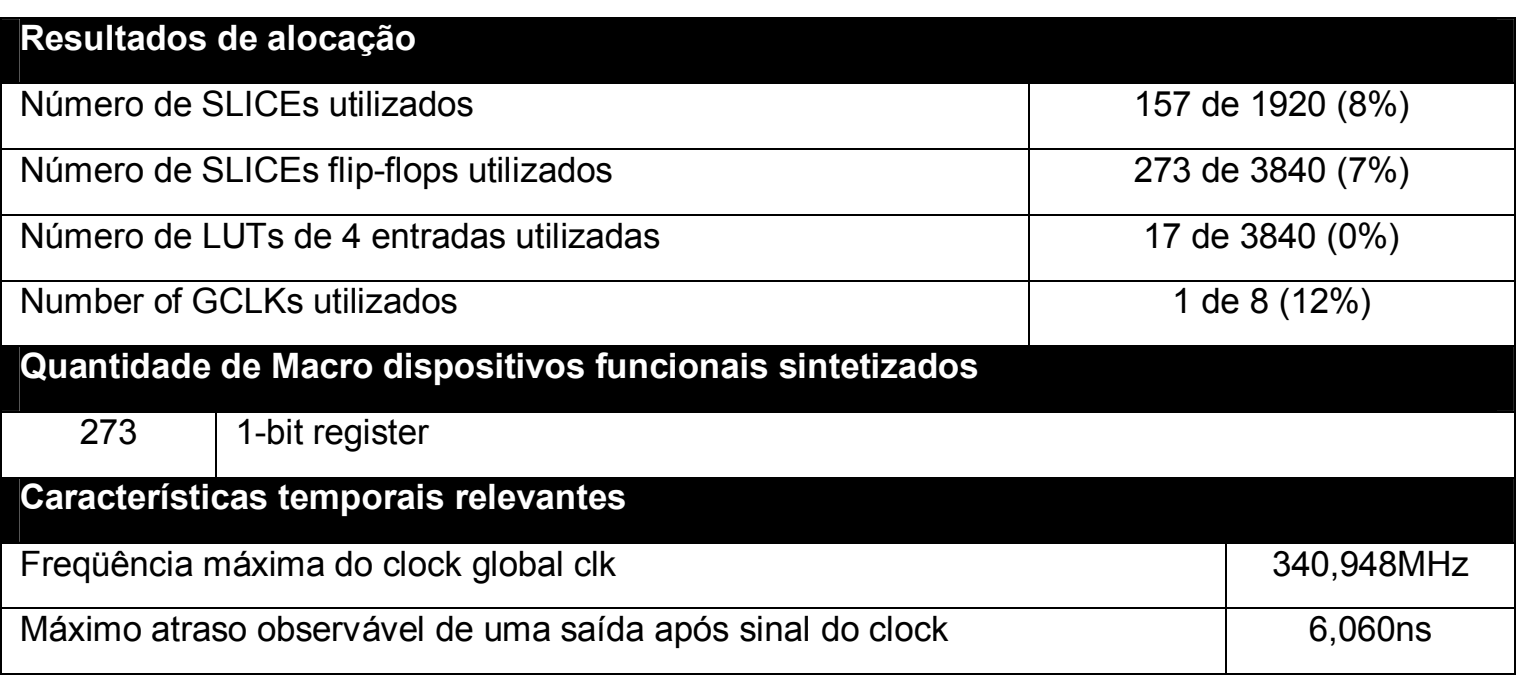

Tabela 6 - Resultado da síntese do módulo VHDL ke.vhd para o FPGA Xilinx 3s200pq208-

4

\begin{tabular}{|l|c|}
\hline Resultados de alocação \\
\hline Número de SLICEs utilizados & 93 de $1920(4 \%)$ \\
\hline Número de SLICEs flip-flops utilizados & 161 de $3840(4 \%)$ \\
\hline Número de LUTs de 4 entradas utilizadas & 11 de $3840(0 \%)$ \\
\hline Number of GCLKs utilizados & 1 de $8(12 \%)$ \\
\hline Quantidade de Macro dispositivos funcionais sintetizados \\
\hline 161 & 1-bit register \\
\hline Características temporais relevantes & $363,636 \mathrm{MHz}$ \\
\hline Freqüência máxima do clock global clk & $6,060 \mathrm{~ns}$ \\
\hline Máximo atraso observável de uma saída após sinal do clock &
\end{tabular}




\subsubsection{Módulo de cálculo de diferenças}

O módulo de cálculo de diferenças, implementado pelo código VHDL diff_kdke.vhd, recebe paralelamente 216 bits armazenados nos buffer kd e ke, e realiza concorrentemente todos os cálculos de diferença para as $2 \beta$ janelas. Os resultados são disponibilizados para o módulo seguinte por 11 barramentos de 72 bits.

A Tabela 7 exibe os resultados da síntese do código fonte VHDL utilizado.

Tabela 7 - Resultado da síntese do módulo VHDL diff_kdke.vhd para o FPGA Xilinx 3s200pq208-4

\begin{tabular}{|l|l|}
\hline Resultados de alocação & 324 de $1920(16 \%)$ \\
\hline Número de SLICEs utilizados & 648 de $3840(16 \%)$ \\
\hline Número de LUTs de 4 entradas utilizadas & \\
\hline Quantidade de Macro dispositivos funcionais sintetizados
\end{tabular}

72

9-bit subtractor

Características temporais relevantes

Máximo atraso observável (considerando atraso do circuito combinacional)

$14,257 n s$

\subsubsection{Módulo de execução da função quadrática}

O módulo VHDL de execução de função quadrática emprega os multiplicadores disponíveis em hardware para efetuar dezenas de cálculos, utilizando como dados de entrada as saídas do módulo de cálculo de diferenças.

Devido à limitação do número de multiplicadores disponíveis em hardware, o módulo foi estruturado em uma máquina de estado seqüencial ( 7 passos), onde a cada passo emprega 11 multiplicadores para processar uma fração dos dados disponibilizados pelo módulo anterior. O módulo resulta em 88 valores de saída, que são processados posteriormente pelo módulo da função somatório. 
A Tabela 8 exibe os resultados da síntese do código fonte VHDL utilizado.

Tabela 8 - Resultado da síntese do módulo VHDL mul_d.vhd para o FPGA Xilinx 3s200pq208-4

\section{Resultados de alocação}

Número de SLICEs utilizados

Número de SLICEs flip-flops utilizados

296 de $1920(15 \%)$

Número de IOBs de interface externa utilizados 512 de $3840(13 \%)$

Número de LUTs de 4 entradas utilizadas

Number of GCLKs utilizados 0 de $141(0 \%)$ 512 de $3840(13 \%)$ 1 de $8(12 \%)$

Quantidade de Macro dispositivos funcionais sintetizados

\begin{tabular}{|c|c|c|}
\hline 1 & \multicolumn{2}{|l|}{ 32-bit adder } \\
\hline 1 & \multicolumn{2}{|l|}{ 32-bit up accumulator } \\
\hline 2 & \multicolumn{2}{|l|}{ 8-bit register } \\
\hline 1 & \multicolumn{2}{|l|}{ 32-bit register } \\
\hline 11 & \multicolumn{2}{|l|}{ 32-bit multiplier } \\
\hline 1 & \multicolumn{2}{|l|}{ 32-bit 2-to-1 multiplexer } \\
\hline \multicolumn{3}{|c|}{ Características temporais relevantes } \\
\hline \multicolumn{2}{|c|}{ Freqüência máxima do clock global clk } & $227,422 \mathrm{MHz}$ \\
\hline \multicolumn{2}{|c|}{ Máximo atraso observável de uma saída após sinal do clock } & $5,115 \mathrm{~ns}$ \\
\hline
\end{tabular}

\subsubsection{Módulo de execução do somatório}

Responsável pelo somatório dos diversos resultados disponibilizados pelo módulo de execução da função quadrática, o módulo do somatório foi estruturado como uma máquina de estado de 11 passos, onde cada passo é responsável por processar o somatório de 8 operações concorrentes de soma. Esta estrutura foi escolhida pela significativa redução da quantidade de dispositivos somatórios necessários para execução concorrente de soma de todos os dados.

A Tabela 9 exibe os resultados da síntese do código fonte VHDL utilizado. 
Tabela 9 - Resultado da síntese do módulo VHDL sum_dii.vhd para o FPGA Xilinx 3s200pq208-4

\begin{tabular}{|c|c|c|}
\hline \multicolumn{3}{|c|}{ Resultados de alocação } \\
\hline \multicolumn{2}{|c|}{ Número de SLICEs utilizados } & 439 de $1920(22 \%)$ \\
\hline \multicolumn{2}{|c|}{ Número de SLICEs flip-flops utilizados } & 92 de $3840(2 \%)$ \\
\hline \multicolumn{2}{|c|}{ Número de IOBs de interface externa utilizados } & 0 de $141(0 \%)$ \\
\hline \multicolumn{2}{|c|}{ Número de LUTs de 4 entradas utilizadas } & 778 de $3840(20 \%)$ \\
\hline \multicolumn{2}{|c|}{ Number of GCLKs utilizados } & 1 de $8(12 \%)$ \\
\hline \multicolumn{3}{|c|}{ Quantidade de Macro dispositivos funcionais sintetizados } \\
\hline 8 & \multicolumn{2}{|l|}{ 16-bit adder } \\
\hline 11 & \multicolumn{2}{|l|}{ 16-bit 2-to-1 multiplexer } \\
\hline 83 & \multicolumn{2}{|l|}{ 1-bit register } \\
\hline \multicolumn{3}{|c|}{ Características temporais relevantes } \\
\hline \multicolumn{2}{|c|}{ Freqüência máxima do clock global clk } & $202,388 \mathrm{MHz}$ \\
\hline \multicolumn{2}{|c|}{ Máximo atraso observável de uma saída após sinal do clock } & $6,172 \mathrm{~ns}$ \\
\hline
\end{tabular}

\subsubsection{Comparadores de magnitude}

Responsáveis pela detecção do mínimo peso dos resultados da função custo, isto é, detecção da janela que apresentou melhor correspondência entre os quadros.

Diversos comparadores de magnitude foram utilizados no módulo VHDL cmp_S.vhd. O módulo é estruturado em uma máquina de estados de 6 passos, onde cada passo compara dois a dois os resultados disponibilizados pelo módulo do somatório, encontrado sucessivamente o índice da janela que apresentou menor resultado da função custo.

O resultado disponibilizado a cada novo pixel processado representada diretamente a profundidade relativa observada e é armazenada sucessivamente para construção do denso mapa de disparidade.

A Tabela 10 exibe os resultados da síntese do código fonte VHDL utilizado. 
Tabela 10 - Resultado da síntese do módulo VHDL cmp_S.vhd para o FPGA Xilinx 3s200pq208-4

\begin{tabular}{|c|c|c|}
\hline \multicolumn{3}{|c|}{ Resultados de alocação } \\
\hline \multicolumn{2}{|c|}{ Número de SLICEs utilizados } & 22 de $1920(1 \%)$ \\
\hline \multicolumn{2}{|c|}{ Número de SLICEs flip-flops utilizados } & 16 de $3840(0 \%)$ \\
\hline \multicolumn{2}{|c|}{ Número de IOBs de interface externa utilizados } & 0 de $141(0 \%)$ \\
\hline \multicolumn{2}{|c|}{ Número de LUTs de 4 entradas utilizadas } & 40 de $3840(24 \%)$ \\
\hline \multicolumn{2}{|c|}{ Number of GCLKs utilizados } & 1 de $8(12 \%)$ \\
\hline \multicolumn{3}{|c|}{ Quantidade de Macro dispositivos funcionais sintetizados } \\
\hline 1 & \multicolumn{2}{|l|}{ 16-bit comparator greater } \\
\hline 1 & \multicolumn{2}{|l|}{ 32-bit register } \\
\hline 1 & \multicolumn{2}{|l|}{ 8-bit register } \\
\hline 6 & \multicolumn{2}{|l|}{ 1-bit register } \\
\hline \multicolumn{3}{|c|}{ Características temporais relevantes } \\
\hline \multicolumn{2}{|c|}{ Freqüência máxima do clock global clk } & $257,202 \mathrm{MHz}$ \\
\hline \multicolumn{2}{|c|}{ Máximo atraso observável de uma saída após sinal do clock } & $6,060 \mathrm{~ns}$ \\
\hline
\end{tabular}

\subsubsection{0 - Módulo de comunicação serial padrão RS-232}

O módulo de comunicação serial (UART) tem função utilitária no projeto, permitindo transmissão e recepção de dados para o PC de desenvolvimento.

A rotina deriva sinal de clock de $1843,2 \mathrm{kHz}$ para funcionamento de sua máquina de estados, permitindo transmissão e recepção de dados à taxa de $115200 b p s$.

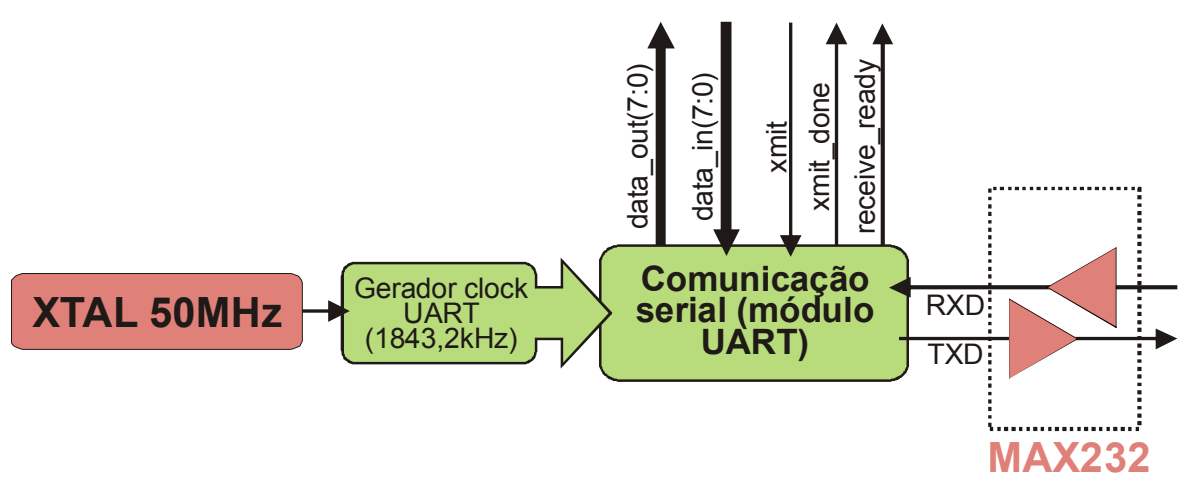

Figura 40 - Estrutura interna módulos de comunicação serial 
Internamente dois dutos paralelos são disponibilizados entrada e saída de dados, além de três sinais de controle, responsáveis pela sincronização e sinalização de eventos.

Este sub-circuito é especialmente útil no monitoramente do conteúdo da memória externa SRAM, permitindo a observação do seu conteúdo durante o funcionamento do algoritmo.

A Tabela 11 e Tabela 12 exibem os resultados da síntese dos códigos fonte VHDL utilizados nestes módulos.

Tabela 11 - Resultado da síntese do módulo Verilog sasc_brg.v para o FPGA Xilinx 3s200pq208-4

\begin{tabular}{|c|c|c|}
\hline \multicolumn{3}{|c|}{ Resultados de alocação } \\
\hline \multicolumn{2}{|c|}{ Número de SLICEs utilizados } & 21 de $1920(1 \%)$ \\
\hline \multicolumn{2}{|c|}{ Número de SLICEs flip-flops utilizados } & 25 de $3840(0 \%)$ \\
\hline \multicolumn{2}{|c|}{ Número de IOBs de interface externa utilizados } & 19 de $141(10 \%)$ \\
\hline \multicolumn{2}{|c|}{ Número de LUTs de 4 entradas utilizadas } & 32 de $3840(0 \%)$ \\
\hline \multicolumn{2}{|c|}{ Number of GCLKs utilizados } & 1 de $8(12 \%)$ \\
\hline \multicolumn{3}{|c|}{ Quantidade de Macro dispositivos funcionais sintetizados } \\
\hline 2 & \multicolumn{2}{|l|}{ 8-bit up counter } \\
\hline 1 & \multicolumn{2}{|l|}{ 2-bit up counter } \\
\hline 7 & \multicolumn{2}{|l|}{ 1-bit register } \\
\hline 2 & \multicolumn{2}{|l|}{ 8-bit comparator equal } \\
\hline \multicolumn{3}{|c|}{ Características temporais relevantes } \\
\hline \multicolumn{2}{|c|}{ Freqüência máxima do clock global clk } & $261,712 \mathrm{MHz}$ \\
\hline \multicolumn{2}{|c|}{ Máximo atraso observável de uma saída após sinal do clock } & $5,835 \mathrm{~ns}$ \\
\hline
\end{tabular}

Tabela 12 - Resultado da síntese do módulo Verilog sasc_top.v para o FPGA Xilinx 3s200pq208-4

\begin{tabular}{|l|c|}
\hline Resultados de alocação \\
\begin{tabular}{|l|c|}
\hline Número de SLICEs utilizados & 46 de $1920(2 \%)$ \\
\hline Número de SLICEs flip-flops utilizados & 59 de $3840(1 \%)$ \\
\hline Número de IOBs de interface externa utilizados & 27 de $173(15 \%)$ \\
\hline Número de LUTs de 4 entradas utilizadas & 71 de $3840(1 \%)$ \\
\hline Number of GCLKs utilizados & 1 de $8(12 \%)$ \\
\hline
\end{tabular}
\end{tabular}


Tabela 12 (continuação)

\begin{tabular}{|c|c|c|}
\hline 2 & \multicolumn{2}{|l|}{ 4x8-bit dual-port distributed RAM } \\
\hline 4 & \multicolumn{2}{|l|}{ 2-bit adder } \\
\hline 2 & \multicolumn{2}{|l|}{ 4-bit up counter } \\
\hline 1 & \multicolumn{2}{|l|}{ 10-bit register } \\
\hline 29 & \multicolumn{2}{|l|}{ 1-bit register } \\
\hline 4 & \multicolumn{2}{|l|}{ 2-bit register } \\
\hline 4 & \multicolumn{2}{|l|}{ 2-bit comparator equal } \\
\hline 1 & \multicolumn{2}{|l|}{ 10-bit 2-to-1 multiplexer } \\
\hline 1 & \multicolumn{2}{|l|}{ 1-bit xor2 } \\
\hline \multicolumn{3}{|c|}{ Características temporais relevantes } \\
\hline \multicolumn{2}{|c|}{ Freqüência máxima do clock global clk } & $231,803 \mathrm{MHz}$ \\
\hline \multicolumn{2}{|c|}{ Máximo atraso observável de uma saída após sinal do clock } & $8,208 \mathrm{~ns}$ \\
\hline
\end{tabular}

\subsubsection{1 - Módulo de interface com os bancos de memória SRam}

A placa de desenvolvimento Spartan-3 Starter Kit disponibiliza 2Mbits de memória externa através de dois bancos de memória SRam 256kx16 endereçados diretamente ao FPGA Spartan-3.

Devido a ausência de circuitos digitais gratuitos para acesso a estes módulos SRam, desenvolveu-se um sub-circuito digital síncrono capaz de ler e gravar dados aos bancos de memória.

O módulo FIFO disponibiliza dois dutos paralelos de 16-bits para entrada e saída de dados respectivamente, além de um duto de 18-bits para endereçamento contínuo de toda memória SRam disponível.

Uma máquina de estados permite a utilização sincronamente da memória SRam, simplificando a integração com o processo de pipeline proposto. 


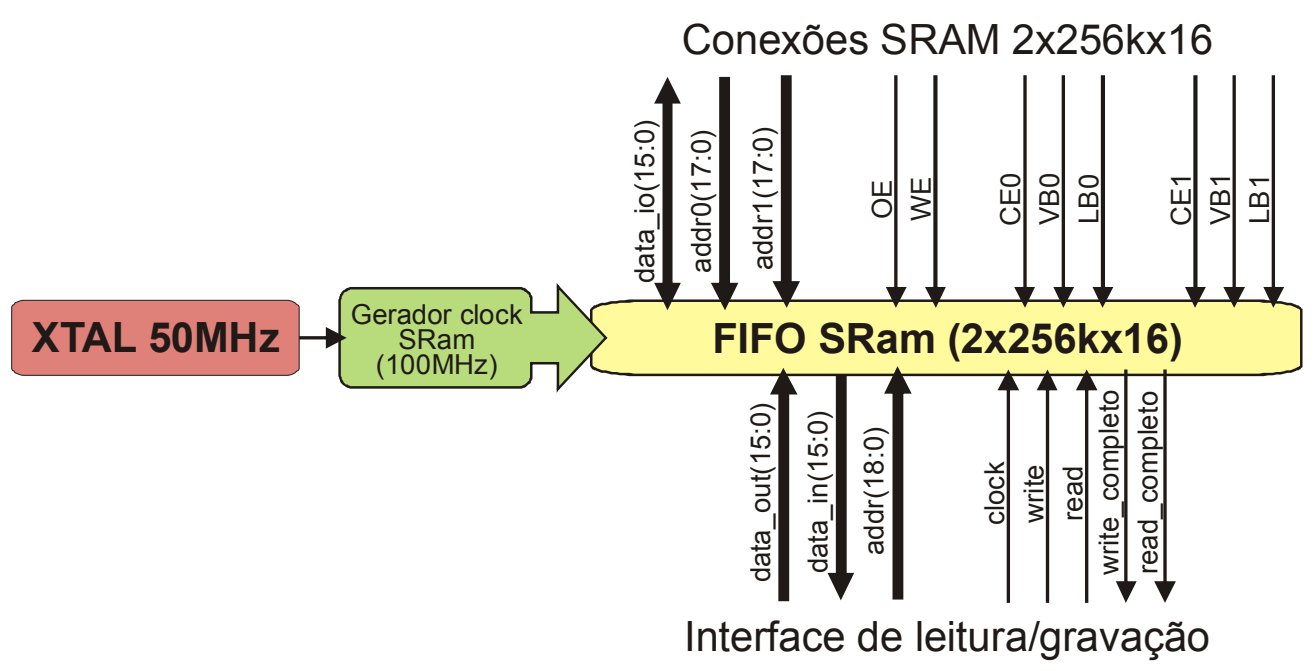

Figura 41 - Estrutura interna de interface com os bancos de memória SRam 2×256kx16

A Tabela 13 e Tabela 14 exibem os resultados da síntese dos códigos fonte VHDL utilizados nestes módulos.

Tabela 13 - Resultado da síntese do módulo VHDL sram.vhd para o FPGA Xilinx 3s200pq208-4

\begin{tabular}{|c|c|c|}
\hline \multicolumn{3}{|c|}{ Resultados de alocação } \\
\hline \multicolumn{2}{|c|}{ Número de SLICEs utilizados } & 70 de $1920(3 \%)$ \\
\hline \multicolumn{2}{|c|}{ Número de SLICEs flip-flops utilizados } & 114 de $3840(2 \%)$ \\
\hline \multicolumn{2}{|c|}{ Número de IOBs de interface externa utilizados } & 109 de $173(63 \%)$ \\
\hline \multicolumn{2}{|c|}{ Número de LUTs de 4 entradas utilizadas } & 94 de $3840(2 \%)$ \\
\hline \multicolumn{2}{|c|}{ Number of GCLKs utilizados } & 1 de $8(12 \%)$ \\
\hline \multicolumn{3}{|c|}{ Quantidade de Macro dispositivos funcionais sintetizados } \\
\hline 1 & \multicolumn{2}{|l|}{ 1-bit register } \\
\hline 3 & \multicolumn{2}{|l|}{ 16-bit register } \\
\hline 1 & \multicolumn{2}{|l|}{ 18-bit register } \\
\hline 1 & \multicolumn{2}{|l|}{ 2-to-1 multiplexer } \\
\hline 2 & \multicolumn{2}{|l|}{ 16-bit tristate buffer } \\
\hline \multicolumn{3}{|c|}{ Características temporais relevantes } \\
\hline \multicolumn{2}{|c|}{ Freqüência máxima do clock global clk } & $233,754 \mathrm{MHz}$ \\
\hline \multicolumn{2}{|c|}{ Máximo atraso observável de uma saída após sinal do clock } & $6,078 \mathrm{~ns}$ \\
\hline
\end{tabular}


Tabela 14 - Resultado da síntese do módulo VHDL sram_interface.vhd para o FPGA Xilinx 3s200pq208-4

\begin{tabular}{|c|c|c|}
\hline \multicolumn{3}{|c|}{ Resultados de alocação } \\
\hline \multicolumn{2}{|c|}{ Número de SLICEs utilizados } & 25 de $1920(1 \%)$ \\
\hline \multicolumn{2}{|c|}{ Número de SLICEs flip-flops utilizados } & 42 de $3840(1 \%)$ \\
\hline \multicolumn{2}{|c|}{ Número de IOBs de interface externa utilizados } & 90 de $173(52 \%)$ \\
\hline \multicolumn{2}{|c|}{ Número de LUTs de 4 entradas utilizadas } & 32 de $3840(0 \%)$ \\
\hline \multicolumn{2}{|c|}{ Number of GCLKs utilizados } & 1 de $8(12 \%)$ \\
\hline \multicolumn{3}{|c|}{ Quantidade de Macro dispositivos funcionais sintetizados } \\
\hline 5 & \multicolumn{2}{|l|}{ 1-bit register } \\
\hline 1 & \multicolumn{2}{|l|}{ 18-bit register } \\
\hline 1 & \multicolumn{2}{|l|}{ 8-bit register } \\
\hline 3 & \multicolumn{2}{|l|}{ 2-to-1 multiplexer } \\
\hline 1 & \multicolumn{2}{|l|}{ 8-bit tristate buffer } \\
\hline \multicolumn{3}{|c|}{ Características temporais relevantes } \\
\hline \multicolumn{2}{|c|}{ Freqüência máxima do clock global clk } & $254,130 \mathrm{MHz}$ \\
\hline \multicolumn{2}{|c|}{ Máximo atraso observável de uma saída após sinal do clock } & $7,883 \mathrm{~ns}$ \\
\hline
\end{tabular}

\subsubsection{2 - Módulo de interface Câmera-SRam}

Este sub-circuito digital foi desenvolvido exclusivamente para fins de depuração, permitindo que os módulos de interface do sensor CMOS e de interface da memória SRam fossem interconectados, alocando duas matrizes na memória SRam com os conteúdos dos frame buffers dos sensores CMOS.

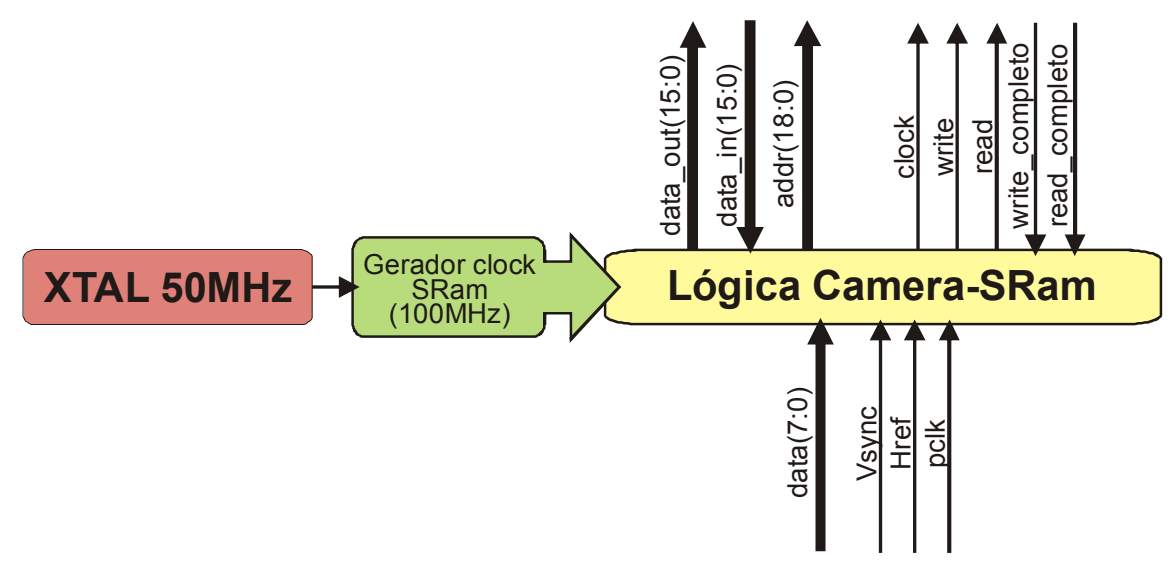

Figura 42 - Estrutura interna da interface sensor CMOS com a memória externa SRam 


\subsubsection{Módulo de interface UART-SRam}

Este sub-circuito digital foi desenvolvido para monitoramento do conteúdo da memória SRam, permitindo assim depuração dos resultados dos outros módulos.

A interface gera os sinais necessários para os módulos UART e SRam, sincronizando o processo de envio para serial e leitura dos dados da SRam.

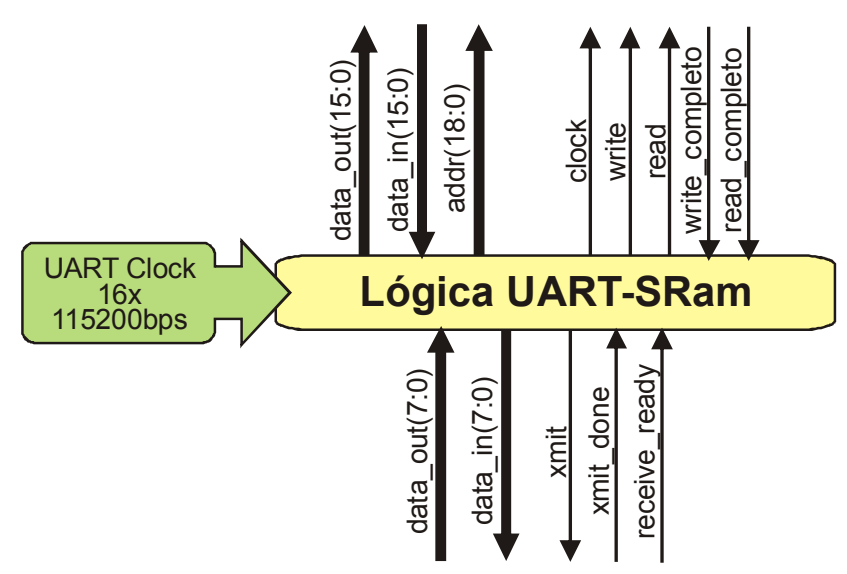

Figura 43 - Estrutura interna da interface de comunicação entre a memória externa SRam e o módulo de comunicação serial

\subsubsection{Montagem do pipeline e módulos acessórios}

A fase final de implementação do sistema consistiu em agrupar todos os módulos previamente desenvolvidos e avaliados em uma grande estrutura pipeline, capaz de processar as informações das câmeras em tempo real.

A Tabela 15 mostra a alocação de recursos do FPGA utilizado, sem interconexão dos módulos.

Durante a integração dos módulos, em decorrência da grande quantidade de interconexões necessárias, o sintetizador VHDL não conseguiu alocar toda a montagem dentro do FPGA disponível devido a falta de IOBs de interconexão interna. Esse problema poderia ser solucionado pela adoção de um FPGA de maior capacidade ou pela reestruturação dos processos lógicos e conexões. 
Tabela 15 - Resultado da síntese parcial do sistema para o FPGA Xilinx 3s200pq208-4 Resultados de alocação

\begin{tabular}{|l|c|}
\hline Número de SLICEs utilizados & 1629 de $1920(85 \%)$ \\
\hline Número de SLICEs flip-flops utilizados & 1475 de $3840(38 \%)$ \\
\hline Número de IOBs de interface externa utilizados & 122 de $141(87 \%)$ \\
\hline Número de LUTs de 4 entradas utilizadas & 2412 de $3840(63 \%)$ \\
\hline Number of GCLKs utilizados & 3 de $8(38 \%)$ \\
\hline
\end{tabular}

Desta forma não foi possível avaliar o funcionamento contínuo do processo, sendo possível apenas a verificação, módulo a módulo das saídas esperadas.

Para levantamento dos resultados apresentados, diversas montagem parciais foram elaboradas, incluindo a interface RS232, interface de leitura e gravação da memória externa SRAM, o módulo com o sub-processo de interesse e um pequeno módulo de controle.

Dados previamente tratados no PC eram transferidos para memória SRAM e um sinal de controle gerado para execução do sub-processo. Os resultados eram então finalmente retornados ao PC para análise. 


\section{RESULTADOS FINAIS}

Para verificação do algoritmo proposto utilizou-se o simulador e posterior aquisição dos dados dos sub-processos implementados no FPGA.

Para análise foram utilizadas pares de fotos do repositório JISCT, cuja base de dados é comumente utilizada para execução de testes e comparação de algoritmos.

Os pares de imagens foram pré-processados, sendo o tamanho reduzido em $1 / 4$ (por simples média $4: 1$ ) e um filtro gaussiano aplicado para redução dos componentes de alta freqüência das imagens (reduzindo consideravelmente o ruído contido nas imagens).

A Tabela 16 exibe o resultado do processamento de diversos pares de imagens. Alguns dos pares escolhidos foram utilizados nos trabalhos de BIRCHFIELD e TOMASI (1998), permitindo uma comparação visual de resultados.

Tabela 16 - (a,b) Pares de imagens do repositório JISCT. (c) Mapa de disparidade resultante.

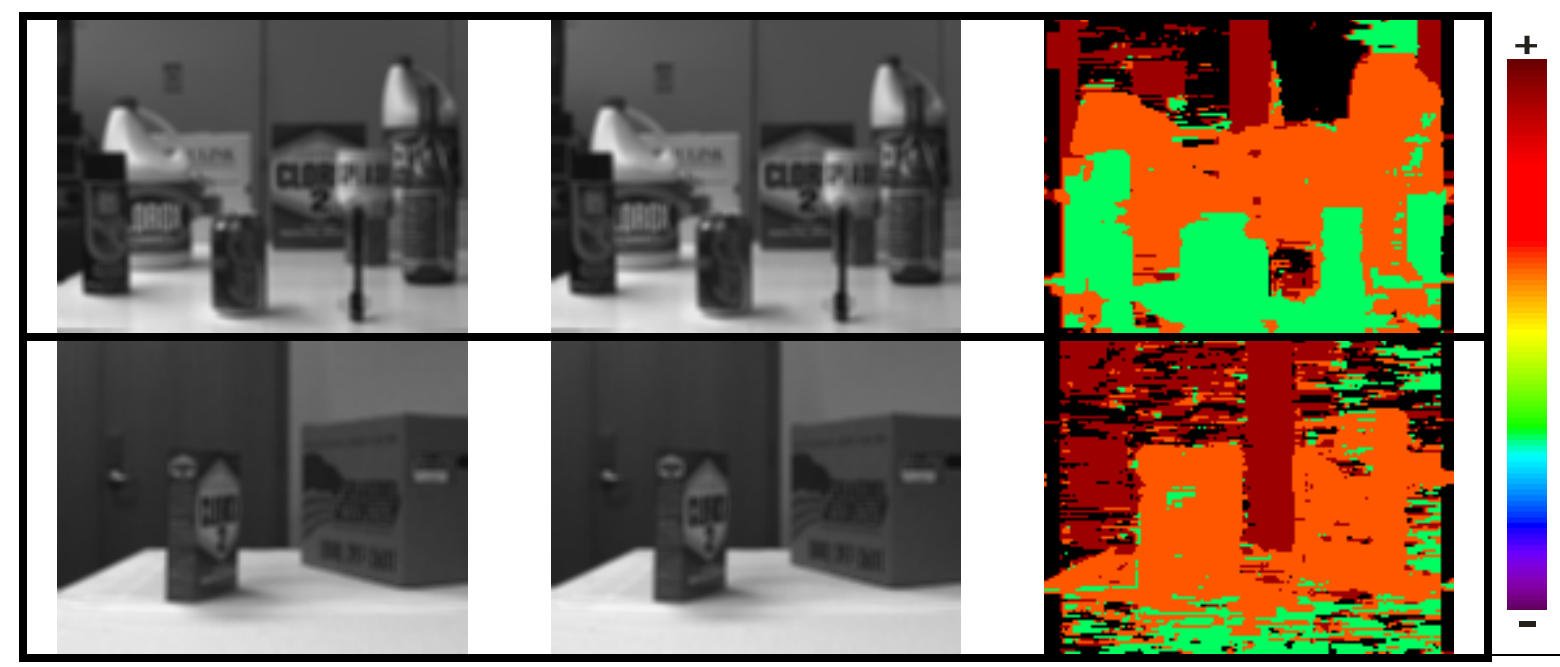


Tabela 16 (continuação)

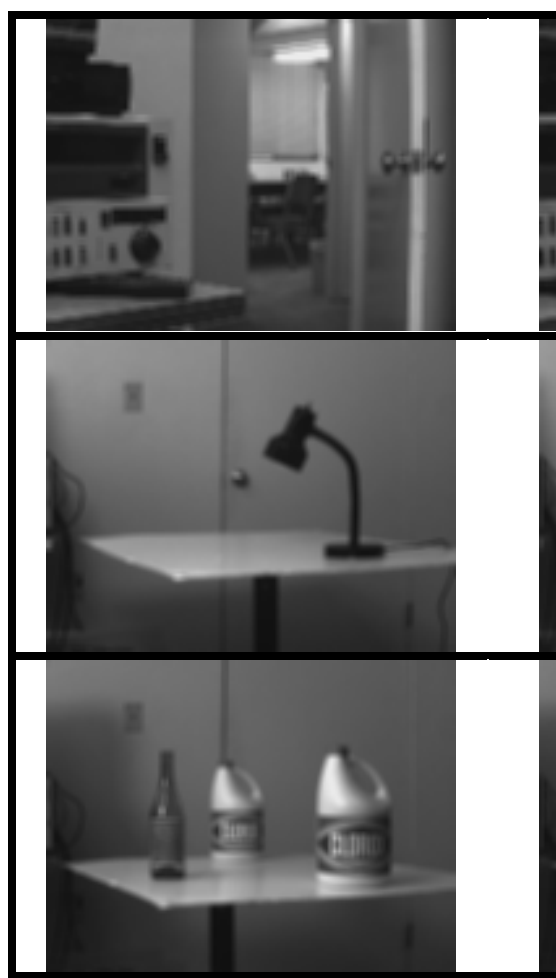

(a)

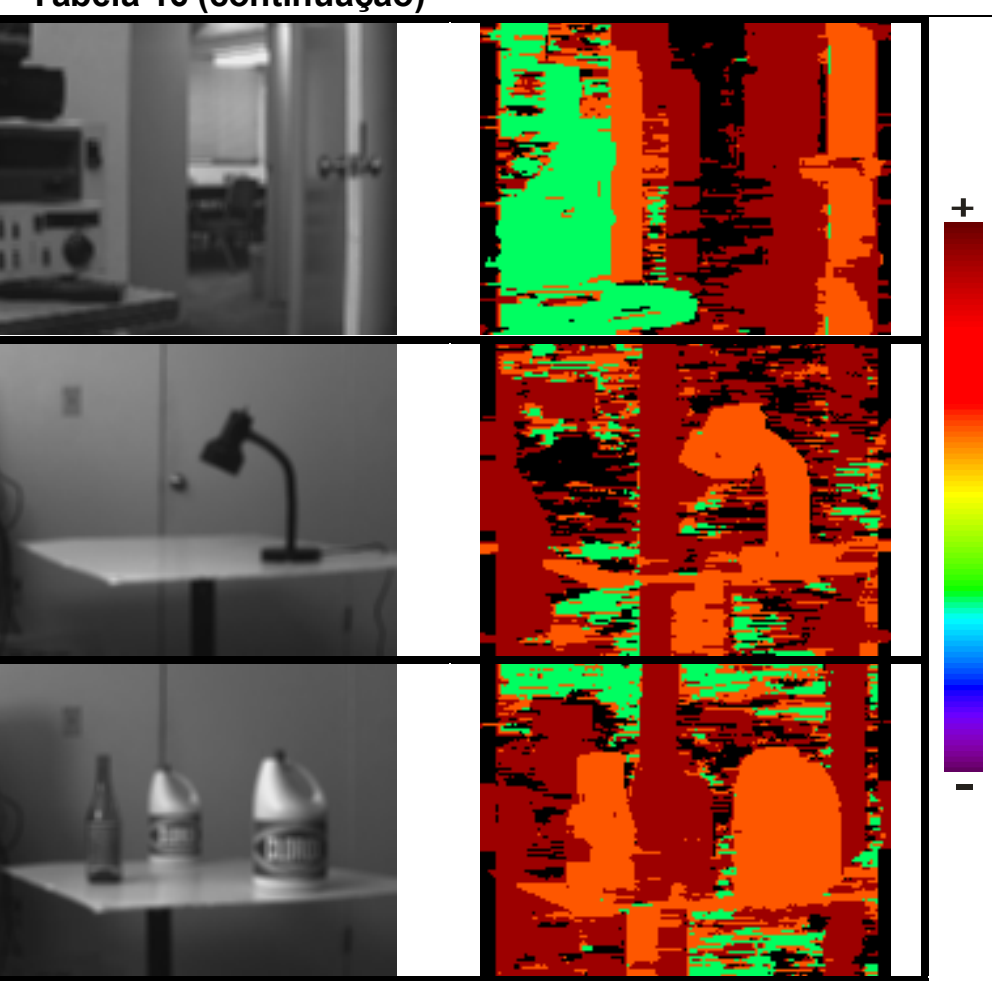

(b)

(c)

Também foram avaliadas pares de imagem da universidade de Tsukuba. Diferentes valores dos coeficientes $\omega$ e $\beta$ foram empregados devido às diferenças do FOV das câmeras. Parâmetro $\omega=4$ e $\beta=30$ foram utilizados para processamentos dos pares de imagens. Os resultados são apresentados na Tabela 17 - (a,b) Pares de imagens do repositório Tsukuba. (c) Mapa de disparidade resultante.

Tabela 17 - (a,b) Pares de imagens do repositório Tsukuba. (c) Mapa de disparidade resultante.

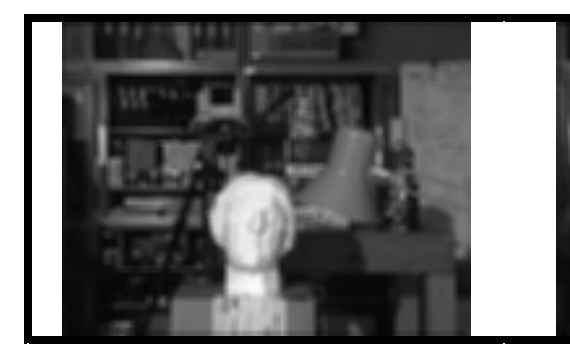

(a)

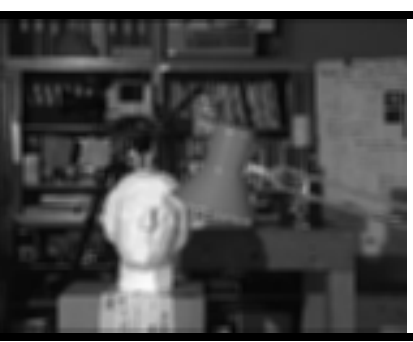

(b)

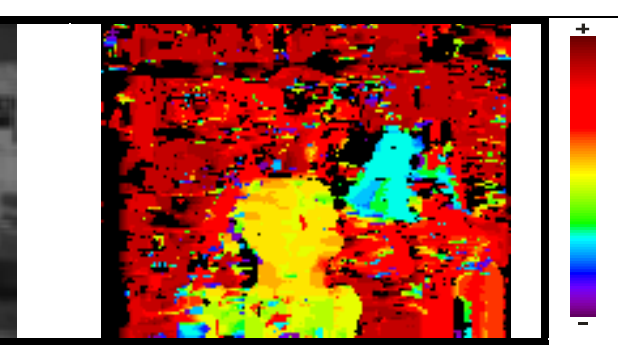

(c) 
Pares de imagens sintéticas (geradas totalmente por algoritmos de raytrace), disponibilizadas pelo grupo de visão computacional da Universidade de Bonn, também foram analisadas.

Estas imagens sintéticas, geradas por um software de ray-tracing (MRTStereo - Modular Rendering Tools), apresentam regiões bastante definidas para avaliação do mapa de disparidade e efeito das oclusões no algoritmo. Os resultados são apresentados na Tabela 18. Parâmetros $\omega=5 \mathrm{e}$ $\beta=7$ foram empregados para processamento das imagens.

Tabela 18 - (a,b) Pares de imagens sintéticas do repositório Bonn. (c) Mapa de disparidade resultante

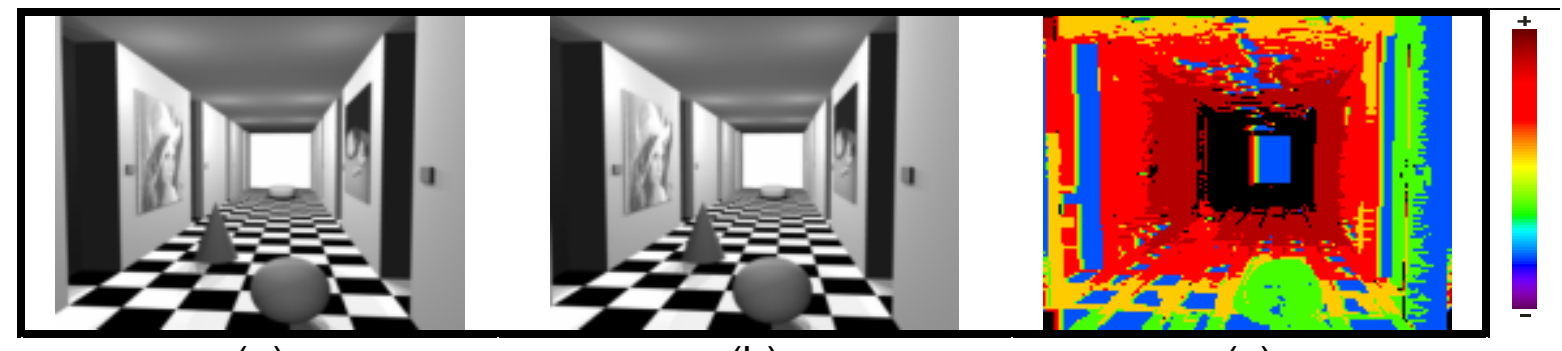

(a)

(b)

(c) 
PÁGINA INTENCIONAMENTE DEIXADA EM BRANCO 


\section{CONCLUSÕES E TRABALHOS FUTUROS}

Os resultados apresentados indicaram a viabilidade de implementação de um algoritmo de alto desempenho para visão computacional, mantendo simplicidade funcional e baixo-custo.

Apesar de apresentar limitações conhecidas (como a incapacidade de lidar com oclusões), o sistema se mostra adequado para obtenção dinâmica de referência de profundidade em dispositivos robóticos móveis. Em especial, os densos mapas de disparidade disponibilizados em tempo-real pelo FPGA, permitem abastecer continuamente os softwares de navegação e mapeamento com enorme quantidade de informações pré-processadas, reduzindo a sobrecarga usual decorrente da decodificação e processamento de imagens estereoscópicas por métodos tradicionais de software.

Um exemplo simples da aplicação do mapa de disparidade obtido através do algoritmo proposto é mostrado na Figura 44. O mapa de disparidade obtido foi segmentado por limiares de intensidade, cada qual representando uma profundidade especifica no campo visual. Em seguida aplicou-se um rápido algoritmo de erosão, para redução de ruídos e eliminação de pequenos objetos da cena. Os dados resultantes permitem uma avaliação dos objetos próximos e, por exemplo, a alteração de rota de um robô em movimento.

Vale citar também que a estrutura proposta permite a adição de algoritmos de pré e pós-processamento com mínimo impacto no tempo total de execução, habilitando o uso de filtros, algoritmos de detecção de características, reconhecimento de objetos, entre tantas outras possibilidades. 

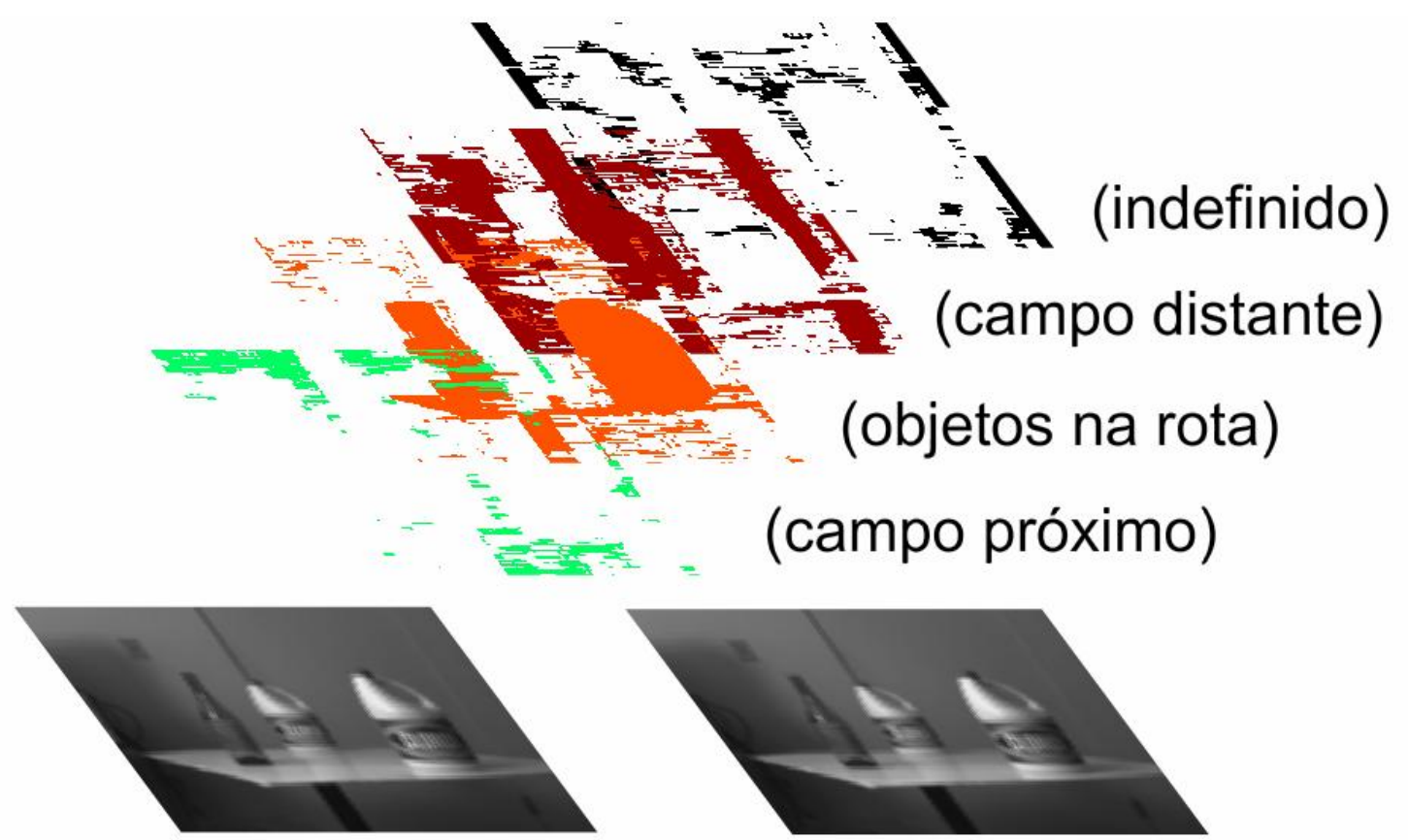

Figura 44 - Exemplo de aplicação do mapa de disparidade

Devido a dificuldades de ordem técnica, não foi possível obter completa integração de cada um dos sub-processos no FPGA, o que resultaria em um sistema funcional para utilização da câmera. Desta forma as verificações funcionais em hardware consistiram em processar manualmente blocos de dados pré-definidos, e obtenção dos resultados pela interface RS232 implementada no sistema.

Os maiores problemas encontrados durante a fase de implementação no dispositivo FPGA foram decorrentes da falta de suporte e documentação pelo fabricante da placa de desenvolvimento e do dispositivo FPGA, assim como as limitações impostas pelo programa de simulação. Em especial não havia disponíveis gratuitamente (ou para avaliação) códigos funcionais básicos, como acesso à memória externa SRAM ou comunicação serial. Essas peças fundamentais para o desenvolvimento foram projetadas manualmente, ocasionando considerável atraso no cronograma do projeto.

A integração de todos os módulos também apresentou considerável dificuldade. Cada módulo separadamente utiliza uma pequena quantidade dos recursos disponíveis no FPGA empregado. Entretanto, durante a fase de integração, em decorrência da grande quantidade de interconexões 
necessárias inter-módulos, o sintetizador VHDL não conseguiu alocar toda a montagem dentro do FPGA disponível. Revisão futura estará sendo feita com intuito de minimizar os processos lógicos e interconexões necessárias para execução do algoritmo no dispositivo.

Os trabalhos aqui apresentados resultaram em duas publicações. A primeira, disponível no Anexo A - Artigo Periódico LAAR, foi aceito para publicação no Periódico Latin American Applied Research.

A segunda publicação, disponível no Anexo B - Artigo SPL2006 foi submetida e aceita na conferencia SPL2006 - Southern Conference on Programmable Logic, realizada na cidade de Mar Del Plata, Argentina, em janeiro de 2006.

Trabalhos futuros prevêem solução dos diversos problemas de ordem técnica, possivelmente pela troca das ferramentas de desenvolvimento e do dispositivo FPGA, além da adição de um framework padrão que permita fácil conexão de filtros de pré e pós-processamento ao núcleo funcional do algoritmo proposto. 
PÁGINA INTENCIONAMENTE DEIXADA EM BRANCO 


\section{REFERÊNCIAS}

BELHUMER, P. N. (1993). A Binocular Stereo Algorithm for Reconstructing Sloping, Creased, and Broken Surfaces in the Presence of Half-Occlusion. Proceedings of the Fourth International Conference on Computer Vision, pages 431-438, May 1993.

BIRCHFIELD, S.; TOMASI, C. (1998); Depth Discontinuities by Pixel-to-Pixel Stereo. Proceedings of the 1998 IEEE International Conference on Computer Vision, Bombay, India.

. (1998); A Pixel Dissimilarity Measure That is Insensitive to Image Sampling. IEEE Transactions on Pattern Analysis And Machine Intelligence, Vol. 20, No. 4, Apr. 1998.

BONATO, VANDERLEI ; FERNANDES, MÁRCIO MERINO ; MARQUES, EDUARDO . A smart camera with gesture recognition and SLAM capabilities for mobile robots. International Journal of Electronics, Londres, v. 93, p. 385-401, 2006.

COX, I. J.; HINGORANI, S. L.; RAO, S. B.; MAGGS, B. M. (1996). A Maximum Likelihood Stereo Algorithm. Computer Vision and Image Understanding, vol. 63, pages 542-567, May 1996.

DARABIHA, A., ROSE, J., MACLEAN, W. J. (2003). Video-Rate Stereo Depth Measurement on Programmable Hardware. Proc. of the 2003 IEEE Computer Society Conf. on Computer Vision and Pattern Recognition, vol. 1, pages 203210, June 2003.

GROSSO, E.; TISTARELLI, M. (1995). Active/Dynamic Stereo Vision. IEEE Trans. On Pattern Analysis and Machine Intelligence, vol. 17, no. 9, pages 868879, Sept. 1995.

HILE, H.; ZENG, C. (1996). Stereo Vision Processing for Depth Map. University of Washington.

MURRAY, D.; JENNINGS, C. (1997). Stereo vision based mapping and navigation for mobile robot. Proceedings of the 1997 IEEE International Conference on Robotics and Automation, pages 1694-1699, Albuquerque, New Mexico, Apr. 1997. 
SILVIA, L.C., PETRAGLIA, A., PETRAGLIA, M.R. (2003). Stereo vision system for real time inspection and $3 D$ reconstruction. Industrial Electronics, 2003. ISIE '03. 2003 IEEE Int. Symp, vol. 1, pages 607-611, June 2003.

SUNYOTO, H., VAN DER MARK, W., GAVRILA, D.M. (2004). A comparative study of fast dense stereo vision algorithms. Intelligent Vehicles. Symposium, 2004 IEEE, pages 319-324.

TAKENO, J.; HACHIYAMA, S. (1991). New Technology on Stereo Vision for Mobile Robots. IEEE 1991.

YOSHIDA, K.; HIROSE, S. (1992). Real Time Stereo Vision with Multiple Arrayed Camera. Proceedings of the 1997 IEEE International Conference on Robotics and Automation, pages 1765-1770, Nice, France, May 1992.

Projetos com FPGA, Famílias Modernas.

MENDONÇA, A.; ZELONOVKY, R.

http://www.mzeditora.com.br/artigos/fpga_fam.htm

Último acesso em 06/08/2005.

Câmeras Digitais e sensores CMOS

http://electronics.howstuffworks.com/digital-camera2.htm

Último acesso em 05/07/2005. 


\section{ANEXO A - ARTIGO PERIÓDICO LAAR}

Artigo publicado no periódico LAAR - Latin American Applied Research (http://www.laar.uns.edu.ar).

\section{Citação bibliográfica}

CALIN, G.; RODA, V. O. (2006). Real-time disparity map extraction in a dual head stereo vision system. Latin American Applied Research, v. 37, p. 21-24, 2006. 
PÁGINA INTENCIONAMENTE DEIXADA EM BRANCO 


\title{
REAL-TIME DISPARITY MAP EXTRACTION IN A DUAL HEAD STEREO VISION SYSTEM
}

\author{
G. CALIN ${ }^{\dagger}$ and V. O. RODA ${ }^{\dagger}$ \\ † Escola de Engenharia de São Carlos, Universidade de São Paulo, São Carlos, Brazil \\ gcalin@uol.com.br,valentin@sel.eesc.usp.br
}

\begin{abstract}
This paper describes the design of an algorithm for constructing dense disparity maps using the image streams from two CMOS camera sensors. The proposed algorithm extracts information from the images based on correlation and uses the epipolar constraint. For real-time performance, the processing structure of the algorithm was built targeting implementation on programmable logic, where pipelined structures and condensed logic blocks were used.
\end{abstract}

Keywords- Stereo vision, disparity map, programmable logic.

\section{INTRODUCTION}

Researchers have been giving especial attention to computer vision systems capable of delivering accurate $3 \mathrm{D}$ information of an observed scene, which leads to the construction of robust intelligent vehicles. Using low cost sensors, it has been possible to develop stereo vision systems capable of extracting $3 \mathrm{D}$ features by passive sensing of the environment.

Most stereo vision implementations are based on a two camera configuration setup, where each camera delivers a two 2D representation of a given scene, as show in Fig. 1. Stereo vision is achieved by extracting $3 \mathrm{D}$ information by processing two or more $2 \mathrm{D}$ images of a given scene. The processing for extracting the $3 \mathrm{D}$ information creates a map that describes which point in the $2 \mathrm{D}$ images corresponds to the same point in the $3 \mathrm{D}$ scene. Detailed description of the stereo vision problem has been widely studied in past and it is not presented. Refer, for instance, to Grosso et al. (1989) and Grosso and Tistarelli (1995) for a detailed study of this subject.

Several stereo algorithms have been proposed in recent years to solve the problem of finding the correspondence of the right and left image. Simple methods employ the measure of absolute or squared differences of the pixels intensities, to measure the similarity between the images (Sunyoto et al., 2004). Other methods, in order to increase accuracy, employ window-based matching, where a cost function is evaluated around the pixel of interest to find the best match. These methods usually do not consider occlusions and present problems in regions displaying little or repetitive textures, leading to similar cost functions and being unable to find the proper match (Darabiha et al., 2003; Silva et al., 2003; Cox et al., 1996).

Birchfield and Tomasi (1998a, b) employed dynamic programming to solve the matching problem, where each scanline -and in some cases in-between scanlinesare described as a dynamic cost function and evaluated with addition of some penalties criteria, like occlusions and large jumps in disparity.

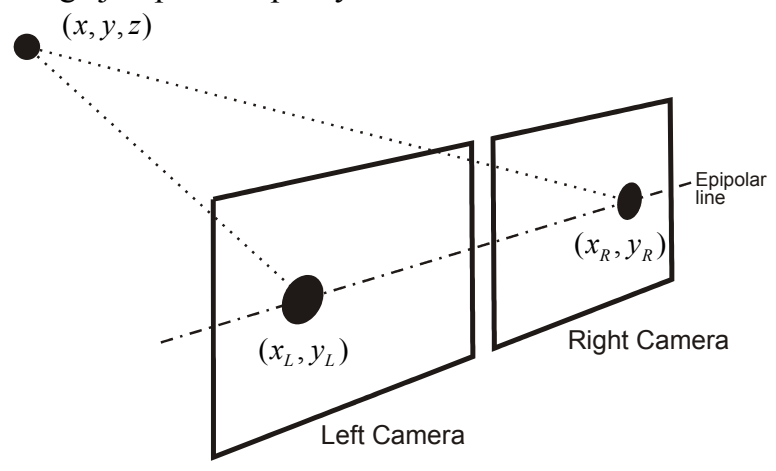

Figure 1. Typical Stereo Vision problem: two cameras, acquiring images of the same scene, have two different $2 \mathrm{D}$ representation of a common 3D point. With proper processing, the position and depth of the $3 \mathrm{D}$ point can be extracted from the images

\section{PROPOSED METHOD}

The proposed method employs a windows-based matching technique to find the disparity map on a pair of stereo images. Similar solutions were proposed in many past papers and represent a simple solution to the matching problem. Although it presents some known limitations, as being unable to process occlusions and large disparity jumps, the windows-based matching technique was chosen and used as base for this study due its potential of being ported to a small FieldProgrammable Gate Array (FPGA) device.

For the proposed system, $F_{e}$ and $F_{d}$ denote the left and right frames from the CMOS camera sensors, located respectively at right and left sides of the scene. The source frame is $w$ pixels large and of $h$ pixels height, with 8-bit grayscale intensities.

The video frames $F_{e}$ and $F_{d}$ are addressed as vectors, $\vec{e}$ and $\vec{d}$ of $(w \cdot h)$ length, where the first vector position stores the intensity of the upper-left pixel and the last position stores the bottom-right pixel intensity.

$I_{e}(k)$ and $I_{d}(k)$ is the intensity of a given pixel $k$ located respectively in vectors $\vec{e}$ and $\vec{d}$, where $k \in\{0,1, \ldots,(w \cdot h)-1\}$. 
The parameter $\omega$ is defined as the window width and $\beta$ the observation region around pixel $k$, as shown in Figure 2.

In Eq. (1) the similarity function $S(j)$ is defined. This function measures the squared distance from a window in vector $\vec{e}$ (centered in a given pixel $k$ ) and a window in vector $\vec{d}$, displaced by $j$ pixels.

$$
S(j)=\sum_{\substack{i=k-\frac{1}{2} \pi \\ 2}}^{\substack{k+-\pi \\ 2}}\left[I_{e}(i)-I_{d}(i+j)\right]^{2},
$$

where $i \in Z, \omega \in\{1,3,5,7, \ldots\}$

$C(k)$, defined in Eq. (2), returns the best match (minimum distance) for a given window centered in pixel $k$, when compared with $2 \beta$ windows in vector $\vec{d}$.

$$
C(k)=\min _{-\beta+1 \leq j \leq \beta}\{S(j)\},
$$

Since only a limited number of pixels are need for the matching process, vectors $\vec{e}$ and $\vec{d}$ can be trimmed to reduce the memory allocation.

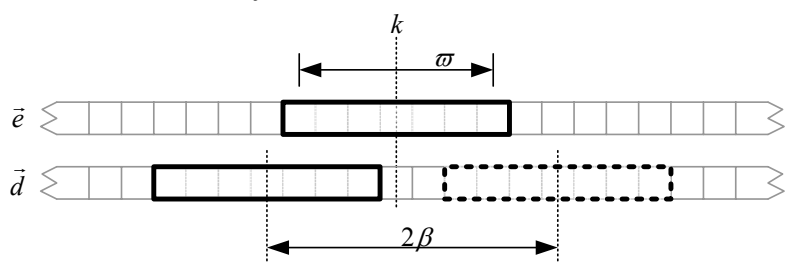

Figure 2. Windows based match. A windows around pixel $k$ in the $\vec{e}$ vector is compared with $2 \beta$ windows in vector $\vec{d}$

\section{DESIGN OF A STEREO VISION SYSTEM}

In this paper, for parallel, efficient and condensed hardware implementation of the proposed algorithm, some constrains have been included: 1) CMOS camera sensors with digital interface were used, avoiding implementation of a video interface to digitalize signals from a regular analog video camera; 2) The parameters $\omega$ and $\beta$ were fixed, based in the results of the simulations and camera setup (typically $\omega=11$ and $\beta=4$ were used). This allowed a small use of resources, since just a small number of pixels must be present for processing; 3) External memory was used only for storing the final processed disparity map (for debugging purposes).

Also the simplicity of the formulation allowed implementation of all elemental functions with available in-hardware math blocks or by creating simple logic constructions, such as subtraction and magnitude comparison blocks.

\section{A. Pipeline Structure}

The developed architecture of the stereo vision system is illustrated in Fig. 3. It consists of a five stage pipeline process capable of processing $160 \times 120$ pixels grayscale frames at video rate speed (30 frames/s). Each new pixel, delivered by the cameras, moves the pipeline forward, creating a FIFO process at pixel-rate speed. This allowed a very condensed implementation in terms of logic allocation and memory, and the possibility for future addition of other post-processing algorithms.

Higher clocks frequencies were used to allow execution of machine states within a pixel-rate period. This was needed because some processes could not be parallelized in hardware and needed to be executed in sequential order.

\section{B. Pipeline Stages}

In pipeline stage 1 , vectors $\vec{e}$ and $\vec{d}$ allocate limited memory, since a small history of pixels is needed to process the disparity. In the first pipeline state every new pixel available by the cameras are shifted in the vectors, and the oldest pixel is discarded. This process occurs in two steps, first shifting the vectors and then adding the new available pixels.

Stage 2 is responsible for measuring the all pixel distance from the two vectors, making data available for computing the squared distance in stage 3 .

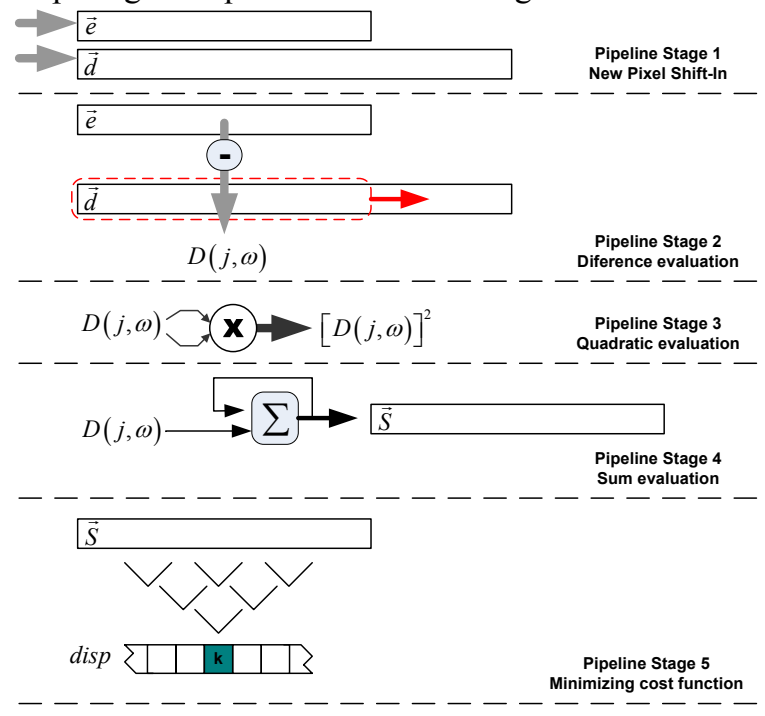

Figure 3. Pipeline structure used to process the proposed stereo vision algorithm

Stage 3 employs hardware multipliers to compute the square function of all data processed in state 2 . Since only a limited number of multipliers are available, this stage was broken in several small processes.

Stage 4 computes the sum function for every compared window. This results in a set of data representing the cost function.

Stage 5 uses a tree comparison structure to analyze the data from stage 4 . The minimum distance is detected and a disparity coefficient is assigned.

\section{Pipeline Structure evaluation}

Prior to hardware implementation, the pipeline structure was tested and evaluated using custom developed soft- 
ware. Delphi development platform was used due its facilities to emulate low-level binary processes and possibility to quick output results in graphic form for analysis.

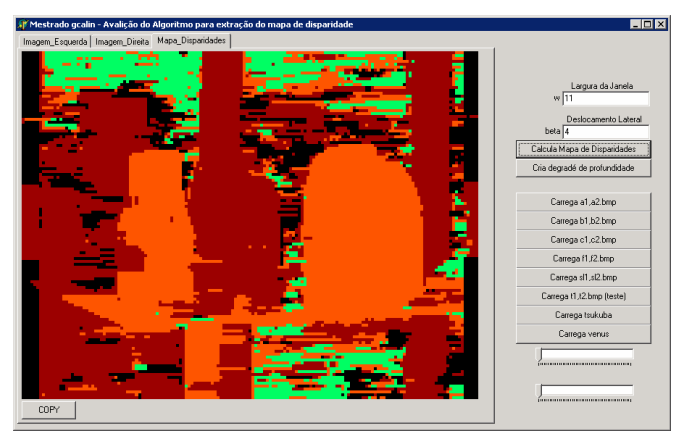

Figure 4. Custom software interface used to evaluate he presented pipeline structure prior to hardware implementation

The results obtained by software emulation were very important during hardware implementation, allowing quick comparison of results and identification of hardware programming errors.

\section{Hardware}

To test the algorithm, a Xilinx Spartan-3 development board was used. This board uses a Spartan-3 FPGA (model XC3S200), a low-cost FPGA, with 200k logic blocks and twelve 18-bit hardware multipliers.

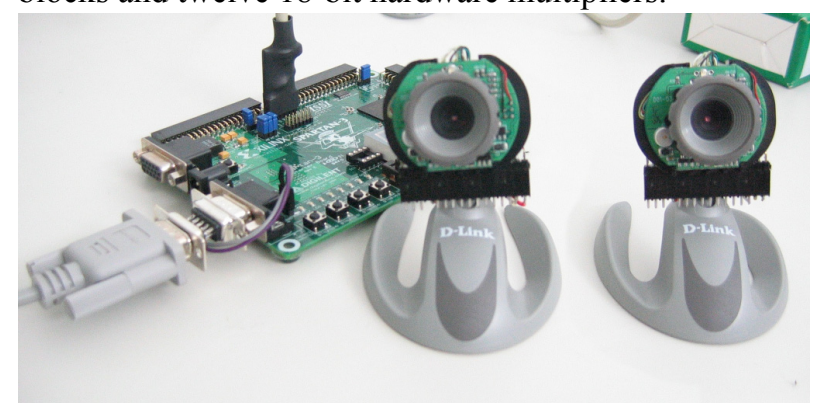

Figure 5. Hardware setup, including the Xilinx FPGA development board and the two CMOS cameras.

A base clock of $50 \mathrm{MHz}$ was used for synthesizing all required system clocks.

To acquire the images, a pair of low cost OmniVision CMOS sensor were used. Two web-cams were disassembled and its image sensors wired to obtain the raw digital data, at video-rate speed.

Employed OminiVision sensors (model OV7648) were able to delivery frames in digital format $(160 \times 120$ pixels 8-bit grayscale) at required frame rate (30 frames/s).

In addition a serial interface was build for debugging purposes. The processed disparity map was stored in an external SRAM memory, also available in the development board. Many special debug utilities were developed because very a limited hardware debugging support was provided on Spartan development board.

All hardware implementation were made using Xilinx ISE IDE. This IDE provided by Xilinx Corp. allows programmable hardware development using VHDL and Verilog language, as well traditional graphic blocks schematic programming.

Although ISE provides simulation capabilities, an external VHDL simulator was used. For this purpose MentorGraphics ModelSim simulator was employed for verification of all created VHDL code.

Additional utilities were developed to convert the sample images to a compatible ModelSim file format.

\section{E. Results}

To verify the proposed algorithm, pairs of pictures from JISCT repository were used (dataset provided by research groups at JPL, INRIA, SRI, CMU and Teleos). This dataset features groups of images properly obtained for stereo vision processing.

The use of this dataset if specially interesting for future comparison of the obtained results with results of algorithms proposed by other researchers.

The source images were pre-processed, with a $4: 1$ reduction of size and use of an average anti-aliasing filter. This pre-processing stage was applied to adequate the pictures to the correct size and aspect ratio, as well to reduce the image high frequency components that would add excessive noise in the depth map.

The results shown in Table 1, Table 2 and Table 3 (column c) were artificially colored to evidence the depth of the objects in the scene. An arbitrary color map was used, where the nearest to the furthermost objects were shown from violet to red tonalities respectively.

The pipelined structure, running at pixel-rate speed $(576 \mathrm{kHz})$ could delivery the first disparity pixel after approximately $8.68 \mu \mathrm{s}$. This allowed observing the disparity map of the scene without any noticeable delay or framing loss.

To process the pair of stereo images, a special routine uploaded them to the external SRAM of the stereo vision system, and after $33 \mathrm{~ms}$ the disparity map was downloaded back to the computer, for analysis.

In the current research stage, fully integrated processing is being designed, adding pos-processing capabilities in the current pipeline structure. It is necessary for proper evaluation of the algorithm in real case scenario, such as robotic navigation and 3D scene mapping.

Also stereo pair from Tsukuba University was evaluated. Different $\omega$ and $\beta$ coefficients were employed due to differences in cameras field of view. Parameter $\omega=4$ and $\beta=30$ were used to process these images. Result is presented in Table 2 .

A pair of synthetic images, available by computer vision group at Bonn University, was also analyzed.

These synthetic images, generated by a ray tracing software (MRTStereo - Modular Rendering Tools), feature ground truth disparity and occlusions. Result is presented in Table 3. Parameter $\omega=5$ and $\beta=7$ were used to process these images. 
Table 1. Results for the proposed algorithm: (a) and (b) are the source pair of stereo images, from JISCT dataset. (c) Shows the dense depth map for each scene. The results were colored from violet (nearest) to red (farthest) to enhance the images contrast.

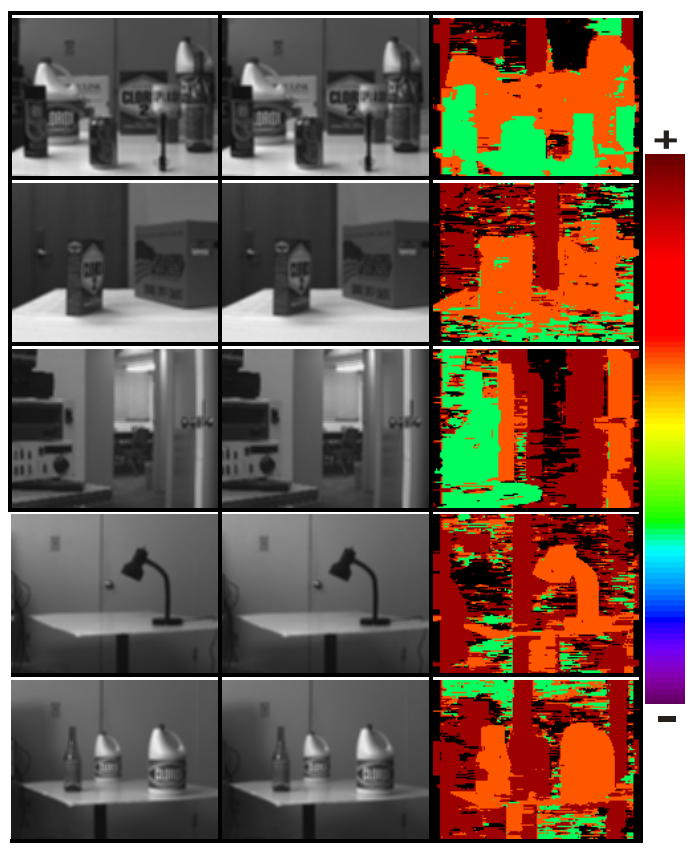

(a)

(b)

(c)

Table 2. Results for the proposed algorithm: (a) and (b) are the source pair of Tsukuba stereo images. (c) Shows the resulting dense depth map. The result was colored from violet (nearest) to red (farthest) to enhance the image contrast.

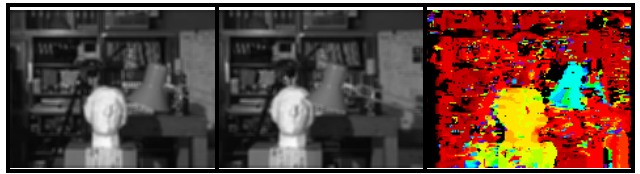

(a)

(b)

(c)

Table 3. Results for the proposed algorithm: (a) and (b) are the source pair of synthetic stereo images. (c) Shows the resulting dense depth map. The result was colored from violet (nearest) to red (farthest) to enhance the images contrast.

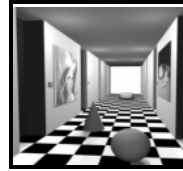

(a) (b)

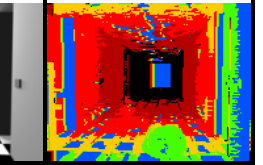

(c)

\section{CONCLUSIONS}

This paper has shown the feasibility of constructing high performance stereo vision system on programmable logic, while maintaining construction simplicity and low-cost.

Although there are some limitations, the system seems suitable for serving as an artificial depth reference for autonomous vehicle guidance. In special, the dense real-time depth maps provided by programmable hardware may continuously delivery high amounts of information to navigation and mapping software, lowering the usual computational burden involved in decoding and processing stereo camera images by conventional software methods.

Also, the proposed structure enables addition of post and pre-processed with low impact on processing time, allowing implementation of filters, algorithms for feature tracking, object recognition, among other possible proposals.

\section{REFERENCES}

Birchfield, S. and C. Tomasi, "Depth Discontinuities by Pixel-to-Pixel Stereo," Proc of the 1998 IEEE Int. Conf. on Computer Vision, Bombay, India 10731080 (1998a).

Birchfield, S. and C. Tomasi, "A Pixel Dissimilarity Measure That is Insensitive to Image Sampling," IEEE Trans. on Pattern Analysis and Machine Intelligence, 20, 401-406 (1998b).

Cox, I.J., S.L. Hingorani, S.B. Rao and B.M. Maggs, “A Maximum Likelihood Stereo Algorithm," Computer Vision and Image Understanding, 63, 542567 (1996).

Darabiha, A., J. Rose and W.J. MacLean, "Video-Rate Stereo Depth Measurement on Programmable Hardware," Proc. of the 2003 IEEE Computer Society Conf. on Computer Vision and Pattern Recognition, 1, 203-210 (2003).

Grosso, E., G. Sandini and M. Tistarelli, "3D object reconstruction using stereo and motion," IEEE Trans. System, Man and Cybernetics, 19, $1465-$ 1476 (1989).

Grosso, E. and M. Tistarelli, "Active/Dynamic Stereo Vision," IEEE Trans. On Pattern Analysis and Machine Intelligence, 17, 868-879 (1995).

Silva, L.C., A. Petraglia and M.R. Petraglia, "Stereo vision system for real time inspection and 3D reconstruction," Industrial Electronics, 2003. ISIE '03. 2003 IEEE Int. Symp., 1, 607-611 (2003).

Sunyoto, H., W. van der Mark and D.M. Gavrila, "A comparative study of fast dense stereo vision algorithms," IEEE Intelligent Vehicles Symposium, 319-324 (2004)

Received: April 14, 2006.

Accepted: September 8, 2006.

Recommended by Special Issue Editors Hilda Larrondo, Gustavo Sutter. 


\section{ANEXO B - ARTIGO SPL2006}

Artigo submetido e aceito na SPL 2006 (Southern Conference on Programmable Logic) realizada entre os dias 8 a 10 de Março de 2006 
PÁGINA INTENCIONAMENTE DEIXADA EM BRANCO 


\title{
Real-time disparity map extraction in a dual head stereo vision system
}

\author{
Gabriel Calin, Valentin Obac Roda \\ Universidade de São Paulo - Escola de Engenharia de São Carlos, São Carlos, Brazil, \\ gcalin@uol.com.br \\ valentin@sel.eesc.usp.br \\ http://www.eesc.sc.usp.br
}

\begin{abstract}
This paper describes the design of an algorithm for constructing dense disparity maps using the image streams from two CMOS camera sensors. The proposed algorithm extracts information from the images based on correlation and uses the epipolar constraint. For real-time performance, the processing structure of the algorithm was built targeting implementation on programmable logic, where pipelined structures and condensed logic blocks were used.
\end{abstract}

\section{Introduction}

Researchers have been giving especial attention to computer vision systems capable of delivering accurate $3 \mathrm{D}$ information of an observed scene, which leads to the construction of robust intelligent vehicles. Using low cost sensors, it has been possible to develop stereo vision systems capable of extracting $3 \mathrm{D}$ features by passive sensing of the environment.

Most stereo vision implementations are based on a two camera configuration setup, where each camera delivers a two 2D representation of a given scene, as show in Fig. 1. Stereo vision is achieved by extracting $3 \mathrm{D}$ information by processing two or more $2 \mathrm{D}$ images of a given scene. The processing for extracting the 3D information creates a map that describes which point in the $2 \mathrm{D}$ images corresponds to the same point in the $3 \mathrm{D}$ scene.

Several stereo algorithms have been proposed in recent years to solve the problem of finding the correspondence of the right and left image. Simple methods employ the measure of absolute or squared differences of the pixels intensities, to measure the similarity between the images. Other methods, in order to increase accuracy, employ window-based matching, where a cost function is evaluated around the pixel of interest to find the best match. These methods usually do not consider occlusions and present problems in regions displaying little or repetitive textures, leading to similar cost functions and being unable to find the proper match.

Some researchers employ dynamic programming to solve the matching problem, where each scanline - and in some cases in-between scanlines - are described as a dynamic cost function and evaluated with addition of some penalties criteria, like occlusions and large jumps in disparity. 


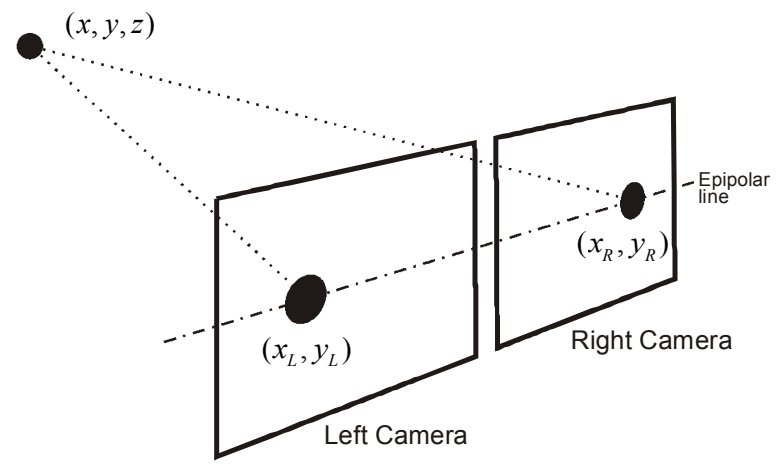

Fig. 1. Typical Stereo Vision problem: two cameras, acquiring images of the same scene, have two different $2 \mathrm{D}$ representation of a common $3 \mathrm{D}$ point. With proper processing, the position and depth of the $3 \mathrm{D}$ point can be extracted from the images

\section{Proposed Method}

The proposed method employs a windows-based matching technique to find the disparity map on a pair of stereo images. Similar solutions were proposed in many past papers and represent a simple solution to the matching problem. Although it has know limitations, as being unable to process occlusions and large disparity jumps, the windows-based matching technique was chosen and used as base for this study because its potential of being ported to a small Field-Programmable Gate Array (FPGA) devices.

For the proposed system, $F_{e}$ and $F_{d}$ denote the left and right frames from the CMOS camera sensors, located respectively at right and left sides of the scene. The source frame is $w$ pixels large and of $h$ pixels height, with 8-bit grayscale intensities.

The video frames $F_{e}$ and $F_{d}$ are addressed as vectors, $\vec{e}$ and $\vec{d}$ of $(w \cdot h)$ length, where the first vector position stores the intensity of the upper-left pixel and the last position stores the bottom-right pixel intensity.

$I_{e}(k)$ and $I_{d}(k)$ is the intensity of a given pixel $k$ located respectively in vectors $\vec{e}$ and $\vec{d}$, where $k \in\{0,1, \ldots,(w \cdot h)-1\}$.

The parameter $\omega$ is defined as the window width and $\beta$ the observation region around pixel $k$, as shown in Fig. 2.

In equation (1) the similarity function $S(j)$ is defined. This function measures the squared distance from a window in vector $\vec{e}$ (centered in a given pixel $k$ ) and a window in vector $\vec{d}$, displaced by $j$ pixels. 


$$
S(j)=\sum_{i=k-\frac{1}{2} \sigma}^{k+\frac{1}{2} \sigma}\left[I_{e}(i)-I_{d}(i+j)\right]^{2} . i \in Z, \omega \in\{1,3,5,7, \ldots\}
$$

$C(k)$, defined in equation (2), returns the best match (minimum distance) for a given window centered in pixel $\mathrm{k}$, when compared with $2 \beta$ windows in vector $\vec{d}$.

$$
C(k)=\min _{-\beta+1 \leq j \leq \beta}\{S(j)\} .
$$

Since only a limited number of pixels are need for the matching process, vectors $\vec{e}$ and $\vec{d}$ can be trimmed to reduce the memory allocation.

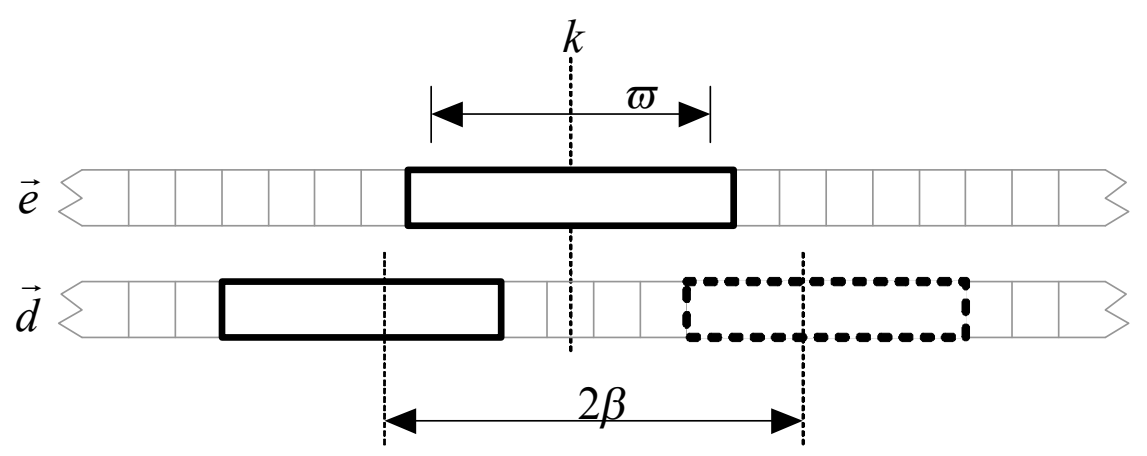

Fig. 2. Windows based match. A windows around pixel $\mathrm{k}$ in the $\vec{e}$ vector is compared with $2 \beta$ windows in vector $\vec{d}$

\section{Design of a Stereo Vision System}

In this paper, for parallel, efficient and condensed hardware implementation of the proposed algorithm, some constrains have been included: 1) CMOS camera sensors with digital interface were used, avoiding implementation of a video interface to digitalize signals from a regular analog video camera; 2) The parameters $w$ and $\omega$ were fixed, based in the results of the simulations. This allowed a small use of resources, since just a small number of pixels must be present for processing; 3) External memory was used only for storing the final processed disparity map (for debugging purposes). 
Also the simplicity of the formulation allowed implementation of all elemental functions with available in-hardware math blocks or by creating simple logic constructions, such as subtraction and magnitude comparison blocks.

\subsection{Pipeline Structure}

The developed architecture of the stereo vision system is illustrated in Fig. 3. It consists of a five stage pipeline process capable of processing 160x120 pixels grayscale frames at video rate speed (30 frames/s). Each new pixel, delivered by the cameras, moves the pipeline forward, creating a FIFO process at pixel-rate speed. This allowed a very condensed implementation in terms of logic allocation and memory, and the possibility for future addition of other post-processing algorithms.

Higher clocks frequencies were used to allow execution of machine states within a pixel-rate period. This was needed because some processes could not be parallelized in hardware and needed to be executed in sequential order.

\subsection{Pipeline Stages}

In pipeline stage 1 , vectors $\vec{e}$ and $\vec{d}$ allocate limited memory, since a small history of pixels is needed to process the disparity. In the first pipeline state very new pixel available by the cameras are shifted in the vectors, and the oldest pixel is discarded. This process occurs in two steps, first shifting the vectors and then adding the new available pixels.

Stage 2 is responsible for measuring the all pixel distance from the two vectors, making data available for computing the squared distance in stage 3.

Stage 3 employs hardware multipliers to compute the square function of all data processed in state 2 . Since only a limited number of multipliers are available, this stage was broken in several small processes.

Stage 4 computes the sum function for every compared window. This results in a set of data representing the cost function.

Stage 5 uses a tree comparison structure to analyze the data from stage 4 . The minimum distance is detected and a disparity coefficient is assigned. 


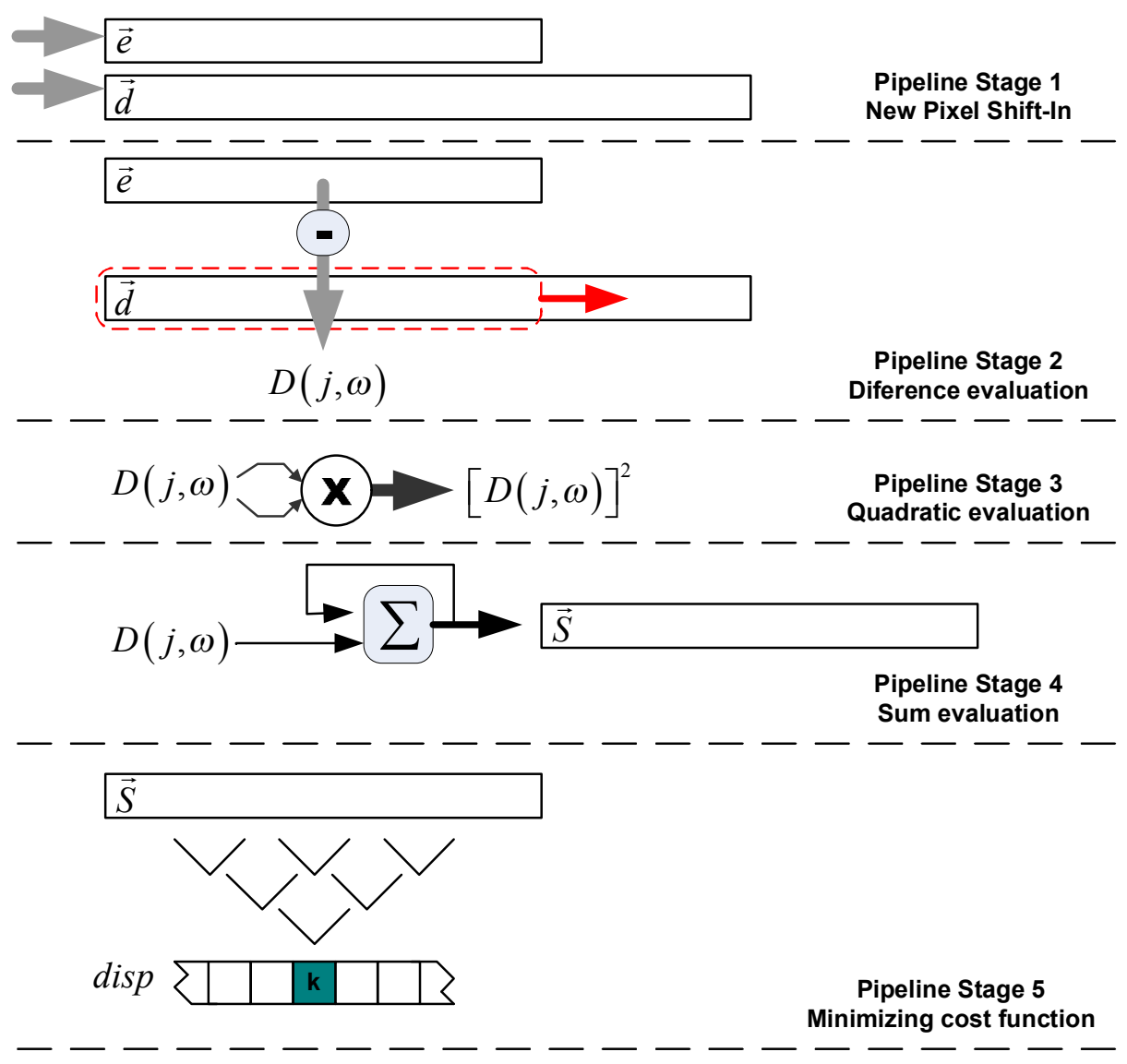

Fig. 3. Pipeline structure used to process the proposed stereo vision algorithm

\subsection{Hardware}

To test the algorithm, a Xilinx Spartan-3 development board was used. This board uses a Spartan-3 FPGA (model XC3S200), a low-cost programmable logic, with 200k logic blocks and twelve 18-bit hardware multipliers.

A base clock of $50 \mathrm{MHz}$ was used for synthesizing all need system clocks.

To acquire the images a pair of low cost OmniVision CMOS sensor were used. Two web-cams were disassembled and its image sensors wired to obtain the raw digital data, at video-rate speed.

In addition a serial interface was build for debugging purposes. The processed disparity map was stored in an external SRAM memory, also available in the development board. 


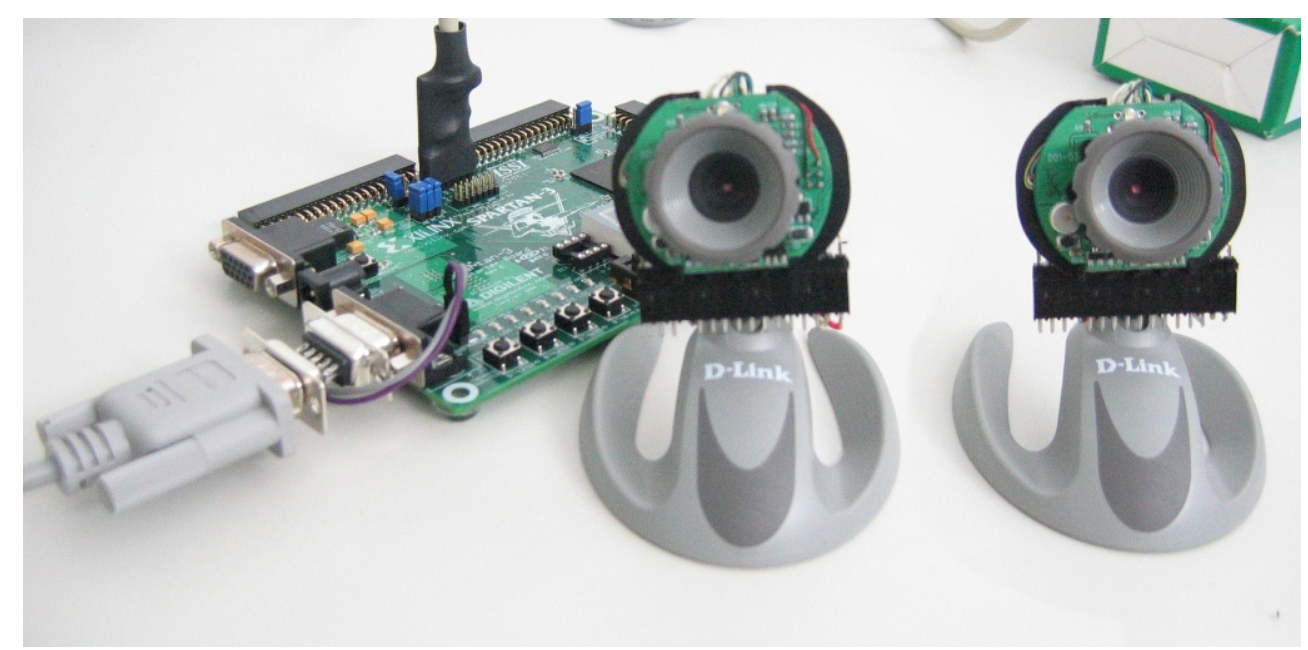

Fig. 4. Hardware setup, including the Xilinx FPGA development board and the two CMOS cameras.

\section{Results}

To verify the proposed algorithm, pairs of pictures from JISCT repository were used. The use of this dataset if specially interesting for future comparison of the obtained results with results of algorithms proposed by other researchers.

The source images were pre-processed, with a 4:1 reduction of size and use of an average anti-aliasing filter.

The results shown in Table 1 (column c) were artificially colored to evidence the depth of the objects in the scene. An arbitrary color map was used, where the nearest to the furthermost objects were shown from violet to red tonalities respectively.

The pipelined structure, running at pixel-rate speed $(576 \mathrm{kHz})$ could delivery the first disparity pixel after approximately $8.68 \mu \mathrm{s}$. This allowed observing the disparity map of the scene without any noticeable delay or framing loss.

To test images from JISCT dataset, a special routine uploaded them to the external SRAM of the stereo vision system, and after $33 \mathrm{~ms}$ the disparity map was downloaded back to the computer, for analysis. 


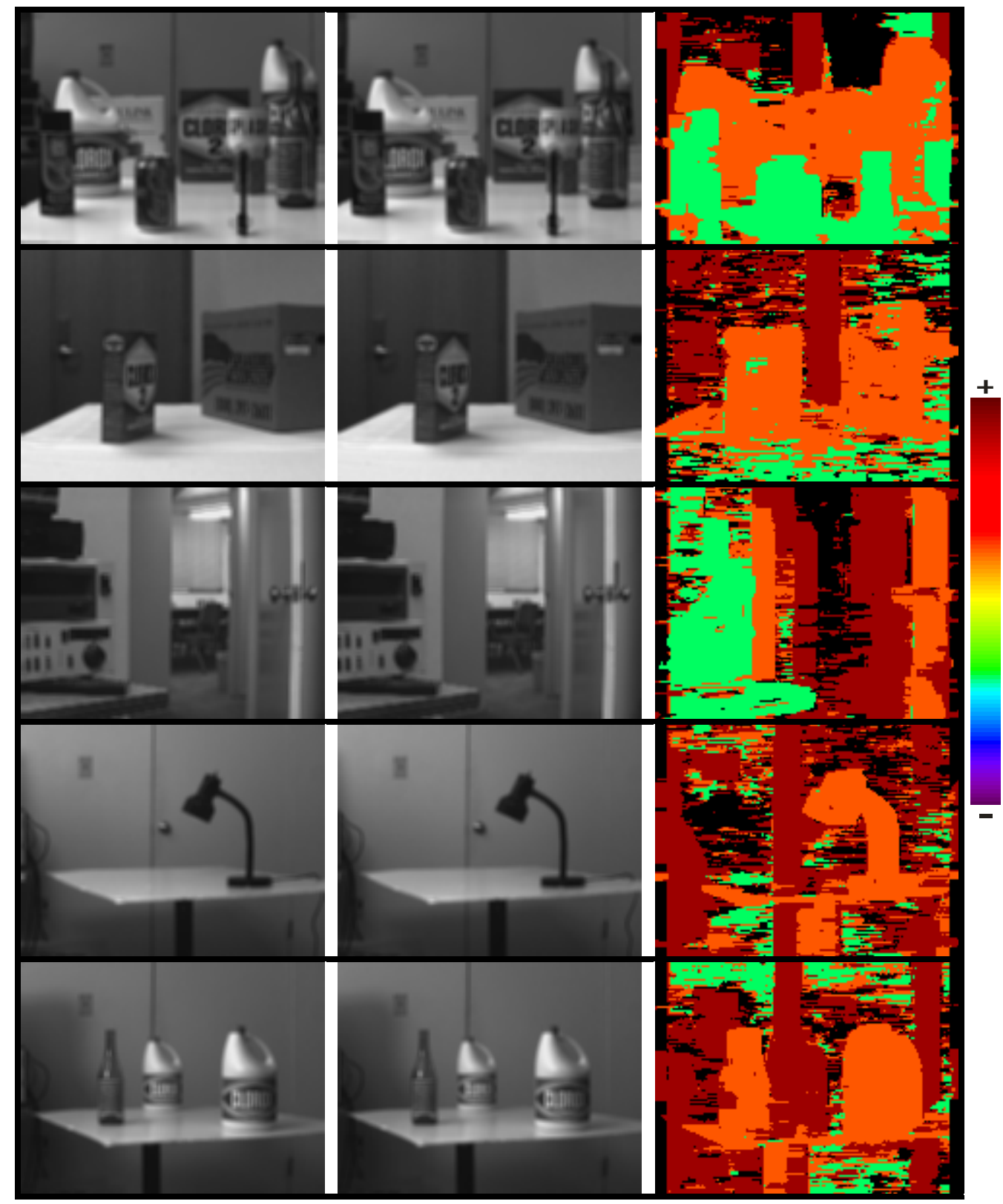

(a)

(b)

(c)

Table 1. Results for the proposed algorithm: (a) and (b) are the source pair of stereo images, from JISCT dataset. (c) Shows the dense depth map for each scene. The results were colored from violet (nearest) to red (farthest) to better contrast of the images. 


\section{Conclusions}

This paper has shown the feasibility of constructing high performance stereo vision system on programmable logic, while maintaining construction simplicity and low-cost.

Although there are some limitations, the system seems suitable for serving as an artificial depth reference for autonomous vehicle guidance.

Also, the proposed structure enables addition of post and pre-processed with low impact on processing time, allowing implementation of filters, algorithms for feature tracking, object recognition, among other possible proposals.

\section{References}

1. Belhumer, P. N.: A Binocular Stereo Algorithm for Reconstructing Sloping, Creased, and Broken Surfaces in the Presence of Half-Occlusion. Proc. of the Fourth Int. Conf. on Computer Vision (1993) 431-438.

2. Birchfield, S., Tomasi, C.: Depth Discontinuites by Pixel-to-Pixel Stereo. Proc of the 1998 IEEE Int. Conf. on Computer Vision, Bombay, India.

3. Birchfield, S., Tomasi, C.: A Pixel Dissimilarity Measure That is Insensitive to Image Sampling IEEE Trans. on Pattern Analysis and Machone Intelligence, Vol. 20, No. 4, Apr. 1998.

4. Cox, I. J., Hingorani, S. L., Rao, S. B., Maggs, B. M.: A Maximum Likelihood Stereo Algorithm. Computer Vision and Image Understanding, vol. 63, pages 542-567, May 1996.

5. Darabiha, A., Rose, J., MacLean, W. J.: Video-Rate Stereo Depth Measurement on Programmable Hardware. Proc. of the 2003 IEEE Computer Society Conf. on Computer Vision and Pattern Recognition, vol. 1, pages 203-210, June 2003.

6. Grosso, E.; Tistarelli, M.: Active/Dynamic Stereo Vision. IEEE Trans. On Pattern Analysis and Machine Intelligence, vol. 17, no. 9, pages 868-879, Sept. 1995.

7. Silva, L.C., Petraglia, A., Petraglia, M.R.: Stereo vision system for real time inspection and 3D reconstruction. Industrial Electronics, 2003. ISIE '03. 2003 IEEE Int. Symp, vol. 1, pages 607611, June 2003.

8. Sunyoto, H., van der Mark, W., Gavrila, D.M.: A comparative study of fast dense stereo vision algorithms. Intelligent Vehicles Symposium, 2004 IEEE, pages 319-324.

9. Yoshida, K.; Hirose, S.: Real Time Stereo Vision with Multiple Arrayed Camera. Proceedings of the 1997 IEEE Int. Conf. on Robotics and Automation, pages 1765-1770, Nice, France. 